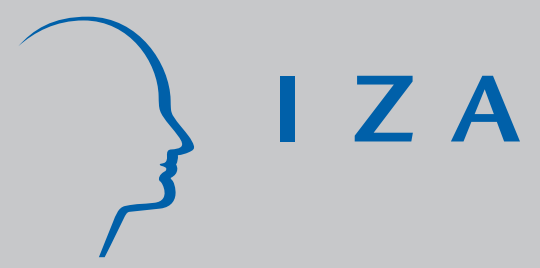

IZA DP No. 1115

Who Is Against Immigration?

A Cross-Country Investigation of Individual Attitudes toward Immigrants

Anna Maria Mayda

April 2004 


\title{
Who Is Against Immigration? A Cross-Country Investigation of Individual Attitudes toward Immigrants
}

\author{
Anna Maria Mayda \\ Georgetown University \\ and IZA Bonn
}

\section{Discussion Paper No. 1115 \\ April 2004}

\author{
IZA \\ P.O. Box 7240 \\ 53072 Bonn \\ Germany \\ Phone: +49-228-3894-0 \\ Fax: +49-228-3894-180 \\ Email: iza@iza.org
}

\begin{abstract}
Any opinions expressed here are those of the author(s) and not those of the institute. Research disseminated by IZA may include views on policy, but the institute itself takes no institutional policy positions.
\end{abstract}

The Institute for the Study of Labor (IZA) in Bonn is a local and virtual international research center and a place of communication between science, politics and business. IZA is an independent nonprofit company supported by Deutsche Post World Net. The center is associated with the University of Bonn and offers a stimulating research environment through its research networks, research support, and visitors and doctoral programs. IZA engages in (i) original and internationally competitive research in all fields of labor economics, (ii) development of policy concepts, and (iii) dissemination of research results and concepts to the interested public.

IZA Discussion Papers often represent preliminary work and are circulated to encourage discussion. Citation of such a paper should account for its provisional character. A revised version may be available on the IZA website (www.iza.org) or directly from the author. 


\section{ABSTRACT \\ Who Is Against Immigration? A Cross-Country Investigation of Individual Attitudes toward Immigrants*}

This paper empirically analyzes both economic and non-economic determinants of attitudes toward immigrants, within and across countries. The two individual-level survey data sets used, covering a wide range of developed and developing countries, make it possible to test for interactive effects between individual characteristics and country-level attributes. The paper identifies and investigates a strong empirical regularity concerning the relationship between individual skill and attitudes toward immigrants. I find that individuals with higher levels of skill are more likely to be pro-immigration in high per capita GDP countries and less likely in low per capita GDP countries. Additional results, based on a smaller sample of countries, suggest a labor-market explanation for this cross-country pattern. The variation across countries in the correlation between skill and preferences appears to be related to differences in the skill composition of natives relative to immigrants across destination economies. This finding is consistent with the predictions of the Heckscher-Ohlin model, in the absence of factor-price-insensitivity, and of the factor-proportions-analysis model. Finally, non-economic variables also appear to be correlated with immigration attitudes but they do not seem to alter significantly the results on the economic explanations.

JEL Classification: F22, F1, J61

Keywords: international migration, political economy, immigration preferences, trade preferences

Anna Maria Mayda

Department of Economics, ICC 552

Georgetown University

37th and O Streets, NW

Washington DC, 20057

USA

Email: amm223@georgetown.edu

\footnotetext{
* I would like to thank Alberto Alesina, Elhanan Helpman, and especially Dani Rodrik for support and many insightful comments. For helpful suggestions, I would also like to thank Eugene Beaulieu, Francesco Caselli, Claudia Goldin, Bryan Graham, Timothy Hatton, Dale Jorgenson, Michael Kremer, Marc Melitz, Mark Rosenzweig, Matthew Slaughter, Abigail Waggoner, Jeffrey Williamson and participants in the international, development and labor Workshops at Harvard University. I am grateful to Robert Barro for providing cross-country data on religious adherence. I would also like to thank the Center for International Development for making available office space. All errors are mine.
} 


\section{Introduction}

Are attitudes toward foreigners influenced by economic considerations or are they driven exclusively by non-economic issues? Do individuals feel threatened by the labor-market competition of foreigners? Are people concerned about security and cultural issues? More generally, who is against immigration, why, and in which countries?

I address these questions by empirically analyzing attitudes toward immigrants within and across countries, using two individual-level survey data sets. ${ }^{1}$ I investigate both economic and noneconomic explanations of preference formation and relate the results on the economic determinants to standard trade and labor-economics theories of immigration.

I find evidence that both sets of factors, economic and non-economic ones, are important. In a wide range of countries, attitudes toward immigrants appear to be related to labor-market concerns, security and cultural considerations, as well as individual feelings toward political refugees and illegal immigration. In particular my analysis reveals that, controlling for non-economic factors, the economic variables play a key and robust role in preference formation over immigration policy. My results are consistent with the predictions of standard economic models and reject a view of the world in which only non-economic considerations shape attitudes toward foreigners.

There are three main motivations behind this type of analysis. First, individual-level opinions on immigration offer indirect information about the distributional impact of factor movements, as perceived by the public. Controlling for non-economic determinants, it is possible to test whether these preferences are consistent with the effect of immigration on individual returns, as predicted by standard economic models. The main focus of this paper is on models that explain preferences in terms of individuals' and countries' factor endowments, the Heckscher-Ohlin trade model and the factor-proportions-analysis labor model. The value of this approach, based on individual attitudes, is that it provides new ground for testing the income-distribution predictions of theories of immigration.

Another reason why it is interesting to analyze immigration attitudes is that they are likely to be a primary determinant of international migration flows. Individual preferences shape the demand side of immigration-policy decisions which are also affected, on the supply side, by policymakers' preferences and the institutional structure of government (Rodrik 1995). Immigration policies, in turn, are likely to be a major factor explaining the recent evolution of labor movements. The size of immigrant flows depends on both the host country's demand for immigrants (i.e., immigration policies) and migrants' decisions to move, according to political and economic incentives. Empirical evidence suggests that the economic forces driving the supply side of international immigration cross-country wage and income differentials, reduced transport, communication and information costs, opportunities for risk diversification - have become stronger in the last decades. Restrictive policies, then, most likely explain the relatively small scale of international immigration (Faini 2001)..$^{2}$

Finally, there is yet another reason to look at individual attitudes toward immigrants. Recent

\footnotetext{
${ }^{1}$ I will use the terms attitudes and preferences interchangeably in the text. By either term, I mean individual stated opinions, which determine how the respondent would vote on a certain issue.

${ }^{2}$ The comment on the small size of immigrant flows is relative to the past (nineteenth century) and to other globalization forces such as trade flows, as is explained later on.
} 
years have witnessed a remarkable push toward globalization. However, there are noticeable differences in the magnitude of changes in volumes of trade, international capital flows and immigration (Findlay and O'Rourke 2002 and Obstfeld and Taylor 2002). For example, the extraordinary increase in trade volumes in the post WWII era has not been matched by a parallel rise in labor flows. Domestic policies have been characterized by an evident asymmetry with respect to trade and capital movements on the one hand, and immigration on the other (Bilal et al. 1998, Faini 2002, and Rodrik 2001). ${ }^{3}$ Individual preferences can reveal whether this difference in policy outcomes originates from a different attitude of the public toward these policies. The data sets used in this paper make it possible to compare individual-level opinions on trade with attitudes toward immigration policy, both within and across countries.

Pro-immigration attitudes appear to vary systematically according to the demographic and socio-economic background of the individual. I investigate the heterogeneity across countries in the impact of individual-level variables. I find that there exists a great deal of cross-country variation in terms of the correlation between the level of individual skill and attitudes in favor of immigrants. I identify a robust empirical regularity related to these two variables. The richer the host country is, the more positive is the impact of schooling on favorable opinions about immigrants. Individual skill is positively correlated with pro-immigration preferences in high per capita GDP countries and negatively correlated with pro-immigration preferences in low per capita GDP countries.

Additional results, based on a smaller sample of countries, suggest a labor-market explanation for this cross-country pattern. The correlation between the individual level of education and pro-immigration attitudes appears to be related to the skill composition of natives relative to immigrants, which varies across destination economies. This result suggests that individual attitudes are affected by the change, in the host country, of the relative supply of skilled to unskilled labor, due to the inflow of foreigners. My findings are consistent with the predictions of the Heckscher-Ohlin model, in the absence of factor-price-insensitivity, and of the factor-proportions-analysis model. In both factor-endowments models, individual attitudes toward foreigners depend on the impact on factor prices of immigration-induced changes in relative factor supplies. The robustness of the factor-endowments explanation is confirmed by additional results based on individual-level data on occupation. Individuals in occupations which experience a bigger increase in relative supply due to immigration, i.e. with a higher ratio of immigrants to natives, are less likely to be pro-immigration.

I next analyze correlation patterns between attitudes toward immigrants and individual answers to questions on non-economic issues. The inclusion in the empirical model of these additional regressors allows me to test the robustness of the empirical regularity previously observed. Noneconomic factors do not seem to alter significantly the results on the economic explanations. After controlling for how individuals feel about the impact of immigration on crime rates and on cultural and national identity, and taking into account people's racist attitudes and their feelings about political refugees and illegal immigration, I still find evidence of the same cross-country pattern, in terms of the correlation between individual skill and pro-immigration attitudes.

Finally, while preferences on immigration and trade are positively correlated, individuals appear

\footnotetext{
${ }^{3}$ The policy stances toward goods trade and labor flows have been characterized, historically, by a reversal in opposite directions. Immigration policies have experienced a tightening in the last century relative to the previous one, starting after WWI. Trade policies have been increasingly liberalized across the two centuries (except in the interwar period), especially after WWII (Faini 2002).
} 
to be, on average, more pro-trade than pro-immigration. My empirical results point out that one important source of this difference in attitudes is the cleavage in trade preferences, absent in immigration attitudes, between individuals working in traded sectors and individuals working in non-traded sectors.

Various papers have analyzed preferences on immigration policy but, in most cases, they have been characterized by the use of indirect measures of people's attitudes or by the focus on a single country, for example the United States and Great Britain. ${ }^{4}$ In addition, few empirical works have related their results to the predictions of theoretical models. This paper combines three elements of the previous literature: the use of a direct measure of individual immigration preferences, the comparison of attitudes both within and across different countries, and the interpretation of the empirical results in terms of the predictions of theoretical models.

Indirect measures of policy opinions, such as those based on voting and lobbying, are imperfect measures of preferences, because they are jointly determined by individual attitudes and the institutional structure of government (Scheve and Slaughter 2001b, 2001c). In a cross-country work, such as in this paper, this would be a serious shortcoming, since institutions are certainly different across nations. ${ }^{5}$ To get around this problem, I use two individual-level data sources: the 1995 National Identity module of the International Social Survey Programme and the third wave of the World Value Survey data set, carried out in 1995-1997. The first source contains data on 23 countries, mostly developed economies, while the second data source gives information on more than 40 nations, most of which are developing countries. Where possible, I test the robustness of the results using both data sets. The cross-country dimension of the two surveys allows me to test for interactive effects between individual-level characteristics and country-level variables. This empirical strategy makes it easier to overcome interpretational ambiguities that arise in single-country studies or in multi-country analyses that do not explore cross-country heterogeneity of coefficients.

From a methodological point of view, the empirical paper most related to my work is Scheve and Slaughter (2001b), who analyze individual preferences on immigration policy in the United States using the 1992 National Election Studies survey. The focus of their work is on determinants of immigration preferences working through the labor market. As in my paper, Scheve and Slaughter use a direct measure of individual opinions and closely relate the empirical analysis to the results of theoretical models. The main differences between Scheve and Slaughter's study and my analysis is that I adopt a cross-country perspective, which is richer in terms of theoretical predictions, and I focus on both economic and non-economic determinants of immigration preferences.

The outline of the paper is as follows. Section 2 describes the data sets. Section 3 focuses on economic explanations of attitudes, while Section 4 introduces non-economic determinants of preferences. In the last part of the paper, Section 5, I analyze immigration preferences and attitudes toward free trade in comparative terms and, in Section 6, I conclude.

\footnotetext{
${ }^{4}$ The empirical literature on individual preferences over immigration policy includes some works focusing on the United States (Citrin et al. 1997, Espenshade and Hempstead 1996, Kessler 2001, and Scheve and Slaughter 2001b) and on Great Britain (Dustmann and Preston 2001a and 2001b) and a few papers with a cross-country perspective (Bauer et al. 2000, Brücker et al. 2001, Chiswick and Hatton 2002, Gang et al. 2002, and O'Rourke and Sinnott 2003). The literature also offers historical accounts of the political economy of immigration restrictions at the turn of last century (Goldin 1994 and Timmer and Williamson 1996).

${ }^{5}$ That is, using indirect measures, it is not clear whether the variation in outcomes is due to differences in attitudes or in institutions.
} 


\section{Data}

This paper uses two individual-level survey data sets - that contain responses to questions on immigration - and additional data on international migration and on the characteristics of destination and origin countries of immigrant flows. The first survey with information on immigration attitudes comes from the International Social Survey Programme (ISSP). I use the 1995 ISSP National Identity module (ISSP-NI) covering more than 20,000 respondents from 23 countries, including the United States, Canada, Japan and several Western European countries. The survey also includes a few Eastern European countries and one developing country, the Philippines. ${ }^{6}$ For each individual, the data set contains socio-economic and demographic background variables and a variety of opinions on topics such as immigration and trade policies, patriotism, and national identity.

I focus on survey answers to the question: "There are different opinions about immigrants from other countries living in (respondent's country). (By "immigrants" we mean people who come to settle in (respondent's country).) Do you think the number of immigrants to (respondent's country) nowadays should be: (a) reduced a lot, (b) reduced a little, (c) remain the same as it is, (d) increased a little, or (e) increased a lot". ${ }^{7}$ Besides the five ordered answers, the survey format also allows for "can't choose" (CC) and "not available" (NA) responses.

The ISSP-NI data set includes a host of other questions on immigration-related issues. I focus on the question above because, in the theoretical section, I will consider the comparative-statics effects of changes in the number of immigrants. However, in various specifications, I use responses to other immigration-related questions as explanatory variables. For example, respondents are asked whether they think that immigrants increase crime rates and whether they believe that immigrants make the country more open to new ideas and cultures. This information is useful, because it allows me to control for some important non-economic determinants of immigration preferences.

I recode respondents' answers ( $1=$ "reduced a lot", to $5=$ "increased a lot"), and I call this variable Immig Opinion. I also create a dichotomous variable, Immig Opinion Dummy, equal to one for individuals who express pro-immigration attitudes (i.e., for those replying "increased a little" or "increased a lot"). ${ }^{8}$ Country-level summary statistics of the two dependent variables and of the other immigration-related questions are presented in Data Appendix 1 and 2.

Immigration opinions across countries are characterized by very large fractions of "can't choose" responses. As Appendix A.2 explains, omitting "can’t choose" responses may result in a selection bias. Given that I find no evidence that selection is an issue (see Appendix A.2), I restrict the sample to individuals who express an opinion and I use Immig Opinion and Immig Opinion Dummy as dependent variables. Since ordered probit results are harder to summarize, I will present and discuss the results from probit estimation based on the dichotomous variable. ${ }^{9}$

To control for each individual's socio-economic background, I use information from ISSP-NI

\footnotetext{
${ }^{6}$ See Data Appendix 1 for a list of the countries covered in the ISSP-NI data set.

${ }^{7} \mathrm{~A}$ similar question has been analyzed in most of the empirical literature on individual immigration preferences (Espenshade and Hempstead 1996, Scheve and Slaughter 2001b, Citrin et al. 1997, and Kessler 2001).

${ }^{8}$ I exclude non-nationals from the sample. "Can't choose" and NA responses are coded as missing values for both variables.

${ }^{9}$ Estimates of the ordered probit coefficients, using either one of the two data sets, are consistent with the results based on the dichotomous variable and are available upon request. Similarly, my results don't change when I keep $\mathrm{CC}$ and NA responses.
} 
questions on age, gender, parents' foreign citizenship, years of education, area of residence (rural vs urban), subjective social class, political affiliation with the right and trade union membership. I also use each respondent's individual real income as a basic indicator of individual economic status. ${ }^{10}$ A measure of individual skill is constructed from data on years of education and is used to test the implications of the factor-endowments models. Survey answers on individuals' occupation are also employed, to test the robustness of the results related to the factor-endowments models. Responses on topics such as national pride and identity, multiculturalism, illegal immigration and political refugees are used to control for non-economic determinants of immigration policy preferences. ${ }^{11}$

The ISSP-NI data set mostly covers high and middle-income economies. I complement the results from this source with the findings based on the third wave of the World Value Survey (WVS), carried out in 1995-1997. The WVS data set includes more than 50,000 respondents from 44 mostly developing economies. The immigration question in the WVS asks the following: "How about people from other countries coming here to work. Which one of the following do you think the government should do? (a) Let anyone come who wants to? (b) Let people come as long as there are jobs available? (c) Place strict limits on the number of foreigners who can come here? (d) Prohibit people coming here from other countries? (e) Don't know." I transformed answers to the WVS immigration question into two dependent variables: an ordered variable, Immig Opinion (WVS), and a dichotomous variable, Immig Opinion Dummy (WVS), both constructed after excluding "Don't know" responses from the sample. ${ }^{12}$ Again, for expositional clarity, I will present and discuss the results based on the dichotomous variable, whose country-level summary statistics are included in Data Appendix 6. The tables at the end of the paper - based on either the ISSP-NI or the WVS data sets - present the probit marginal effects and corresponding $z$ values of each regressor, holding all other variables at their mean. All the regressions include country fixed effects, to control for additive country-specific unobserved effects, and have standard errors adjusted for clustering on country.

The WVS, like the ISSP-NI data set, contains information at the individual level on the socioeconomic background of each respondent and on his labor market characteristics. Thus, in both data sets, it is possible to identify both stated immigration policy preferences and individual characteristics that explain immigration opinions in standard economic models.

Individual-level information from both data sources is combined with outside data on immigration flows and stocks from the International Migration Statistics data set for OECD countries (OECD 1997). Immigrants' flows numbers are based on the OECD's Continuous Reporting System on Migration (SOPEMI). Data on the origin and labor market characteristics of immigrants' stocks is based on survey and census data from Eurostat and national governments.

In particular, in this paper I use statistics on immigrant inflows into OECD countries in the

\footnotetext{
${ }^{10}$ Please see footnote at the end of Table 1 for definitions of these variables.

${ }^{11}$ The details about the construction of these variables are given in a related paper on trade policy preferences, Mayda and Rodrik (2003), and in the Tables and Data Appendix.

${ }^{12}$ I exclude from the analysis people who were not born in the country where the survey is carried out. I then recode respondents' answers to construct the variable Immig Opinion (WVS), which ranges from 1= "prohibit people coming here from other countries" to $4=$ "Let anyone come who wants to". Immig Opinion Dummy (WVS) is defined as follows: Immig Opinion Dummy $(\mathrm{WVS})=1$, if Immig Opinion (WVS)=3 or 4; 0, if Immig Opinion (WVS)=1 or 2. See Appendix A.2 for how I deal with "Don’t Know" responses.
} 
period 1990-1995; on native and immigrant populations by level of education in $1995^{13}$; and on native and immigrant populations by occupation in 1995, according to the 1988 International Standard Classification of Occupations (ISCO)..$^{14}$

Data on religious adherence in the host country and in the main countries of origin of foreigners come from Barro and McCleary (2002), while statistics on language in the destination and source countries of immigrants and on the colonial relationship between pairs of countries come from Glick and Rose's website. ${ }^{15}$ Finally, data on exchange rates, purchasing power parity conversion factors and population come from the 2001 World Development Indicators CD-ROM, developed by the World Bank. Tables in the Data Appendix contain country-level summary statistics of the main variables used in the paper.

\section{Economic Determinants of Individual Attitudes}

Most likely, both economic and non-economic factors shape individual preferences over immigration policy. Among the economic determinants, one of the most important is likely to be the impact of immigrants on natives' returns through factor markets. Focusing on two factors, skilled and unskilled labor, this effect will take place in labor markets. The main results of my analysis are related to this determinant. ${ }^{16}$ By considering this aspect of preference formation, I investigate whether individuals reveal, through their attitudes, a self-interest maximizing or economicallyrational behavior, as assumed in the models of Section 3.2.

The variation in attitudes toward foreigners may also depend on differences in individual perceptions of the economy-wide benefits and costs of immigration. I test the robustness of the results based on maximization of individual utility to this alternative explanation. Finally, another important economic factor shaping people's stance is the perceived fiscal impact of immigration on the welfare state. In some receiving countries immigrants are likely to belong to the bottom of the income distribution, which makes them probable beneficiaries of costly welfare programs. My results shed light on this issue as well.

Non-economic factors affecting immigration opinions include security issues as well as nationalidentity and cultural considerations. Racist feelings also are likely to shape attitudes toward foreigners. Finally, individual beliefs about civil and human rights - specifically concerning political refugees - and the attitude toward illegal immigration are additional important elements of people's opinions about foreigners. I will consider such non-economic determinants in Section 4.

\footnotetext{
${ }^{13}$ Education levels are coded according to the International Standard Classification of Education (ISCED): 1. less than first stage of 2nd level (ISCED 00, 01 and 02); 2. completed 2nd stage of 2nd level (ISCED 03 and 04 ); 3. completed 3rd level (ISCED 05 and over); 4. other general education, not applicable and no answer. ISCED level 02 usually refers to a ninth grade education.

${ }^{14}$ Occupations by 1988 ISCO are classified as follows: 1 . Armed forces; 2. Legislators and managers; 3. Professionals; 4. Technicians; 5. Clerks; 6. Service and sales workers; 7. Agricultural and fishery workers; 8. Craft and related trades workers; 9. Plant and machine operators; 10. Elementary occupations.

${ }^{15}$ Data on religious affiliation from Barro and McCleary (2002) use figures for the 1980s from the first edition of the World Christian Encyclopedia (Barrett 1982).

${ }^{16}$ Since the models I will present in Section 3.2 assume full employment, the impact of immigration on natives in factor-markets occurs through changes in factor prices.
} 
Before narrowing the focus of the analysis, it is interesting to look at the most basic patterns in the two surveys. Table 1a, based on the ISSP-NI data set, and Table 1b, based on the WVS figures, present the results from a benchmark model of immigration attitudes, whose focus is on the social, demographic and economic background of each respondent. ${ }^{17}$ As both sets of results show, older people favor immigration restrictions, as do individuals living in more rural areas and in smaller towns. ${ }^{18}$ More educated individuals and respondents with family ties to non-nationals are more open to immigration. The gender effect, quite strong in the ISSP-NI data set, disappears using the WVS statistics. ${ }^{19}$ Affiliation with more conservative political parties is negatively correlated with pro-immigration preferences, in both sets of findings. Using the ISSP-NI data set, individual (real) income, social class, and trade union membership do not have a significant impact on immigration preferences. On the other hand, relative income positively affects attitudes toward foreigners in the WVS sample of countries.

One of the most robust findings in the benchmark model, estimated with both the ISSP-NI and the WVS data sets, is a significant and positive impact of education on pro-immigration attitudes. The variables used in Tables $1 \mathrm{a}$ and $1 \mathrm{~b}$ as measures of schooling, years of education (in the ISSP-NI data set) and educational attainment (in the WVS data set), are among the most often employed in the labor and growth literatures as indicators of levels of skill. Thus, these initial results reveal that, on average, in the sample of countries considered, there is a positive and significant correlation between individual skill and pro-immigration preferences. In the following empirical analysis, I will qualify this result.

In the next section I address the following question: Does the correlation between individual socio-economic characteristics and immigration attitudes vary across countries? I find empirical evidence of cross-country heterogeneity with respect to the impact of individual skill on immigration attitudes and investigate what explains this pattern (Section 3.1). A range of empirical tests shows that the effect of individual skill is, in fact, working through the labor market. I therefore look into the labor-market predictions of two factor-endowments models, which I present in Section 3.2. Additional empirical analysis in Section 3.3 tests more directly the theoretical findings and produces results consistent with them. I next use individual-level data on occupation to examine whether individuals in occupations with a higher fraction of immigrants to natives are more likely to be anti-immigration (Section 3.4). By interpreting each occupation as a different factor of production, this analysis allows me to further test the robustness of the factor-endowments explanation.

\subsection{Does the correlation between individual socio-economic characteristics and immigration attitudes vary across countries?}

In the benchmark model, I constrain the coefficients on individual characteristics to be equal for all countries in the samples. However, the impact of socio-economic and demographic variables

\footnotetext{
${ }^{17}$ The regressors included are age, male, rural (area of residence: rural vs urban), parents' foreign citizenship, years of education, (log of) real income, political affiliation with the right, upper social class, trade union membership (in ISSP); age, male, educational attainment, upper social class, political affiliation with the right, town size, relative income, national pride (1) and national pride (2) (in WVS).

${ }^{18}$ The statistical significance of these results changes across specifications.

${ }^{19}$ The gender effect disappears using the ISSP-NI data set too, once I control for individual occupation (Table 3 ).
} 
on immigration attitudes is likely to differ across economies. I take advantage of the panel-data structure of the two data sets and investigate cross-country heterogeneity of coefficients. I find that, while the effect of most variables does not vary, the impact of individual skill differs considerably across countries. ${ }^{20}$

Before presenting the results of the econometric analysis, it is informative to look at the graphs in Figure 1, which offer preliminary evidence on the main result in the paper. I choose three countries in the sample, with different levels of per capita GDP. For each country, I plot the percentages of individuals who are pro-immigration by education group. In the United States, a high-income country, the more advanced the education category, the bigger the fraction of individuals who are pro-immigration. I find the same pattern for the other high per-capita-GDP countries in the two samples (not shown). The graph for one of the lowest-income countries in the data sets, Nigeria, looks quite different: the higher the education group, the lower the fraction of individuals who are pro-immigration. Finally, for a middle-income country in the sample, such as Uruguay, the fractions of pro-immigration individuals do not appear to vary significantly across education groups. ${ }^{21}$

I next present the results from probit estimation, which allows me to control for each individual's socio-economic background. I first estimate the model separately for each economy.

The country-specific regressions show that there is a great deal of cross-country variation in terms of the correlation between individual skill and attitudes. Figures 2, 3a and 3b summarize the evidence across countries. Figure 2 for the ISSP-NI sample presents the country-specific marginal effect of years of education on pro-immigration preferences (y axis) as a function of per capita GDP of the destination economy (x axis). ${ }^{22}$ Figures 3a and 3b for the WVS data set are similarly constructed. ${ }^{23}$ All three graphs show a positive relationship between per capita GDP of the host economy and the size of the country-specific impact of individual skill on attitudes in favor of foreigners.

I can gain additional insight on this pattern by, again, pooling all countries together in a single regression. As before, I use per capita GDP as a summary measure of each destination economy to differentiate the effect of schooling by host country. Specifically, I include in the model specification both the direct effect of individual skill and an interaction variable, education ${ }^{*} g d p$, which is the product of the education measure times each country's (log) per capita GDP in 1995 (in international dollars). Column (1) of Table 2a presents the marginal effects of this specification, estimated using the ISSP-NI data set.

\footnotetext{
${ }^{20}$ In particular, with the ISSP-NI data the correlation between immigration attitudes and, respectively, age, gender, parents' foreign citizenship, real income is not significantly different across countries, when I use per capita GDP (in 1995, PPP-adjusted) as a summary measure of each country. Instead, the impact of political affiliation with the right varies according to the level of national income.

${ }^{21}$ The per capita GDP levels in 1995, PPP-adjusted, of the United States, Nigeria, and Uruguay are respectively and approximately: 28,000; 825; and 8000 international dollars.

${ }^{22}$ I estimate a separate probit model for each country. In Figure 2 the y axis measures, for each country, the estimated marginal effect of years of education on the probability of being pro-immigration, holding all other regressors at their mean value. I control for age, male, and education.

${ }^{23}$ In both Figures 3a and 3b, for each country, the y axis measures the estimated marginal effect of the highest education level attained on the probability of being pro-immigration, holding all other regressors at their mean value. I control for age, male, country of birth, upper social class, political affiliation with the right, and education. The first graph refers to the whole sample of countries, the second one only to countries with 1995 per capita GDP (PPP) less than 15,000 international dollars.
} 
I find strong evidence of a reversal in the impact of the individual skill level on immigration preferences. Individual skill appears to be positively correlated with pro-immigration preferences in high per capita GDP countries and negatively correlated with pro-immigration preferences in low per capita GDP countries.

In particular, the estimates for years of education (-0.0454, significant at the $1 \%$ level) and education ${ }^{*} g d p$ (0.0054, significant at the $1 \%$ level) imply that any country with per capita GDP in 1995 (PPP-adjusted) lower than approximately $\$ 4480$ is characterized by a negative correlation between skill and pro-immigration preferences, while individuals from countries with per capita GDP above this threshold are more likely to be in favor of immigration the more educated they are. These results are consistent with the empirical regularity uncovered by the country-specific regressions and summarized in Figures 2, 3a and 3b. In addition, I will show that these findings are very robust, using various specifications and different skill measures, in both the ISSP-NI and the WVS data sets.

In testing the robustness of my main result, I investigate several empirical issues. I first question whether the coefficient on schooling is really capturing the impact of individual skill, i.e. whether the estimated effect is working through the labor market. I next check that the main results are robust to changes in the samples of countries considered. Finally, in Sections 3.2 and 3.3, I explore which aspect of the destination country I am accounting for, when I use per capita GDP as a summary measure of its economy.

Table 2a, based on the ISSP-NI data set, and Table 2b, based on the WVS figures, present the results of various robustness checks.

Both skill measures (years of education and educational attainment) are likely to be correlated with individual characteristics which have an impact on immigration preferences. Such omitted variables could bias the estimates and drive the main result. To (partly) address this problem, in regressions (2)-(5) in Table $2 \mathrm{a}$ I include additional controls, relative to the core specification of column (1). In regression (2), the inclusion of the variable political affiliation with the right does not considerably affect the main cross-country pattern. The individual likelihood of being pro-immigration still increases with education in high per capita GDP countries, but it decreases with it if the destination economy is poor.

This finding does not change after controlling for the (log of) individual real income in column (3). The impact of the latter variable is not significant and does not alter considerably the main result. This rules out the possibility that the education measure is only picking up the effect of economic status. In addition, by controlling for total individual income, I can in part account for ownership of other factors of production owned by the respondent, like capital. ${ }^{24} \mathrm{I}$ also check whether the non-linearity in the impact of education is driven by the reversal of the effect of individual income. I find no evidence of this in regression (4), which shows that it is the impact of education, and not of income, that is non-linear and significant. Finally, since individual contributions to and benefits from the welfare state are usually proportional to individual income, results in columns (3) and (4) are also evidence against a welfare-story explanation of attitudes.

I further investigate the possibility that the effect of education is working through channels other than the labor market. In the ISSP-NI data set, I systematically test the robustness of the results

\footnotetext{
${ }^{24}$ The two data sets do not contain direct information on individual capital ownership.
} 
based on years of education by controlling for the following two regressors: Immig Crime, which represents the respondent's perceived impact of immigration on crime rates and Immig Culture, which quantifies the respondent's perceived cultural effect of immigration. Security issues and cultural considerations are likely to be among the most important non-economic determinants of preferences which are affected by schooling. By comparing two individuals who feel the same in terms of these issues, I hope to better isolate the economic channel, which links individual skill to immigration preferences through the labor market. ${ }^{25}$ The results in regression (5), which controls for Immig Crime and Immig Culture, still show the same pattern as in column (1): better skilled individuals are more likely to be pro-immigration in richer countries, and less likely in poorer countries.

I next verify my results by making use of a different measure of individual skill, which is less vulnerable to omitted-variables problems. In column (6), in place of years of education, I employ a second indicator of skill, skilISCO, which uses information on occupation based on the 1988 ISCO classification. ${ }^{26}$ skilISCO exploits the skill-based nature of the 1988 ISCO categorization of occupations. ${ }^{27}$ As O'Rourke and Sinnott (2001) emphasize, it is a particularly good-quality indicator of individual skill since, in addition to formal schooling, it captures the role of on-the-job training and of the nature of the work. Using skilISCO and its interaction with each country's (log) per capita GDP in 1995, I find evidence of the same pattern as before.

As a final robustness check, to gain more evidence on whether the impact of schooling is indeed working through the labor market, I follow Scheve and Slaughter (2001b) in running two separate regressions, one for the subsample of individuals who belong to the labor force and the other for those who do not. ${ }^{28}$ I expect to see no effect of education for individuals out of the labor force if the correlation between schooling and preferences is in fact driven by labor-market causes.

The estimates in Table 2c confirm that the impact of education on immigration attitudes is in fact related to the labor-market channel. Compared to the full sample, the preferences-skill pattern is more pronounced in the labor-force subsample and, on the other hand, any correlation is absent (the estimates are considerably smaller and not significant) in the group of individuals out of the

\footnotetext{
${ }^{25}$ It is possible that the coefficient estimates on education - in the regressions which control for Immig Crime and Immig Culture - are missing some of the effect of individual skill. That is, it may be that I am overcontrolling, given that these variables are not exogenous. An individual may be against immigrants for economic reasons and, as a consequence, have a negative opinion of them from a cultural and security point of view. Citrin et al. (1997) notice that "...in-group solidarity and out-group hostility themselves are often thought to change in response to material threat" (p.862).

${ }^{26}$ The idea to construct this measure using the International Labour Organisation's 1988 ISCO coding scheme comes from O'Rourke and Sinnott (2001), who use the same ISSP-NI data set in their analysis of trade policy preferences. 1988 ISCO matches each occupation with one of four skill levels, which are defined according to the level of education (by ISCED classification) and to the extent of informal training and experience required to perform a job.

${ }^{27}$ skilISCO equals one if the 1988 ISCO occupation code is 2 (legislators and managers), 3 (professionals) and 4 (technicians); it equals zero if the 1988 ISCO occupation code is 5 (clerks), 6 (service and sales workers), 7 (agricultural and fishery workers), 8 (craft and related trades workers), 9 (plant and machine operators) and 10 (elementary occupations).

${ }^{28}$ The labor force subsample includes individuals who are full-time employed, part-time employed, less than parttime employed (main job); unemployed. The out-of-the labor force subsample includes individuals who are retired; housewifes (men), in home duties; permanently disabled, sick; others, not in labour force, not working. I exclude students from the sample since their number of years of education does not reflect their expected future skill.
} 
labor force. ${ }^{29}$

In Figure 4, I use data from the ISSP-NI data set and I draw regression lines as in Figures 2, 3a and 3b. The regression lines in Figure 4 refer to the two subsamples of individuals who, respectively, are and are not in the labor force. In particular, after dividing the sample into the two groups, I separately estimate the country-specific marginal effect of years of education on pro-immigration preferences for the subsample of individuals who are in the labor force and, next, for the subsample of individuals outside the labor force. Each line in Figure 4 gives the fitted values of the regression of these marginal effects on per capita GDP in 1995. Figure 4 clearly shows that the correlation between the impact of skill on attitudes and the country's level of per capita income disappears for individuals outside the labor force. This is another piece of evidence in favor of the labor-market interpretation of the cross-country pattern.

The empirical regularity is also robust to excluding from the sample the only developing country in the ISSP-NI data set (the Philippines) in column (7) and to dropping observations from lowincome countries (Poland, Bulgaria, Russia, Philippines, Latvia) in column (8).

Finally, my estimates do not change considerably (not shown) when I control for Immig Economy, which measures the impact of immigration on the country's economy, as perceived by the individual. Economy-wide benefits and costs of immigration appear to be important, but they do not drive the results on individual skill (the latter ones relate to the distributional impact of immigration).

The results from Table $2 \mathrm{~b}$, which are based on the WVS figures, confirm the strength of the main result found with the ISSP-NI data set. I use survey questions to construct four different measures of individual skill: the highest education level attained by the individual, the age at which the respondent has completed education, and two skill measures based, respectively, on occupation data for the individual and for the chief-wage-earner in the household. ${ }^{30}$ Using any of the four indicators of skill, the impact of education on immigration preferences once again is positive for high-income countries and negative for low-income countries. Hence, Table $2 \mathrm{~b}$ suggests that the previous estimates, based on the ISSP-NI data set, are not driven by the particular sample of countries there considered. Indeed, the WVS data set mostly includes developing countries and thus complements the ISSP-NI sample.

\subsection{Factor-Endowments Models of Immigration-Policy Attitudes}

The empirical results, so far, reveal a robust empirical regularity - a positive and significant correlation between per capita GDP and the size of the impact of individual skill on pro-immigration preferences - and evidence that the effect is working through the labor market. I now look at the predictions of two economic models - the Heckscher-Ohlin (HO) model and the factor-proportionsanalysis (FPA) model - as regards the impact of labor movements on individual attitudes working

\footnotetext{
${ }^{29}$ Table 2c, based on the ISSP-NI data set, mirrors Table 4 (constructed using US data) in Scheve and Slaughter (2001b). Notice that the results in Table 2c are robust to changes in the sample of countries considered, as I find evidence of the same patterns when I use the WVS data set.

${ }^{30} \mathrm{I}$ consider the second measure - the age at which the respondent has completed education - the least reliable one of all, given that in some countries the duration of schooling required to reach a given level of skill is higher, because of deficiencies in the education system.
} 
through labor markets. In terms of the distributional effect of immigration, the interaction between individual factor type and each country's factor endowments plays a key role in both the HO model and the FPA model. Hence, I will refer to both models as factor-endowments models.

The HO model is one of the workhorse models of international trade. The model focuses on small open economies, characterized by constant returns to scale and perfect competition in each sector. ${ }^{31}$ At least two goods are assumed to be produced, so that trade can take place between countries. In addition, there exists a national labor market for each factor of production, that is, factors are perfectly mobile within country borders.

The key feature of the HO model is differences across economies in relative factor endowments. Through trade, each country either exports or imports the services of a factor of production according to whether it is abundantly or poorly endowed with it, relative to the rest of the world.

The predictions of the HO model, with regard to the impact of immigration on factor rates of return, depend on a key condition that relates the number of internationally-traded goods produced in the country $(n)$ to the number of primary factors of production $(m)$. If $n \geq m$, ceteris paribus a sufficiently small increase of a factor's supply does not have any effect on factor rates of return: factor-price-insensitivity holds. If the shock to the factor's supply is substantial or if $n<m$, a change in a factor endowment changes factor prices. Thus, in the HO model, the impact of immigration on factors' rates of return depends on the extent of diversification of the country's production, in terms of internationally-traded goods, and on the size of the factor supply shock.

To gain intuition regarding these predictions, I present a simple model that suits the empirical analysis in the paper: the $3 \times 2 \mathrm{HO}$ model with and without diversification. (See Appendix A.1 about factor-price-insensitivity in the $m \times n \mathrm{HO}$ model.) The $3 \times 2 \mathrm{HO}$ model encompasses both factorendowments models since, in terms of labor-market predictions, the case without diversification (one-good model) corresponds to the factor-proportions-analysis (FPA) model described in Borjas (1999a).

Consider a small open economy with three factors (skilled labor, unskilled labor, and capital) which produces two goods. Capital is assumed to be internationally mobile. That is, the supply of capital is elastic and the rental rate of capital always equals the international one $\left(r=r^{*}\right)$, so that $d r=0$. The native workforce has a fraction $b$ of skilled workers and a fraction $(1-b)$ of unskilled workers $(N=b * N+(1-b) * N)$. The immigrant workforce has a fraction $\beta$ of skilled workers and a fraction $(1-\beta)$ of unskilled workers $(M=\beta * M+(1-\beta) * M) .{ }^{32}$ The total labor force is $L=N+M$.

Two sets of conditions hold in equilibrium on the production side, the production equilibrium conditions - price is equal to unit cost in each sector - and the set of factors' full-employment conditions:

\footnotetext{
${ }^{31}$ For what matters in this paper - i.e., the sensitivity of factors' prices to changes in factors' endowments - it is not important whether trade is free or if, instead, there exist some barriers to free trade (like tariffs or quotas) which create a wedge between international prices and domestic prices.

${ }^{32}$ I assume that immigrants only own skilled and unskilled labor. Therefore immigration directly changes the destination country's supply of skilled and unskilled labor. Immigration also induces changes in the supply of capital but, in this paper, I will assume that any immigration-induced change in the supply of capital is given by changes in capital owned by the rest of the world.
} 


$$
\begin{gathered}
p_{i}=b_{i}\left(w_{S}, w_{U}, r\right), \quad i=1,2 \\
S=\sum_{i=1}^{2} y_{i} b_{i S}(\cdot) \\
U=\sum_{i=1}^{2} y_{i} b_{i U}(\cdot) \\
K=\sum_{i=1}^{2} y_{i} b_{i K}(\cdot)
\end{gathered}
$$

where $p_{i}$ and $y_{i}, i=1,2$ are respectively prices and quantities produced of each good and $b_{i}(\cdot), i=$ 1,2 are sectors' unit cost functions, characterized by partial derivatives (with respect to each factor price) $b_{i k}(\cdot), k=S, U, K \cdot{ }^{33} S=b N+\beta M, U=(1-b) N+(1-\beta) M$ and $K$ are respectively the total supply of skilled workers, unskilled workers and capital, and $w_{S}, w_{U}$ and $r$ are respectively the price of skilled labor, unskilled labor and capital.

Let's consider the case when the country produces both goods and the immigration shock is sufficiently small. Systems (1) and (2) show that factor-price-insensitivity holds: factor prices are insensitive to changes in factor endowments induced by immigration. ${ }^{34}$ System (1), in 2 equations and 2 unknowns $\left(w_{S}, w_{U}\right.$, while $r$ always equals $\left.r^{*}\right)$, pins down the rates of return to factors. ${ }^{35}$ Based on (1), unless goods' prices change in international markets or technology improves, factor prices do not change. Therefore, a small increase in the number of immigrants $(d M>0)$ does not change factor prices $\left(d w_{S}=d w_{U}=0\right)$, even though it affects the endowment of factors. In this case, immigration-induced changes in factor supplies only concern system (2) and are absorbed through Rybczynski effects, with reallocation of factors across sectors.

If the country only produces one good or if the immigration shock is big enough to change which goods are produced, rates of return to factors change due to immigration. ${ }^{36}$ In the former case, without diversification, the labor-market predictions of the (open-economy) HO model are the same as in the (closed-economy) factor-proportions-analysis (FPA) model, which has been widely used in the labor economics literature (Borjas 1999a, Borjas et al. 1996 and Borjas et al. 1997). One of the critical assumptions of the FPA model is that there exists a single aggregate output market. In addition, as in the HO model, a national labor market characterizes every factor of production, that is factors can move costlessly across economic sectors.

The FPA model predicts that any change in the country's relative factor endowments has an impact on factor prices. ${ }^{37}$ In particular, in the host country, the sign of the derivative of the skilled (unskilled) wage with respect to $M$ is unambiguously determined by the difference between $b$ and

\footnotetext{
${ }^{33}$ The partial derivatives $b_{i k}(\cdot)$ give the cost-minimizing requirement of input $k$ necessary to produce one unit of $\operatorname{good} i$.

${ }^{34}$ The case when both goods are produced is such that the number of primary factors of production (excluding capital, which is internationally mobile) is no greater than the number of goods $(n)$.

${ }^{35}$ I assume that no factor-intensity reversals occur.

${ }^{36}$ The intuition about the first condition is that, with only one equation in (1), the full-employment conditions are now necessary to pin down factor prices. The intuition about the second condition is that the equations of system (1) have now changed (some of them correspond to different goods).

${ }^{37}$ The difference between the HO model and the FPA model becomes clearer by thinking in terms of the labor demand curve. In the FPA model, the labor demand curve is downward sloping. In the HO model, the labor demand curve is still downward sloping, but it is also characterized by flat regions, corresponding to the ranges of factors' endowments for which factor-price-insensitivity holds (Scheve and Slaughter 2001b).
} 
$\beta$, that is the difference between the fraction of skilled workers in, respectively, the native and the immigrant workforce (Borjas 1999a): ${ }^{38}$

$$
\begin{array}{ll}
\frac{d w_{S}}{d M}=k_{1}(b-\beta) \frac{w_{S}}{N}, \quad k_{1}>0 \\
\frac{d w_{U}}{d M}=k_{2}(b-\beta) \frac{w_{U}}{N}, \quad k_{2}<0
\end{array}
$$

Hence, the skilled wage is an increasing function of $M$ if $(b-\beta)>0$, a decreasing function of $M$ if $(b-\beta)<0$, and is independent of $M$ if $(b-\beta)=0$. Intuitively, if $(b-\beta)>0$, immigrants are less skilled than natives: thus the relative supply of skilled to unskilled labor decreases with the inflow of foreigners and the skilled wage increases. If $(b-\beta)<0$, skilled labor becomes relatively less scarce after immigration and the rate of return to skill decreases. Finally, if $(b-\beta)=0$, immigration-induced changes in factor supplies do not alter the skill composition of the labor force in the destination country and the structure of factor returns stays the same.

In both factor-endowments models, I assume that individuals in the economy are endowed with different amounts of skilled and unskilled labor and of capital. Income of individual $j$ is therefore equal to $y_{j}=w_{S} \cdot s_{j}+w_{U} \cdot u_{j}+r \cdot k_{j}$. Each individual is characterized by the indirect utility function $v_{j}\left(p_{1}, p_{2}, y_{j}\right)$. If individuals care only about economic self-interest, preferences on immigration policy will depend on the sign of the derivative $\frac{d v_{j}}{d M}$. Individual $j$ will be in favor of an increase in the number of immigrants $(d M>0)$ if and only if $\frac{d v_{j}}{d M} \geq 0$ which, given the assumption of small open economy, becomes: ${ }^{39}$

$$
\frac{\partial v_{j}}{\partial y_{j}} \frac{d y_{j}}{d M} \geq 0
$$

The last inequality is satisfied if and only if $\frac{d y_{j}}{d M} \geq 0$, which implies (given that $d r=0$ ): ${ }^{40}$

$$
\frac{d v_{j}}{d M} \geq 0 \Leftrightarrow \frac{d w_{S}}{d M} \cdot s_{j}+\frac{d w_{U}}{d M} \cdot u_{j} \geq 0 .
$$

Inequality (5) shows that the relationship between immigration preferences and individual factor type $\left(s_{j}\right.$ and $\left.u_{j}\right)$ depends on how immigration changes factor prices. If there is diversification in production $(n \geq m)$ and the supply shock is sufficiently small, there should be no link between individual skill and preferences, since factor-price-insensitivity holds $\left(d w_{S}=d w_{U}=0\right)$. In any other situation, the level of individual skill and attitudes toward immigrants should be correlated, in accordance with the relative skill composition of natives to immigrants, which determine how

\footnotetext{
${ }^{38}$ In particular, the changes of the skilled and unskilled wage given an inflow of immigrants $d M>0$ are respectively equal to (assuming $d r=0)$ :

$\frac{d w_{S}}{d M}=w_{S} \frac{\alpha_{U}}{\left(\alpha_{S}+\alpha_{U}\right)} \frac{1}{N} \frac{(b-\beta)}{b(1-b)}$ and $\frac{d w_{U}}{d M}=-w_{U} \frac{\alpha_{S}}{\left(\alpha_{S}+\alpha_{U}\right)} \frac{1}{N} \frac{(b-\beta)}{b(1-b)}$,

where $\alpha_{i}$ is the share of national income accruing to factor $i$ and $M=0$ at the beginning of the period. These formulas correspond to Borjas's (1999a) results in the case of a Cobb-Douglas production function.

${ }^{39}$ The hypothesis of small open economy implies $\frac{\partial p_{i}}{\partial M}=0, i=1,2$ (since goods' prices are set in international markets).

${ }^{40} \mathrm{I}$ assume that the individual level of skill and capital among natives is not affected by immigration.
} 
factor prices are affected. To summarize, more broadly, according to the factor-endowments models, individual attitudes on immigration policy are determined by each respondent's factor type, the receiving country's relative factor supply and the relative factor endowment of the flow of immigrants. ${ }^{41}$

\subsection{Additional empirical evidence on the correlation between individual skill and immigration attitudes}

My results in Section 3.1 show that individual skill is positively correlated with pro-immigration preferences in high per capita GDP countries and, negatively, in low per capita GDP countries. I next investigate which variable per capita GDP is proxying for, using the insights from the theoretical models of Section 3.2.

Per capita GDP is thought to be a good proxy for a country's human capital endowment. However, according to the models in Section 3.2, the (ex-ante) skill composition of the destination country's labor force by itself does not pin down the sign of the relationship between individual skill and preferences. Ceteris paribus, in countries with equal endowments of human capital, skilled individuals may have different attitudes toward immigrants, depending on the skill composition of these foreign workers. In other words, it is the skill composition of natives relative to immigrants which matters.

In a very simple one-sector model where countries share the same production function, economies with higher ratios of skilled to unskilled labor (high per capita GDP countries) have lower rates of return to skilled labor and higher rates of return to unskilled labor. The opposite is true for countries with low values of the skill ratio (low per capita GDP countries). Labor flows are driven by differences in real rates of return to factors. Therefore, in this simple model, skilled labor tends to move from high to low per capita GDP countries and, unskilled labor, in the opposite direction. Based on such simplifying assumptions, it is possible to predict the skill composition of the inflow of immigrants (and, therefore, also relative to natives), as a function of per capita income of the destination country.

However, taking into account cross-country differences in technology levels complicates the theoretical predictions. Given such a model, in richer countries rates of return can be higher than in the rest of the world for all factors, making it difficult to guess the skill composition of the immigrant workforce. ${ }^{42}$

Hence, in order to explain my results in terms of the predictions of the factor-endowments models, I need to test the following claim: per capita GDP in the regressions of Tables 2a and $2 \mathrm{~b}$ is proxying for the relative skill composition of natives to immigrants $\left(\frac{b}{(1-b)} / \frac{\beta}{(1-\beta)}\right) .{ }^{43}$ It is hard to test this hypothesis directly, due to the scarcity of immigration data. For each receiving country, I need information on immigrants and their skill level and, in comparable terms, the same

\footnotetext{
${ }^{41}$ Benhabib (1996)'s political economy paper of immigration policy preferences is similarly constructed.

${ }^{42}$ Davis and Weinstein (2002) stress the same point when they notice that all factors (unskilled labor, skilled labor and capital) are characterized by positive net inflows into the United States.

${ }^{43}$ The relative skill composition of natives to immigrants $\left(\frac{b}{(1-b)} / \frac{\beta}{(1-\beta)}\right)$ is the ratio of skilled to unskilled labor in the native relative to the immigrant populations. The theoretical predictions in (3) and (4) are in terms of the difference $(b-\beta)$. But notice that $\frac{b}{(1-b)} / \frac{\beta}{(1-\beta)}>1$ if and only if $(b-\beta)>0$.
} 
statistics on natives. The OECD International Migration Statistics (IMS-OECD) data allows me to construct the ratio $\frac{b}{(1-b)} / \frac{\beta}{(1-\beta)}$ for fifteen countries, all developed economies. ${ }^{44}$ Indeed, for each of these fifteen countries, the IMS-OECD statistics give figures on native and immigrant populations by ISCED level of education. ${ }^{45}$ However, only some of these countries are included in the ISSP-NI data set (very few of them are present in the WVS data set).

Initial evidence in favor of my hypothesis is the simple correlation between per capita GDP and the relative skill composition of natives to immigrants. Based on the fifteen countries for which data is available, this correlation is equal to 0.6120 (significant at the $1.53 \%$ level).

The regressions in Table 3, based on a smaller number of countries than previous tables, also offer evidence consistent with the theoretical predictions in Section 3.2. ${ }^{46}$ The marginal effects of regressions (1) and (2) resemble the results from Tables $2 \mathrm{a}$ and $2 \mathrm{~b}$. The difference is that now the country-specific impact of individual skill on immigration preferences is modeled directly as a function of the relative skill composition of natives to immigrants. In other words, I have replaced the product term education ${ }^{*} g d p$ with the new interaction variable education ${ }^{*}$ relative skill ratio. ${ }^{47}$

The results in columns (1) and (2) show that the relationship between the individual level of skill and pro-immigration attitudes depends on the relative skill ratio. Educated individuals are more likely to be pro-immigration if the latter variable is above a given threshold. ${ }^{48}$ This result is consistent with the theoretical predictions since, the higher the relative skill composition of natives to immigrants, the smaller the ex-post relative supply of skilled to unskilled labor in the destination economy, and the higher (lower) the skilled (unskilled) wage. Notice that in regression (3), which controls for both interaction terms education* ${ }^{*} d p$ and education ${ }^{*}$ relative skill ratio, only the marginal effect on the latter variable is significant. This result suggests that, in previous regressions, per capita GDP was indeed capturing the effect of the skill composition of natives relative to immigrants.

The last two regressions test a more restrictive hypothesis. Based on the models of Section 3.2, if the skill composition of immigrants exactly mirrors the human capital endowment of the native population $(\beta=b)$, there should be no effect of immigration on factor returns and, therefore, on

\footnotetext{
${ }^{44}$ The fifteen countries with data on skill composition of natives and immigrants are: West Germany, East Germany, Great Britain, Austria, Italy, Ireland, Netherlands, Sweden, Canada, Spain, Portugal, France, Denmark, Belgium, Finland.

${ }^{45}$ Due to unavailability of data on the skill composition of the flow of immigrants, I use the same type of information for the stock of immigrants. In other words, I adopt the same assumption as in Borjas (1999a)'s model: the skill composition of immigrants is assumed not to change over time.

${ }^{46}$ The regressions of Table 3 are based on the following countries: Germany West, Germany East, Great Britain, Austria, Italy, Ireland, Netherlands, Sweden, Canada, Spain. These are the countries in the ISSP-NI sample for which data on $\frac{b}{(1-b)} / \frac{\beta}{(1-\beta)}$ is available.

${ }^{47}$ In particular the relative skill ratio is the log of one plus the relative skill composition of natives to immigrants: relative skill ratio $=\ln \left(1+\frac{b}{(1-b)} / \frac{\beta}{(1-\beta)}\right)$. For both natives and immigrants, the ratio of skilled to unskilled labor is measured as the ratio of the number of individuals with levels of education 2 and 3 to the number of individuals with level 1 of education (see footnote 13). The data used to construct this variable is for the stock of immigrants and natives in 1995 and comes from the IMS-OECD data (OECD 1997).

${ }^{48}$ The analysis in columns (1) and (2) assumes that individuals across countries think of an increase in the number of immigrants in equal percentage terms, relative to their country's population $\left(\frac{d M}{N}\right)$. If I instead consider the actual number of immigrants relative to the population in 1995 (immigrant) and I construct the interaction variable education* ${ }^{*}$ relative skill ratio*immigrant, the coefficient on the latter variable and the direct effect of education are both positive and significant.
} 
preferences. If instead natives are more (less) skilled than immigrants, the relative supply of skill will be lower (higher) ex-post and real rates of return to skilled labor will be higher (lower). In column (4), SN (skilled natives) is an indicator variable for whether the ratio of skilled to unskilled labor for natives is greater than for immigrants; SM (skilled immigrants) is an indicator for the opposite situation. ${ }^{49}$ In other words, these two variables are constructed using the cut-off point equal to one for the relative skill composition $\frac{b}{(1-b)} / \frac{\beta}{(1-\beta)}$. In the estimates of column (4), as expected in the theoretical models, the marginal effects of the two interaction variables which include SN and $\mathrm{SM}$ are respectively positive and negative. ${ }^{50}$ If natives are more skilled than immigrants $(\mathrm{SN}=1)$, the impact of years of education is positive and bigger in magnitude the more different the two groups are in terms of skill composition. If immigrants are more skilled than natives $(\mathrm{SM}=1)$, then (setting aside the direct effect of individual skill) more educated individuals are less likely to be pro-immigration, with the latter effect becoming stronger as the disparity in skill ratios widens. Finally, the marginal effect of years of education by itself, positive and significant at the $1 \%$ level, contradicts one of the predictions of the factor-endowments models. There should be no effect of immigration on wages and, therefore, on preferences if the skill compositions of immigrants and natives are the same. It is possible that the result depends on the effect of education working through non-economic channels, as discussed above.

To summarize, for the sample of OECD countries on which Table 3 is based, I find the results quite supportive of my hypothesis. My estimates suggest that per capita GDP in previous regressions was proxying for the relative skill composition of natives to immigrants. The correlation between immigration preferences and individual skill is consistent with the change, due to immigration, in the host country's supply of skilled to unskilled labor. More generally, this evidence supports an explanation of the cross-country pattern along the lines of the factor-endowments models. The results for this group of developed countries are consistent with both the predictions of the HO model without factor-price-insensitivity and of the FPA model. They are not in line, however, with an $\mathrm{HO}$ model in which changes in factor endowments do not trigger changes in factor prices and where only Rybczynski effects occur.

For all the other countries not analyzed in Table 3, mostly middle and low-income economies, the interpretation of the skill-attitudes pattern depends on whether there is any immigration at all to such countries and, if so, which type of immigration in terms of skill composition. It is plausible to extend the interpretation based on Table 3 to countries with sizeable immigration intakes. On the other hand, in countries characterized by small immigration numbers, the factor-price-insensitivity result may hold. ${ }^{51}$

\footnotetext{
${ }^{49}$ The countries with SN equal to 1 are: Germany West, Germany East, Great Britain, Austria, Netherlands, Sweden, Canada, France (not included in the regression), Denmark (not included in the regression), Belgium (not included in the regression), Finland (not included in the regression). The countries with SM=1 are: Italy, Ireland, Spain, Portugal (not included in the regression).

${ }^{50}$ The two interaction variables are, respectively, education ${ }^{*} S N^{*}(R S C-1)$ and education ${ }^{*} S M^{*}(1-R S C)$, where $R S C$ is the relative skill composition.

${ }^{51}$ In other words, some countries may have such small immigration inflows that, given that the economy is diversified, factor prices are not affected and no significant difference emerges in preferences, according to individual skill. This interpretation of the results may apply for those countries whose marginal effect of skill is estimated to be not significantly different from zero. Unfortunately, these are also the countries for which reliable data on immigration flows is not available.
} 
If there is indeed immigration to middle and low-income countries, the next step is to investigate which type of immigration, whether skilled or not. One of my empirical results suggest that the ratio $\frac{b}{(1-b)} / \frac{\beta}{(1-\beta)}$ would take on lower values for poorer destination countries than for richer ones, since its correlation with per capita GDP is positive and significant (based on fifteen countries). Only if this is true, is the negative correlation between pro-immigration preferences and individual skill in lower-income countries consistent with the predictions of the factor-endowments models.

Unfortunately, the empirical evidence on size and skill composition of immigration to developing countries is now very scarce. Very few sources in the literature document the extent of immigration to these destinations. ${ }^{52}$ One of them, the International Labor Migration Database (ILO 1998), shows that immigrants' flows to lower-income destinations exist and are sometimes substantial in magnitude (however, this data cannot be used, due to the low degree of harmonization across countries). As for the skill composition of immigration to developing countries, preliminary evidence suggests that it might be consistent with the results of this paper. ${ }^{53}$ Future empirical work on this point should focus on the worldwide increase in short-term mobility of highly-skilled workers, due to the reduction in international business travel and communication $\operatorname{costs}^{54}$, and on medium and long-term flows of skilled labor linked to FDI into low per capita GDP countries.

\subsection{Individual-level Data on Occupation}

In the last four columns of Table 3 (regressions (6)-(9)), I use individual-level data on occupation to further test the robustness of the factor-endowments explanation. ${ }^{55}$ Specifically, I match each individual with the number of immigrants relative to natives in his occupation. I interpret each occupation as a different factor of production and assume that segmented labor markets exist for each of them. I can then use the predictions of the multi-factor version $(m>>n)$ of the factorendowments models. If an occupation has a higher ratio of immigrants to natives, it means that, due to immigration, it has experienced a bigger increase in supply relative to other occupations. Therefore, according to a factor-endowment story, individuals in such occupations will be less likely

\footnotetext{
${ }^{52}$ These sources include: Jenks (1992) (on the other settler societies, especially Argentina), SOPEMI (1997) on Central and Eastern European countries, such as Bulgaria, the Czech and Slovak Republics, Hungary, Poland and the former Soviet Union, which have become in the nineties a new destination of immigration flows; and OECD (2000) on certain Asian countries. Some of these references and additional ones are documented in Freeman (1995).

${ }^{53}$ For example, SOPEMI (1997) documents the following: "Several developing South-East Asian countries have emerged as both sending and receiving countries for skilled and unskilled workers....China, which is experiencing shortages of highly skilled labour and which is now receiving important inflows of foreign direct investment, counted roughly 80,000 foreign workers in 1995, one third of whom were from Japan, 20 per cent from the United States and 13 per cent from Germany." (p.48). Also remember that what matters in the model is the relative skill composition of natives to immigrants, where the average level of skill of natives in developing countries is generally low.

${ }^{54}$ The implications of these changes are analyzed in Tang and Wood (2000). In their model, highly-skilled individuals from developed countries can work either in the North or in the South, thus affecting the income distribution in the two parts of the world. Even though this type of short-term mobility does not imply a change in residence of highlyskilled workers from the North to the South, it may still be perceived as labor-market competition by skilled labor in the South.

${ }^{55}$ These regressions are based on six countries: Germany West, Germany East, Great Britain, Austria, Ireland and Spain. These are the countries for which data on both individual occupation and on the ratio of immigrants to natives by occupation is available.
} 
to be pro-immigration. In this framework, skilled (unskilled) labor is considered as many different factors as the number of occupations in which it is employed.

In regression (6), I look at the relationship between immigration preferences and the immigrantsto-natives ratio of the individual's occupation ( IN ratio), including among the regressors the usual socio-economic controls (age, male, parents' foreign citizenship, education). ${ }^{56}$ I find that, in occupations characterized by higher fractions of foreigners relative to natives, individuals are more likely to be anti-immigration. The marginal effect of the IN ratio is negative and significant at the $1 \%$ level. ${ }^{57}$ This result is not inconsistent with the models of Section 3.2 given that, at least in the short-run, the multi-factor version of the factor-endowments models is likely to hold, due to the segmentation of labor markets within the economy. In the short run, it is plausible that immigrants only affect the real rates of return of the occupations they take up and, therefore, the preferences of individuals working in the same activity.

In column (7), I add two additional controls, Immig Crime and Immig Culture. The marginal effect of the IN ratio is now smaller in absolute value but still significant at the $1 \%$ level. The decrease (in absolute value) of the effect of the IN ratio suggests that this variable is in part picking up the impact of non-economic factors, such as security and cultural issues. However the latter ones are likely to be influenced by the pressure that a worker faces in terms of labor-market competition.

The result in regression (6) is driven by a short-run view of the labor market, in which individuals are on average immobile across occupations. One way to investigate this finding is to account for the degree of individual mobility. Column (8) includes in the model a new regressor, which is meant to proxy for the individual willingness to move across occupations. ${ }^{58}$ The estimates in regression (8) are not all significant but they suggest that mobility is an important determinant. The extent to which individuals in occupations with a higher IN ratio are more likely to be anti-immigration depends on their individual degree of mobility. The more mobile an individual is, the weaker the impact of the $I N$ ratio on his anti-immigration attitude. ${ }^{59}$

Finally, in regression (9), I investigate which version of the factor-endowments models is consistent with stated opinions about immigration. The multi-factor version, based on occupations, provides a short-run view of the labor market, where we assume individuals on average are not able to move from one occupation to the other. On the other hand, the $3 \times 2$ factor-endowments models in Section 3.2 are based on a long-run view of the economy, in the sense that skilled and unskilled

\footnotetext{
${ }^{56}$ The IN ratio in Table 3 is equal to the log of one plus the ratio in 1995 of the number of foreigners to the number of natives in the individual's occupation (the data for immigrants and natives is for to the stock of immigrants and natives in 1995). Data on immigrants' and natives' occupations follows the 1988 ISCO classification (see Section 2).

${ }^{57}$ The IN ratio in regressions (6)-(9) is equal to (the $\log$ of one plus) $\frac{\alpha M}{a N}$, where $\alpha$ and $a$ are the fractions of, respectively, immigrants and natives in a given occupation. Since country fixed effects are included in the regressions, the coefficient on the IN ratio captures the impact of the ratio of immigrants to natives in a given occupation relative to the country's immigrants-to-natives ratio, in line with the theory (see Section 3.2). In other words, what matters is whether the ratio of immigrants to natives in a given occupation is higher than for the whole economy.

${ }^{58}$ The variable willingness to move measures the individual's stated willingness to move to another city/town, in order to improve work or living conditions ( $1=$ very unwilling, $5=$ very willing). Although it is an imperfect measure of the degree of individual mobility across occupations, it is likely to be a good proxy of this measure.

${ }^{59}$ Even though what matters for the segmentation of labor markets is the average willingness to move across occupations, still an individual who is more willing than average to switch to another occupation is less vulnerable to the adverse impact of immigration.
} 
labor are supposed to be free to move across occupations and equalize real rates of return. By comparing the two models, I investigate which time horizon individuals have in mind when they assess immigration policy, that is, whether they are thinking in terms of the short-run or the long-run impact of immigration or both. The results of column (9) suggest that the relevant time horizon used by individuals to assess the impact of immigration is a long-run one, in which the perceived effect of labor inflows is on national labor markets of skilled and unskilled labor. The marginal effect of the IN ratio is negative but not significant, while the correlation between individual skill and attitudes is significant and displays the usual pattern.

\section{Non-Economic Determinants of Individual Attitudes}

Up to now, the analysis has focused on economic determinants of immigration policy attitudes. I next investigate correlation patterns between attitudes toward immigrants and individual answers to questions about non-economic issues. The inclusion in the empirical model of these regressors allows me to test the robustness of the findings described in the first part of the paper. In some specifications, I already tested the strength of the results by controlling for Immig Crime and Immig Culture (the impact of immigration on, respectively, crime rates and cultural openness, as perceived by each individual). ${ }^{60}$ The regressions including the latter two variables show the strong correlation between these non-economic issues and immigration preferences. In particular, in Table 2a, column (5) shows that if an individual either disagrees or disagrees strongly with the claim that immigrants raise crime rates, the probability that he is in favor of an increase in their number goes up by about 4.7 percentage points. Similarly, a respondent who either agrees or agrees strongly with the statement that immigrants make the country more open to new ideas and cultures will be around 5.1 percentage points more likely to support a raise in immigration.

Both security worries and cultural and national-identity issues are key non-economic factors affecting immigration opinions. Security concerns are related to the perception that immigrants are more likely than natives to be involved in criminal activity. An interesting question is whether this belief is linked to an objective situation - due for example to a negative selection of immigrants to some countries, driven by the type of immigration policy - or whether it is driven by racist and intolerant feelings, although I cannot distinguish these causes in the data.

Cultural and national-identity issues are related to the intrinsic side effect of immigration: the meeting, which often becomes a clash, of people of different ethnic origins and cultures. ${ }^{61}$ The integration of immigrants in the destination society may be perceived as a source of cultural enrichment on both sides, which is what is captured by high values of the variable Immig Culture. On the other hand, immigration may feed cultural and national-identity worries, driven by the belief that the set of values and traditions that characterize the receiving country's society are threatened by the arrival of foreigners. At the extreme, these types of concerns may just be the consequence of the dislike of anything which is different, that is, cultural and racial intolerance.

Cultural and national-identity issues due to migration are likely to be a key input in individual

\footnotetext{
${ }^{60}$ These two variables are available in the ISSP-NI data set only.

61 "In Adam's Smith's words 'man is of all sorts of luggage the most difficult to be transported." (Chiswick and Hatton 2002, p.1)
} 
preferences (see Akerlof and Kranton (2000) on the role of identity in economics). A few survey questions in the ISSP-NI data set, combined with external data on countries of origin of immigrants, allow me to investigate the role of this set of issues. Two main factors influence immigration preferences through the national and cultural-identity channel: first, the individual attitude toward a culturally homogenous society, which I call monoculturalism, as opposed to a multicultural community, labeled multiculturalism; and, next, whether immigrants adapt successfully in the destination country's society or not. The latter is a function of how much immigrants and natives are culturally different. I use information on the five main countries of origin of foreigners for each host country to construct measures of cultural dissimilarity between natives and immigrants.

Table 4a, based on the ISSP-NI data set, shows the results focusing on the non-economic determinants of immigration preferences. As expected, I find that individuals with a taste for multiculturalism are more likely to be pro-immigration, while the opposite is true for respondents with a preference for a more homogeneous society, in terms of customs and traditions (column (1) in Table 4a). I next investigate how these two variables - monoculturalism and multiculturalism - interact with the degree of cultural difference between natives and immigrants. I look at differences based on the main language spoken and on religious affiliation in the origin and destination countries and I explore the role of past colonial relationships. The only significant results of this analysis relate to dissimilarities in religious affiliation and are presented in regression (2), which contains the interaction terms between religious difference and, respectively, monoculturalism and multiculturalism. ${ }^{62}$ I find that, while the marginal effect of monoculturalism does not change with religious difference, individuals with a taste for multiculturalism are negatively affected in their immigration opinion by bigger dissimilarities between natives and immigrants in religious terms. ${ }^{63}$

The variables in column (3) also give information on cultural and national-identity issues. ${ }^{64} \mathrm{In}$ particular, national pride (2) and national pride (3), which are negatively and significantly related to pro-immigration attitudes, quantify the extent of individual attachment to the nation, the latter indicator in a stronger form than the former one. ${ }^{65}$ The results from regression (3) are consistent with the basic intuition that individuals who feel closer to their country's identity are more likely to be anti-immigration. ${ }^{6}$ Column (4) in Table 1b, based on the WVS data set, reveals the same pattern: More patriotic and nationalistic individuals are less likely to be in favor of immigration.

I next look at the relationship between immigration preferences and individual feelings about illegal immigration and political refugees (regression (4), Table 4a). Both variables have the expected sign and are highly significant. Individuals who are against illegal immigration and who do

\footnotetext{
${ }^{62}$ The variable religious difference, which measures the dissimilarity between natives and immigrants in terms of religious affiliation, is an average across origin countries of the dissimilarity measure $\frac{1}{2} \sum_{r=1}^{R}\left|p_{r}^{D}-p_{r}^{O}\right|$, where $D$ and $O$ are for destination and origin country and $p_{r}$ represents the fraction of the population in religion $r$.

${ }^{63}$ Regression (2) is based on the following countries: Germany West, Germany East, Great Britain, United States, Netherlands, Norway, Sweden, Canada, Japan.

${ }^{64}$ These variables are: town, county, continent, national pride (1), (2), (3), and (4).

${ }^{65}$ The four variables national pride (1)-(4) measure the emphasis with which an individual declares respectively: (1) "feeling close to own country"; (2) "rather be citizen of own country"; (3) "own country better than others"; (4) "in favor of country's interests at any cost". See Data Appendix 4 for summary statistics of these variables and Mayda and Rodrik (2003) for details about their construction.

${ }^{66}$ This confirms one of the main results in Espenshade and Hempstead (1996), which concerns the link between immigration preferences and isolationist feelings (p.543).
} 
not welcome political refugees are also more likely to oppose an increase in immigration. On the other hand, column (5) suggests that whether an individual belongs to the dominant ethnic group in society does not have a significant impact on opinions about foreigners.

Finally, in the last column of Table 4a, I put together all the main factors shaping immigration attitudes into a single specification. By combining both sets of variables, economic and noneconomic ones, I can investigate how robust my previous findings are. The picture of individual preferences that emerges from this final set of results is multi-faceted. Both economic and noneconomic indicators appear to be important. But, in particular, regression (6) shows that the cross-country pattern in the correlation between preferences and skill - negative relationship for lower-income countries, positive one for higher-income destinations - is still present when I control for non-economic determinants of attitudes. This result remains robust when I use the WVS data set.

As mentioned before, intolerance on the basis of race may explain a lot of the variation in immigration preferences and may be the driving force behind other types of explanations. The WVS data set includes a question that allows me to construct a measure of racist feelings. ${ }^{67}$ The regressions in Table $4 \mathrm{~b}$, in which I focus on this measure of individual racist feelings, highlight two important points. First, racism is highly correlated with anti-immigration feelings, as shown in column (1). A respondent who would rather not have as neighbors individuals of a different race is more than eight percentage points less likely to be in favor of an increase in immigration. In addition, the cross-country pattern in the correlation between skill and preferences is almost unaffected by the inclusion of the racism variable (columns (2) and (3)). Labor-market based explanations survive this robustness test. ${ }^{68}$

To conclude the analysis on immigration attitudes, I investigate how well I am explaining the variation in immigration preferences across individuals. Based on my preferred specifications (column (6) in Table 4a for the ISSP-NI data set and column (2) in Table 4b for the WVS data set), I can calculate the percentage of answers correctly predicted by the model. ${ }^{69}$ In the ISSP-NI data set, out of the total sample of individuals for whom I have both actual and fitted immigration preferences, I can correctly predict approximately $70 \%$ of the answers (the variable predicted can take up three values). ${ }^{70}$ In the WVS sample, the percentage of answers correctly predicted by the model is around $48 \%$ (the variable predicted can take up four values). ${ }^{71}$ Thus, for both data sets, the estimated models fare better than a random assignment of answers to individuals. ${ }^{72}$

\footnotetext{
${ }^{67}$ The ISSP-NI data set does not include any question that allows me to construct a measure of racist feelings.

${ }^{68} \mathrm{I}$ get the same result if I add the interaction of the racism variable with per capita GDP.

${ }^{69}$ I estimate my preferred specifications using an ordered probit model with the three-valued Immig Opinion $(1=$ "reduced a lot" or "reduced a little", $2=$ "remain the same as it is", $3=$ "increased a little" or "increased a lot") as the dependent variable for the ISSP-NI data set (Immig Opinion (WVS) for the WVS data set). I assign to each individual the answer whose predicted probability is the highest among all possible answers.

${ }^{70}$ In particular, I can correctly predict around $91 \%$ of the answers of those individuals who would like the number of immigrants to decrease (either a little or a lot) and whose opinion can be predicted with the model. The same percentages for individuals who would like the number of immigrants to stay the same or to increase (either a little or a lot) are respectively $37 \%$ and $12 \%$.

${ }^{71}$ In particular, I can correctly predict around $37 \%$ of the answers of those individuals who would like immigration to be prohibited or strictly limited and whose opinion can be predicted with the model. The same percentage for individuals who would like immigrants to come, given availability of jobs or without any conditions, is around $80 \%$.

${ }^{72}$ Moreover, considering that in the ISSP-NI sample the percentage of individuals answering in favor of a reduction
} 
This measure of goodness of fit - the percentage of answers correctly predicted - is one of the most common after estimation of probit models. It is also informative to run OLS regressions for the preferred specifications and look at the corresponding $R^{2}$ measures. The percentage of the total variance explained by the preferred specifications (including the dummy variables) is approximately $26 \%$ for the ISSP-NI sample of countries and much lower, $10 \%$, using the WVS data set.

\section{Trade and Immigration Policy Attitudes: A Comparison}

International economic integration can take place through both trade in goods and services and through factor movements, for example immigration. A comparative analysis of individual preferences on trade versus immigration policy can shed light on whether the variation in policy outcomes in these two dimensions originates from differences in peoples' attitudes.

Trade and immigration affect the destination country's labor markets in a parallel way. Both trade and immigration allow countries to exchange services of factors of production - indirectly and directly, respectively - thus changing labor market conditions and possibly altering the structure of factor returns. To the extent that changes in labor markets due to trade and immigration are qualitatively similar, individual preferences on trade and immigration should be correlated. ${ }^{73}$

Both trade and immigration affect the receiving country's society but to differing degrees. While it is true that trade creates social tensions through the pressure it exerts toward "arbitrage in national norms and social institutions" (Rodrik 1997, p.29), still the societal and cultural effects of immigration can be expected to be much more direct.

In light of these considerations, it is interesting to investigate how preferences toward trade and immigration are related to each other. Based on the two ordinal measures of attitudes Immig Opinion and Trade Opinion in Data Appendix 1a and 1b (ISSP-NI data set), the country-specific percentages of respondents in favor of trade are much higher than for immigration. The two variables are also positively and significantly correlated in twenty of the 23 countries considered, as shown in Data Appendix 5. This evidence is consistent with the intuition that a few common factors affect both types of preferences, while some of the forces at work in anti-immigration attitudes are absent or softened in the case of trade.

I next compare economic determinants of trade and immigration attitudes. One of the strongest results of this paper is the skills cleavage in preference formation over immigration policy. This finding is reminiscent of a parallel one in O'Rourke and Sinnott (2001) and in Mayda and Rodrik (2003) (see columns (1) and (6) in Table 5). These two papers show that attitudes toward free trade are significantly and robustly correlated with individuals' human capital levels, in accordance with the predictions of the Heckscher-Ohlin model. Skilled individuals are more likely than unskilled ones to be in favor of trade liberalization in skill-abundant countries, and less likely in skill-scarce countries. This result is consistent with the theoretical prediction that owners of a country's abundant factors gain from trade liberalization (Stolper-Samuelson theorem). The parallelism

in immigration is approximately $64 \%$ and this type of answer is the most popular one, the model I estimated is a better predictor of answers than matching every individual with the most popular answer (the percentage for the most popular answer is, in the WVS data set, $44 \%$ ).

${ }^{73}$ Other aspects of the destination country's economy, other than the labor market, are affected by trade and immigration in a dissimilar way (for example, the fiscal impact on the welfare state). 
between the two sets of results - on immigration and trade preferences, respectively - suggests that the changes in relative supplies of factors brought about by trade and immigration are qualitatively similar.

In Mayda and Rodrik (2002) the sector-specific model is tested. Regressions (2)-(5) in Table 5 compare immigration policy preferences to attitudes toward trade policy, using the sector classification adopted in Mayda and Rodrik (2002)..$^{74}$

Replicating the results from Mayda and Rodrik (2002) on trade preferences, column (5) shows that respondents who work in comparatively-disadvantaged (CD) sectors are significantly less likely to be pro-trade, compared to individuals in non-traded sectors. Pro-immigration preferences also are significantly and negatively affected by whether the respondent works in a CD sector (column (2)). This result is consistent with the evidence, documented in the literature (Faini and Venturini 1994 and Coppel et al. 2001), that import-competing sectors rely heavily on migrant labor. The result is also plausible from a theoretical point of view: In a Ricardian framework, immigration expands the range of goods produced by the destination country, which absorbs immigrants in sectors with low productivity that would disappear without immigration (Trefler 1997).

While the type of good produced in a sector, whether traded or not, is one of the main cleavages in preference formation over trade policy (column (4), Table 5), the same pattern does not characterize immigration policy attitudes (column (3), Table 5). As is intuitive, workers in non-traded sectors feel shielded from foreign competition working through trade but not from labor-market competition of immigrants. ${ }^{75}$

\section{Main results and conclusions}

The empirical literature on immigration preferences reaches different conclusions on the role of economic versus non-economic factors. For the United States, while Espenshade and Hempstead (1996) find mostly evidence in favor of non-economic explanations behind preference patterns, the results in Scheve and Slaughter (2001a) and in Kessler (2001) draw attention to the importance of economic determinants. The results in Citrin et al. (1997) are presented, instead, as weak evidence for the role of personal economic circumstances in U.S. immigration preferences. Finally, the analysis in Dustmann and Preston (2001b) points out that in Great Britain economic determinants matter for attitudes toward immigrants, but that racial prejudice is definitely the most important factor in preference formation.

I find evidence that both sets of factors, economic and non-economic ones, are important. In a wide range of countries, attitudes toward immigrants appear to be related to labor-market concerns, security and cultural considerations, as well as individual feelings toward political refugees and illegal immigration. In particular, my analysis shows that the economic variables continue to play a key and robust role in preference formation over immigration policy, after controlling for

\footnotetext{
${ }^{74}$ See Mayda and Rodrik (2003), in particular Appendix A, for a description of the sector classification.

${ }^{75}$ From a theoretical point of view, a few assumptions are needed for individuals in non-traded sectors to benefit with a trade liberalization. Prices of non-traded goods are not directly affected by a trade liberalization. However, indirectly, if the income elasticity of demand for non-traded goods is positive, prices of non-traded goods will increase with a trade liberalization, since national income will go up (Scheve and Slaughter 2001c). What matters for the net effect on non-traded sectors is the overall change in relative prices.
} 
non-economic factors. My results, therefore, reject a view of the world in which only non-economic issues shape attitudes toward foreigners.

The evidence presented in the current paper shows that opinions about immigration policy are significantly correlated with individual skill and that there exists a great deal of cross-country variation in terms of this correlation. Individual skill appears to be positively correlated with pro-immigration preferences in high per capita GDP countries and negatively correlated with proimmigration preferences in low per capita GDP countries. This result is robust to various changes in the empirical specification and to the use of two different data sources.

Additional findings, based on a smaller sample of countries, suggest that the correlation between preferences and individual skill depends on the immigration-induced changes in the relative supply of skilled to unskilled labor in the destination economy. This result is consistent with the predictions of the Heckscher-Ohlin model, without factor-price-insensitivity, and of the factor-proportionsanalysis model. Individual-level data on occupation provide more evidence in favor of the factorendowment explanation. Individuals in occupations with a higher ratio of immigrants to natives appear to be more likely to oppose immigration.

Non-economic variables also are found to be significantly correlated with immigration policy preferences. Both concerns regarding the impact of immigration on crime rates and individual perceptions of the cultural effect of foreigners are found to covary with immigration attitudes. In addition, racist feelings have a very strong, negative and significant impact on pro-immigration preferences. However, these non-economic determinants do not seem to alter significantly the results regarding the economic variables. Labor-market explanations of attitudes toward foreigners survive, after taking into account these non-economic factors.

Based on the specification of the model which includes both economic and non-economic explanations, I can look into what accounts for differences in average attitudes across countries. ${ }^{76}$ Let's consider, for example, Canada and Hungary which, in terms of attitudes toward foreigners, are at the opposite extremes (see Data Appendix 1a), with the former country much more open to immigration than the latter one. According to my model, some 34 percent of the difference between Canadians and Hungarians in terms of pro-immigration preferences is explained by the difference in the impact of individual skill (i.e., the combination of the difference in both average individual skill in each country and the country-specific marginal effect of skill), around 6 percent by the difference in the percentages of individuals having parents with foreign citizenship, 10 percent by stronger feelings against illegal immigrants in Hungary relative to Canada and, finally, more than 7 percent by less sympathetic feelings toward political refugees in Hungary than in Canada. ${ }^{77}$

Finally, the last part of the empirical analysis focused on the relationship between individual attitudes toward open trade and opinions about immigration. While preferences on immigration and trade are positively correlated, individuals appear to be, on average, more pro-trade than proimmigration. My empirical results point out that both sets of opinions are affected by the changes in relative factor endowments which occur through goods trade and labor flows. In addition, one important finding is that a key source of the difference in attitudes is the cleavage in trade

\footnotetext{
${ }^{76}$ This decomposition of the difference in average immigration attitudes across countries is based on OLS coefficient estimates of a regression model with the three-valued Immig Opinion as the dependent variable and with the same regressors as in column (6), Table $4 \mathrm{a}$.

${ }^{77}$ The rest of the difference is mostly explained by differences in the two country dummy variables.
} 
preferences, absent in immigration attitudes, between individuals working in traded sectors and individuals working in non-traded sectors. The latter result provides an answer to one of the puzzles pointed out in the recent immigration literature, specifically the asymmetry in policy attitudes toward trade and immigration. ${ }^{78}$

Immigration has become a central theme of political discussions in many countries and it is likely to increasingly draw policymakers' attention, along with trade issues, in the debate about international integration. Indeed goods' trade and labor flows are closely related, with their impact on the economy positively affecting some groups and negatively others. This paper has shed light on the distributional and cultural impact of immigration, as perceived by individuals, and it has related it to the effect of trade on different groups in society. Since individual attitudes are necessarily a key input in policy outcomes and their viability, this work contributes to a better understanding of immigration-policy decisions and, in relation to it, trade-policy ones.

\section{A Appendix}

\section{A.1 The impact of immigration on factor prices in the $m \times n$ Heckscher-Ohlin model}

Consider a small open economy, characterized by constant returns to scale and perfect competition in each sector. The predictions of the HO model, with regard to the impact of immigration on factor rates of return, depend on a key condition that relates the number of internationally-traded goods produced in the country to the number of primary factors of production. To gain intuition regarding this condition, it is useful to think in terms of the system of equations of production equilibrium in each sector - price is equal to unit cost - and the set of factors' market-clearing conditions: ${ }^{79}$

$$
\begin{gathered}
p_{i}=b_{i}\left(w_{1}, \ldots, w_{k}, \ldots, w_{m}\right), \quad i=1, \ldots, n \\
V_{k}=\sum_{i=1}^{n} y_{i} b_{i k}(\cdot), \quad k=1, \ldots, m
\end{gathered}
$$

where $p_{i}$ and $y_{i}, i=1, \ldots, n$ are respectively prices and quantities produced of each good, $V_{k}$ and $w_{k},, k=1, \ldots, m$ are respectively primary factor supplies and prices and, finally, $b_{i}(\cdot), i=1, \ldots, n$ are sectors' unit cost functions, characterized by partial derivatives (with respect to each factor

\footnotetext{
${ }^{78}$ Faini (2001) emphasizes that the difference between non-traded and traded sectors - in individual attitudes towards trade and immigration - is likely to be an important factor explaining why preferences are asymmetric in the two domains. I find empirical evidence consistent with this hypothesis.

${ }^{79}$ In a competitive equilibrium, the price of each good must be equal to its marginal cost, which equals the unit cost under constant returns to scale. Notice also that, given constant returns to scale, the unit cost function in each sector does not depend on the quantity produced of that good.
} 
price) $b_{i k}(\cdot) .^{80}$ Notice that the partial derivatives $b_{i k}(\cdot)$ give the optimum requirement of input $k$ necessary to produce one unit of good $i$.

The system of equations (6) has as many equations as there are sectors $(n)$ and as many unknowns (factor prices) as the number of primary factors of production $(m)$.

If $n \geq m$, ceteris paribus a sufficiently small increase of a factor's supply $\left(d V_{k}>0\right.$ for any $\left.k\right)$ does not have any effect on factor rates of return. That is $d w_{k}=0$, for every $k=1, \ldots, m$, which means that factor-price-insensitivity (FPI) holds: factor prices are insensitive to changes in factor supplies. ${ }^{81}$ The reason for this result is that, with no improvement in technology, changes in factor prices can only be caused by changes in goods' prices, as system (6) shows. ${ }^{82}$ In addition, since the shock to the factor supply is sufficiently small, the economy keeps producing the same range of products, that is the cone of diversification of the country does not change. The factor-supply shock only affects the quantity produced of each good, according to the predictions of the Rybczynski theorem. ${ }^{83}$

If the same condition on the relative number of goods and factors holds $(n \geq m)$ but the increase in the factor's supply is substantial, the country's cone of diversification changes. Hence, it ends up producing a different set of goods. In this case, factor-price-insensitivity does not hold: changes in factor endowments have an impact on factor rates of return. ${ }^{84}$

Finally, if $n<m$ changes in factor endowments always change factor prices since the latter ones are not fully determined by goods' prices.

\section{A.2 "Can't Choose" and "Don't Know" Answers and the Incidental Parameter Problem}

One important issue in the estimation is how to deal with the Can't Choose (CC) and Don't Know (DK) responses to the immigration question, respectively in the ISSP-NI and WVS data sets. The percentages of CC and DK responses in the two data sets are quite high and vary greatly across countries. If the observations corresponding to these values are excluded from the samples, a lot of information is lost. Moreover - and this represents a more serious concern - omitting the CC and DK observations could result in inconsistent estimates, due to a selection bias.

The Heckman selection model is the framework I exploit to test whether deletion of $\mathrm{CC}$ and DK observations causes a selection bias. I use the Stata command "heckprob" which combines two probit models, one for the main model and one for the selection model. By using this command, I

\footnotetext{
${ }^{80} \mathrm{In}(6)$ if trade is perfectly free, goods' prices are equal to international prices, otherwise there is a wedge between the domestic and the international price, equal to the tariff (or tariff-equivalent). In any case goods' prices are given, in the sense that they do not depend on the country's supply and demand.

${ }^{81}$ The label factor-price-insensitivity comes from Leamer and Levinsohn (1995). Notice that the conditions needed for FPE (factor-price equalization) are stronger.

${ }^{82}$ If $n \geq m$, the number of unknowns in system (6) is lower than the number of equations. If in particular $n=m$ and the equations are independent, the system is exactly determined. If instead $n>m$, the system may be overdetermined.

${ }^{83}$ The predictions of the the Rybczynski theorem properly refer to the $2 \times 2$ case. A generalization of the Rybczynski result applies to the case $n=m$.

${ }^{84}$ The intuition about this result is that the equations of system (6) have now changed (some of them correspond to different goods).
} 
give up some of the information in the ordered answers that I could have used in the second stage, as I will explain below. My model looks as follows:

Main model (a):

$$
\begin{array}{cl} 
& y_{j}^{*}=x_{j} \beta+u_{1 j} \text { (latent equation) } \\
y_{j}=1 \text { if } y_{j}^{*} \geq 0 ; 0 \text { otherwise (probit equation) }
\end{array}
$$

Selection model (b):

$$
y_{j}^{\text {select }}=1 \text { if } z_{j} \gamma+u_{2 j} \geq 0 \text { (selection equation) }
$$

where:

$z_{j}$ and $y_{j}^{\text {select }}$ are observed for $\forall j ; y_{j}$ is observed only if $y_{j}^{\text {select }}=1 ; \quad X \subseteq Z$

$\left(u_{1}, u_{2}\right)$ is independent of $Z$ with $u_{1} \sim N(0,1), u_{2} \sim N(0,1), E\left[u_{1} / u_{2}\right]=\rho u_{2}$

$y_{j}^{*}$ can be interpreted as the change in the indirect utility of the individual, due to a change in the number of immigrants. However, we cannot observe this value, we can only observe whether it is greater or equal to zero (i.e., the individual would like the number of immigrants to his country to increase) or negative. What the selection model captures is the fact that, for some individuals, the utility of not choosing a specific answer is greater than the utility of choosing it. One possible explanation of this behavior is a particular cultural attitude toward questioning: in some cultures, some members of society are less likely to express an opinion (for example, women). Another explanation is uncertainty of the right answer, due to lack of knowledge on the topic. Given these explanations for the selection mechanism, it is likely that factors causing whether or not an individual gives an opinion also have an impact on immigration preferences. Hence, to the extent that I am not able to control for these common determinants, the error terms $u_{1}$ and $u_{2}$ could be correlated. That is why it is necessary to test for selection bias.

An alternative to using heckprob would have been to run the two steps of the Heckman procedure separately: in the first stage, a probit equation (selection model) for whether an individual answers the question or not; in the second stage, after excluding the CC and DK observations, an (ordered) probit model (main model), controlling for the estimated inverse Mills ratio. ${ }^{85}$

In the selection model (b), I use all the same regressors as in the main model plus an additional variable, which makes identification possible. For the ISSP-NI data set, I use the information on whether or not the individual has expressed an opinion to the parallel question on trade policy. I check that this variable does not have a significant impact on the dependent variable in the main model (a). For the WVS data set, I use the information on whether or not the individual has given an answer to various questions on environmental policy. ${ }^{86}$

\footnotetext{
${ }^{85}$ I decided not to follow this strategy and opted for heckprob. The reason is that, as Wooldridge (2002, p.564) explains, the standard errors of the coefficient estimates in the second stage are not consistently estimated with this procedure (due to heteroskedasticity and the 2-stages nature of the estimation). In the standard case with a linear regression in the main model, under the null of no selection bias, a standard $t$ test is a valid test of selection bias (i.e., standard errors are consistently estimated). But, given an ordered probit in the main equation, results are not as straightforward.

${ }^{86}$ The questions on environmental policy I consider are the following:
} 
I run heckprob regressions for each single specification of my paper, using both the ISSP-NI and the WVS data sets. For all the specifications of my paper, I cannot reject the null hypothesis of no selection bias. ${ }^{87}$ Since I find no evidence of selection bias, in the empirical analysis of the paper I can disregard the observations corresponding to $\mathrm{CC}$ and DK responses. I then run probit and ordered probit regressions using all the other observations. This regression will give me consistent estimates of the coefficients and marginal effects.

A second issue to consider when using fixed effects with an ordered probit model is the incidental parameter problem. Given a model estimated using a panel data set ( $T$ observations for each unit $i=1, \ldots, N)$, the parameters specific for each unit $i$ are called "incidental" parameters. These parameters are usually estimated introducing dummy variables, that is using a fixed-effect specification, as in this paper. In a probit model, the maximum-likelihood estimator of the incidental parameters is consistent as $T \rightarrow \infty$, for given $N$. However, it is inconsistent for given $T$, as $N \rightarrow \infty$. The intuition behind this result is that, in the latter case, the number of parameters to estimate tends to infinity, while the information used to estimate each parameter does not increase. In my case, given that the panel data sets I am using are very long ( $N$ small, $T$ high), the incidental parameters problem is not an issue.

\section{References}

Akerlof, G. A. and Kranton, R. E. (2000). Economics and identity. The Quarterly Journal of Economics, CXV:715-753.

Barrett, D. B. (1982). World Christian Encyclopedia. Oxford University Press.

Barro, R. J. and McCleary, R. M. (2002). Religion and political economy in an international panel.

Bauer, T. K., Lofstrom, M., and Zimmermann, K. F. (2000). Immigration policy, assimilation of immigrants and natives' sentiments towards immigrants: Evidence from 12 OECD countries. IZA Discussion Paper No. 187.

Benhabib, J. (1996). On the political economy of immigration. European Economic Review, 40:1737-1743.

"I am now going to read out some statements about the environment. For each one I read out, can you tell me whether you agree strongly, agree, disagree or disagree strongly? I would agree to an increase in taxes if the extra money were used to prevent environmental damage (v38). I would buy things at $20 \%$ higher than usual prices if it would help protect the environment (v39). Country's environmental problems can be solved without any international agreements to handle them (v40). Here are two statements people sometimes make when discussing the environment and economic growth; which of them comes closer to your own point of view? Protecting the environment should be given priority, even if it causes slower economic growth and some loss of jobs; economic growth and creating jobs should be the top priority, even if the environment suffers to some extent; other answer (v41)." I construct a variable which gives the relative frequence of times the individual expresses an opinion on any of these environmental issues.

${ }^{87}$ In the case of the WVS data set, the absence of selection bias depends crucially on the inclusion among the regressors of some key socio-demographic variables (upper social class and political affiliation with the right). I control for these variables in all the econometric specifications involving the use of the WVS data set, including the regressions run country by country. 
Bilal, S., Grether, J.-M., and de Melo, J. (1998). Determinants of attitudes towards immigration: A trade-theoretic approach. Center for Economic Policy Research Discussion Paper No. 1877.

Borjas, G. J. (1994). The economics of immigration. Journal of Economic Literature, pages 16671717.

Borjas, G. J. (1995). The economic benefits from immigration. Journal of Economic Perspectives, $9(2): 3-22$.

Borjas, G. J. (1999a). The economic analysis of immigration. In Ashenfelter, O. and Card, D., editors, Handbook of Labor Economics, chapter 28, pages 1697-1760. North-Holland Elsevier Science, The Netherlands.

Borjas, G. J. (1999b). Heaven's Door: Immigration Policy and the American Economy. Princeton University Press, Princeton, N.J.

Borjas, G. J., Freeman, R. B., and Katz., L. F. (1996). Searching for the effect of immigration on the labor market. The American Economic Review, 86(2):247-251.

Borjas, G. J., Freeman, R. B., and Katz., L. F. (1997). How much do immigration and trade affect labor market outcomes? Brookings Papers on Economic Activity, 1:1-90.

Brücker, H., Epstein, G. S., McCormick, B., Saint-Paul, G., Venturini, A., and Zimmermann, K. (2001). Managing migration in the European welfare state.

Chiswick, B. R. and Hatton, T. J. (2002). International migration and the integration of labour markets. In Globalization in Historical Perspective. The University of Chicago Press, Chicago, IL. Forthcoming.

Citrin, J., Green, D., Muste, C., and Wong., C. (1997). Public opinion toward immigration reform: The role of economic motivation. The Journal of Politics, 59(3):858-881.

Coppel, J., Dumont, J.-C., and Visco, I. (2001). Trends in immigration and economic consequences. OECD Economics Department Working Papers No. 284.

Davis, D. R. and Weinstein, D. E. (2002). Technological superiority and the losses from migration. National Bureau of Economic Research Working Paper No. 8971.

Dornbusch, R., Fischer, S., and Samuelson, P. (1977). Comparative advantage, trade, and payments in a Ricardian model with a continuum of goods. The American Economic Review, 67(5):823839 .

Dustmann, C. and Preston, I. (2001a). Attitudes to ethnic minorities, ethnic context, and location decisions. Economic Journal, 111:353-373.

Dustmann, C. and Preston, I. (2001b). Racial and economic factors in attitudes to immigration. IZA Discussion Paper No. 189. 
Espenshade, T. J. and Hempstead, K. (1996). Contemporary American attitudes toward U.S. immigration. International Migration Review, 30(2):535-570.

Faini, R. (2001). Development, trade, and migration.

Faini, R. (2002). Discussion of "International migration and the integration of labor markets" by B. Chiswick and T. Hatton. In Globalization in Historical Perspective. The University of Chicago Press, Chicago, IL. Forthcoming.

Faini, R. and Venturini, A. (1994). Trade, aid and migrations. Some basic policy issues. European Economic Review, 37:435-442.

Findlay, R. and O'Rourke, K. (2002). Commodity market integration 1500-2000. In Taylor, A. and Williamson, J., editors, Globalization in Historical Perspectives. University of Chiacago Press, Chicago.

Freeman, G. (1992). Migration policy and politics in the receiving states. International Migration Review, 26(4):1144-1167.

Freeman, G. (1995). Modes of immigration politics in liberal democratic states. International Migration Review, 29(4):881-902.

Friedberg, R. and Hunt, J. (1995). The impact of immigrants on host country wages, employment, and growth. Journal of Economic Perspectives, 9(2):23-44.

Gang, I. N., Rivera-Batiz, F., and Yun, M.-S. (2002). Economic strain, ethnic concentration and attitudes towards foreigners in the European Union. IZA Discussion Paper No. 578.

Goldin, C. (1994). The political economy of immigration restriction in the United States, 1890 to 1921. In Goldin, C. and Libecap, G., editors, The Regulated Economy: A Historical Approach to Political Economy, pages 223-257. University of Chicago Press, Chicago, IL.

Greene, W. H. (1997). Econometric Analysis. Third Edition. Prentice Hall.

ILO (1988). ISCO-88 International Standard Classification of Occupations. International Labour Organization.

ILO (1998). International labour migration database. International Labor Organization.

Inglehart, R. (2000). World values surveys and European values surveys, 1981-1984, 1990-1993, and 1995-1997 [computer file]. ICPSR version. Institute for Social Research [producer], 2000. Inter-university Consortium for Political and Social Research [distributor], 2000.

ISSP (1995). National-identity data set. International Social Survey Programme.

Jenks, R. (1992). Immigration and Nationality Policies of Leading Migration Nations. Center for Immigration Studies, Washington, DC.

Joppke, L. (1998). Why liberal states accept unwanted immigration. World Politics, 50:266-293. 
Kessler (2001). Immigration, economic insecurity, and the "ambivalent" American public. The Center for Comparative Immigration Studies Working Paper No. 41.

Leamer, E. E. and Levinsohn, J. (1995). International trade theory: The evidence. In Grossman, G. and Rogoff, K., editors, Handbook of International Economics, Vol. III, chapter 26, pages 1339-1394. Elsevier Science B.V.

Money, J. (1997). No vacancy: The political geography of immigration control in advanced industrial countries. International Organization, 51:685-720.

Obstfeld, M. and Taylor, A. M. (2002). Globalization and capital markets. In Taylor, A. M. and Williamson, J. G., editors, Globalization in Historical Perspective. University of Chicago Press, Chicago.

OECD (1997). International migration statistics for OECD countries. Data set.

OECD (2000). Migration and Regional Economic Integration in Asia. OECD, Paris.

OECD (2001). The employment of foreigners: Outlook and issues in OECD countries. In OECD Employment Outlook, chapter 5. OECD, Paris.

O'Rourke, K. H. and Sinnott, R. (2001). What determines attitudes towards protection? Some cross-country evidence. In Collins, S. M. and Rodrik, D., editors, Brookings Trade Forum 2001, pages 157-206. Brookings Institute Press.

O'Rourke, K. H. and Sinnott, R. (2003). Migration flows: Political economy of migration and the empirical challenges. Trinity College Dublin Economic Papers.

Rodrik, D. (1995). Political economy of trade policy. In Grossman, G. and Rogoff, K., editors, Handbook of International Economics, Vol.3, chapter 28, pages 1457-1494. North-Holland Elsevier Science, The Netherlands.

Rodrik, D. (1997). Has Globalization Gone Too Far? Institute for International Economics, Washington, DC.

Rodrik, D. (2001). Comments at the conference on "Immigration policy and the welfare state", Trieste, 2001.

Rosenzweig, M. R. and Stark, O., editors (1997). Handbook of Population and Family Economics. North-Holland Elsevier Science, The Netherlands.

Scheve, K. F. and Slaughter, M. J. (2001a). Globalization and the Perceptions of American Workers. Institute for International Economics, Washington, DC.

Scheve, K. F. and Slaughter, M. J. (2001b). Labor market competition and individual preferences over immigration policy. Review of Economics and Statistics, 83:133-145.

Scheve, K. F. and Slaughter, M. J. (2001c). What determines individual trade-policy preferences? Journal of International Economics, 54:267-292. 
Smith, J. P. and Edmonston, B., editors (1997). The New Americans. Economic, Demographic, and Fiscal Effects of Immigration. National Research Council, National Academy Press, Washington, D.C.

Smith, J. P. and Edmonston, B., editors (1998). The Immigration Debate. Studies on the Economic, Demographic, and Fiscal Effects of Immigration. National Research Council, National Academy Press, Washington, D.C.

SOPEMI (1997). Trends in International Migration. Annual Report 1996. OECD, Paris.

SOPEMI (1999). Trends in International Migration. OECD, Paris.

SOPEMI (2000). Trends in International Migration. OECD, Paris.

Tang, P. J. and Wood, A. (2000). Globalisation, co-operation costs and wage inequalities.

Timmer, A. and Williamson, J. (1996). Racism, xenophobia or markets? The political economy of immigration policy prior to the Thirties. National Bureau of Economic Research Working Paper No. 5867.

Trefler, D. (1997). Immigrants and natives in general equilibrium trade models. National Bureau of Economic Research Working Paper No. 6209.

Wood, A. (2000). Globalisation and wage inequalities: A synthesis of three theories.

Wooldridge, J. M. (2002). Econometric Analysis of Cross Section and Panel Data. The MIT Press, Cambridge, Massachusetts. 
Figure 1: Percentages of individuals who are pro-immigration by education group

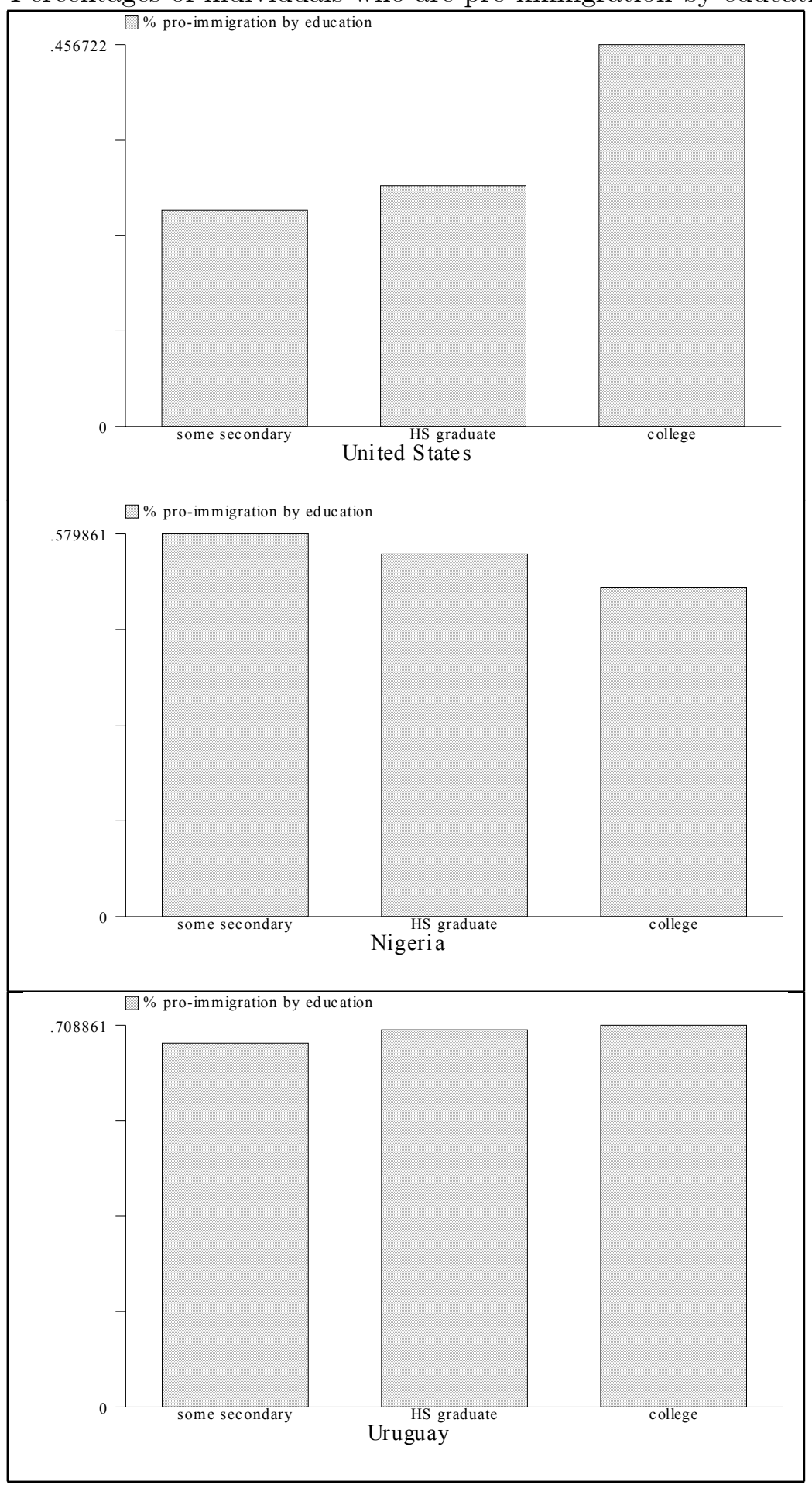


Figure 2: The country-specific impact of education on immigration preferences (ISSP data set)

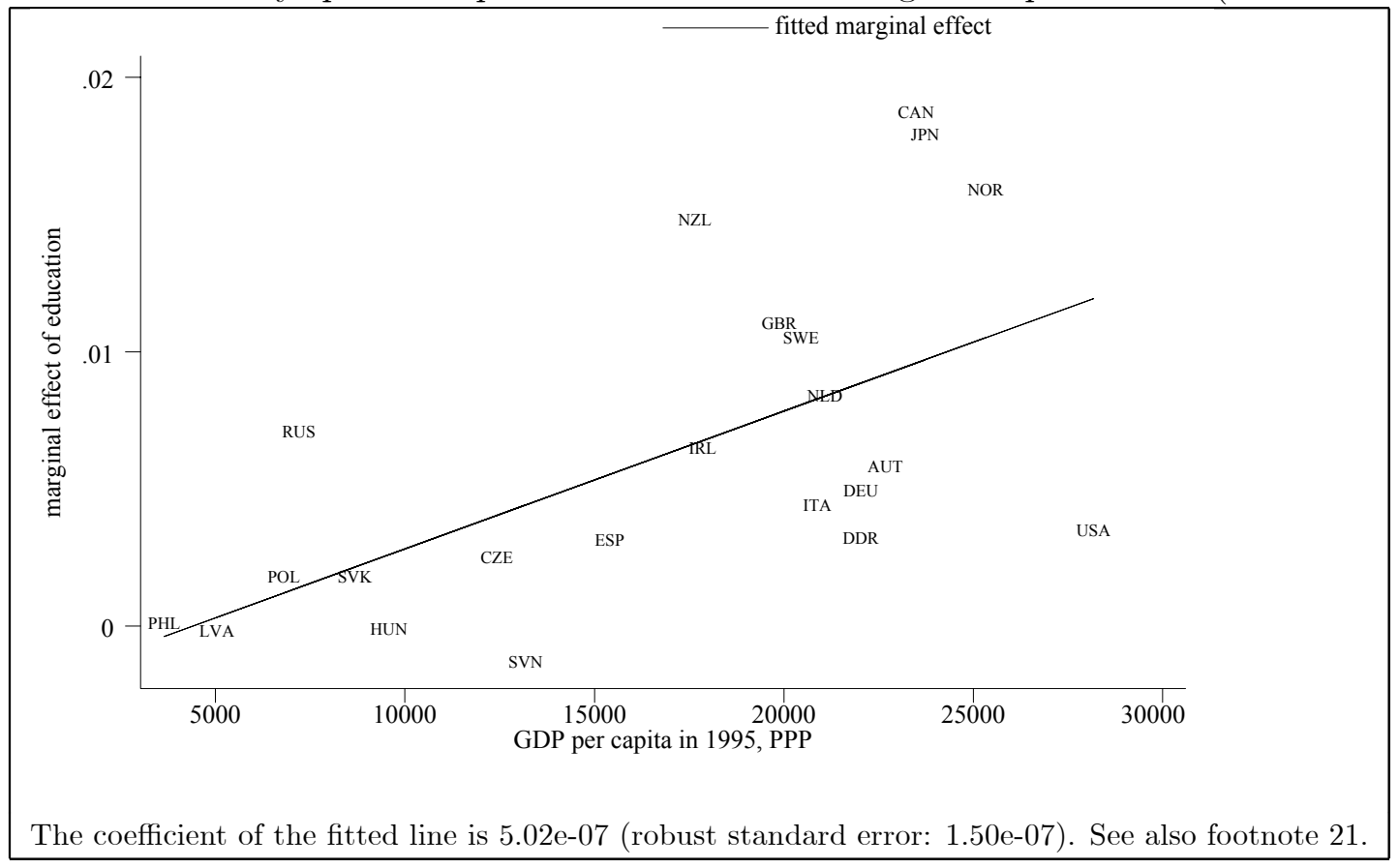


Figure 3: The country-specific impact of education on immigration preferences (2a and 2b) (WVS)

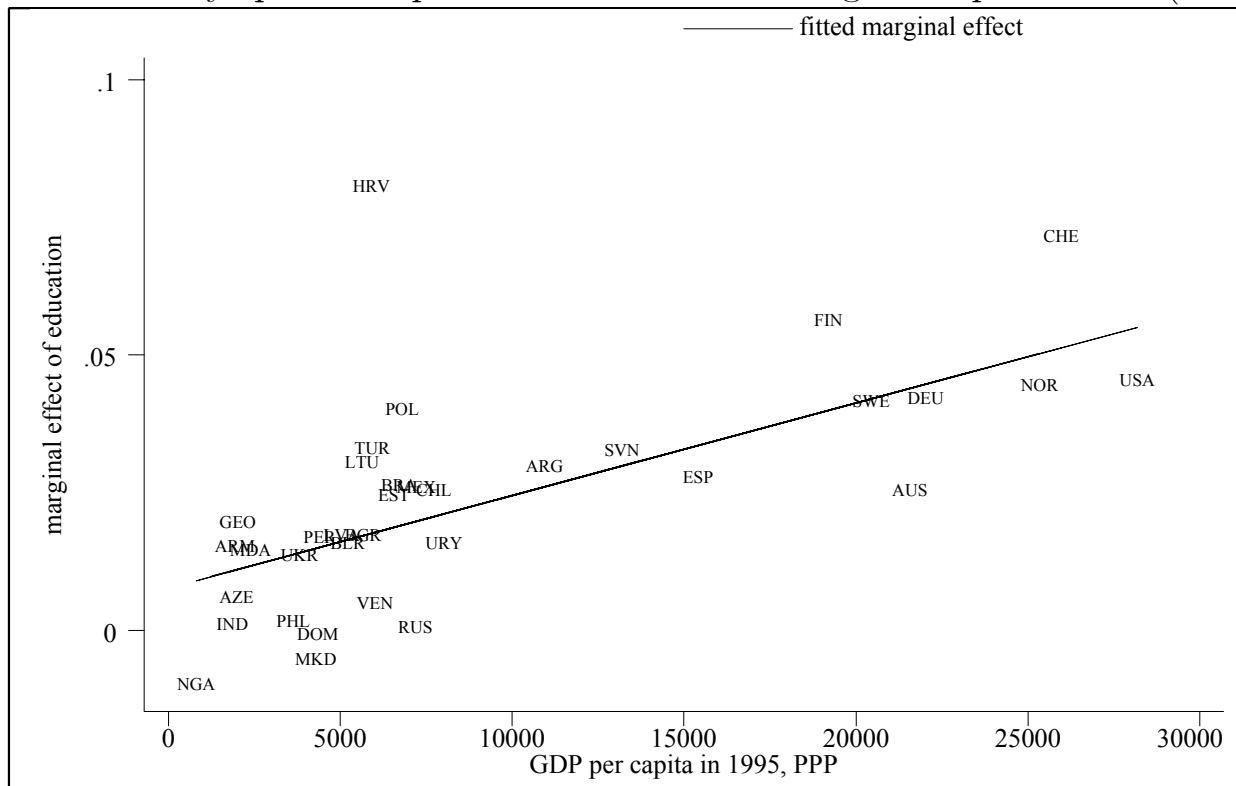

This graph covers the whole sample of countries in the WVS.

The coefficient of the fitted line is 1.68e-06 (robust st.error=2.97e-07). See also footnote 22 .

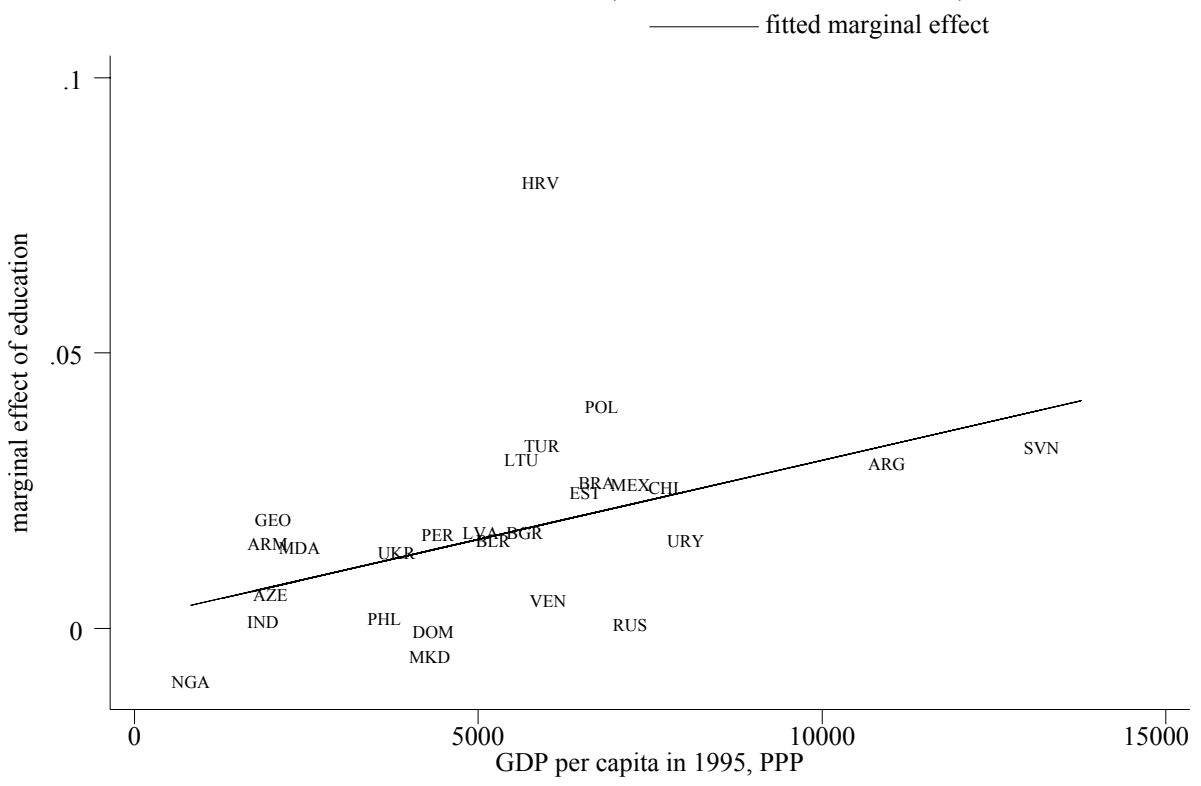

This graph covers lower-income countries in the WVS.

The coefficient of the fitted line is $2.87 \mathrm{e}-06$ (robust st.error $=6.76 \mathrm{e}-07$ ). See also footnote 22 . 
Figure 4: The country-specific impact of education on immigration preferences (ISSP data set)

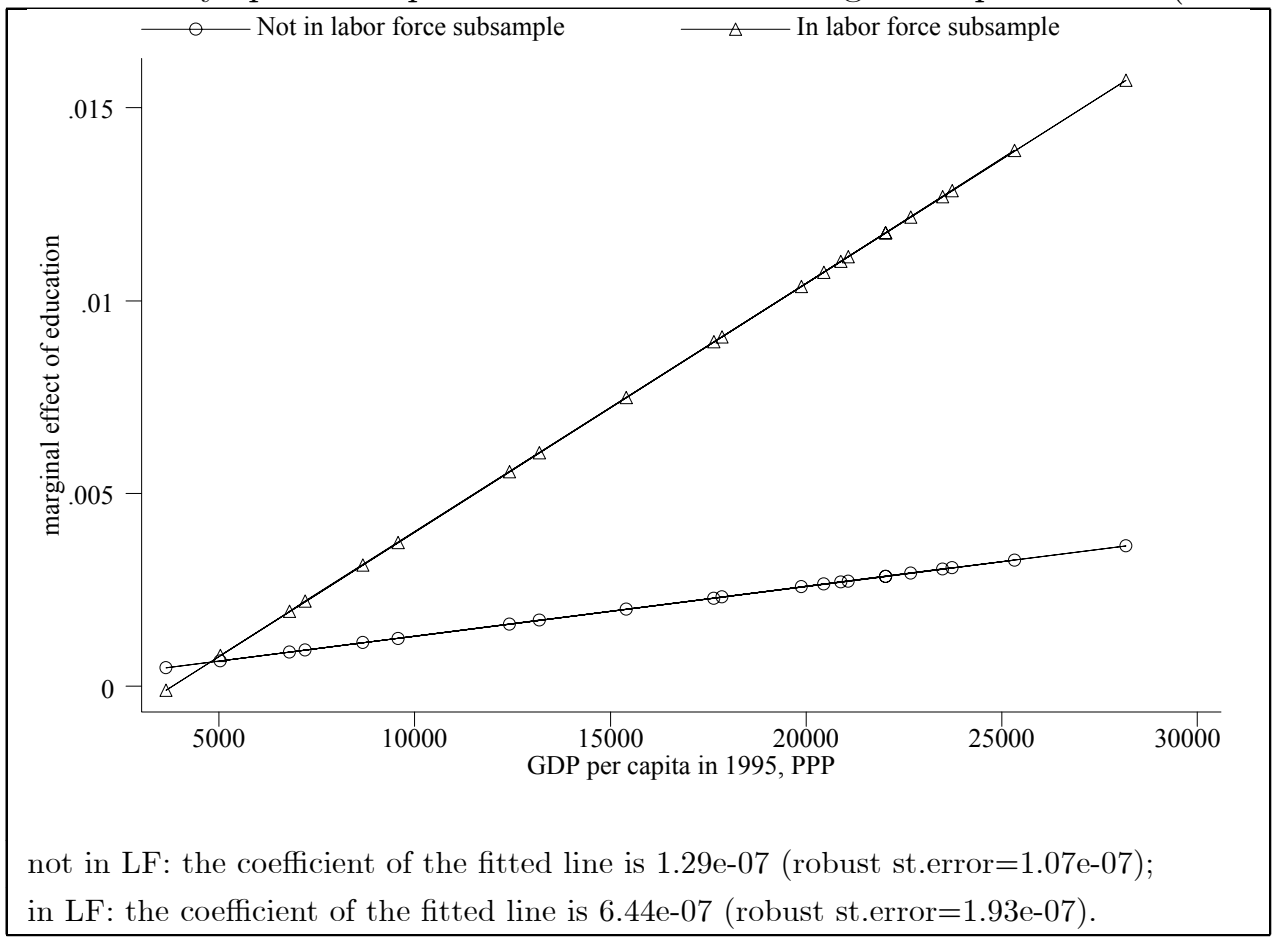


Table 1a: Benchmark Model (ISSP-NI data set)

\begin{tabular}{|c|c|c|c|c|c|c|c|}
\hline Equation & 1 & 2 & 3 & 4 & 5 & 6 & 7 \\
\hline \multirow[t]{2}{*}{ Method } & probit & probit & probit & probit & probit & probit & probit \\
\hline & $\begin{array}{l}\text { with country } \\
\text { dummies }\end{array}$ & $\begin{array}{l}\text { with country } \\
\text { dummies }\end{array}$ & $\begin{array}{l}\text { with country } \\
\text { dummies }\end{array}$ & $\begin{array}{l}\text { with country } \\
\text { dummies }\end{array}$ & $\begin{array}{l}\text { with country } \\
\text { dummies }\end{array}$ & $\begin{array}{l}\text { with country } \\
\text { dummies }\end{array}$ & $\begin{array}{l}\text { with country } \\
\text { dummies }\end{array}$ \\
\hline Dependent variable & \multicolumn{7}{|c|}{ Immig Opinion Dummy } \\
\hline \multirow[t]{2}{*}{ age } & -0.0006 & -0.0004 & -0.0006 & -0.0003 & -0.0004 & -0.0004 & -0.0002 \\
\hline & $3.47 * *$ & $2.00^{*}$ & $3.75 * *$ & 1.94 & $2.47^{*}$ & 1.72 & 0.71 \\
\hline \multirow[t]{2}{*}{ male } & 0.0139 & 0.0142 & 0.0141 & 0.012 & 0.0097 & 0.0086 & 0.0136 \\
\hline & $3.94 * *$ & $6.10 * *$ & $4.08 * *$ & $3.45^{* *}$ & $2.34^{*}$ & 1.76 & $2.61 * *$ \\
\hline \multirow[t]{2}{*}{ rural } & & -0.0054 & & & & & -0.009 \\
\hline & & $2.39 *$ & & & & & $2.28^{*}$ \\
\hline \multirow[t]{2}{*}{ parents' foreign citizenship } & & & 0.0272 & & & & 0.0349 \\
\hline & & & $5.69 * *$ & & & & $4.27^{* *}$ \\
\hline \multirow[t]{2}{*}{ education (years of education) } & & & & 0.0061 & 0.0076 & 0.0065 & 0.0074 \\
\hline & & & & $5.25 * *$ & $5.65^{* *}$ & $3.38 * *$ & $4.44 * *$ \\
\hline \multirow[t]{2}{*}{ log of real income } & & & & & 0.0015 & & \\
\hline & & & & & 0.39 & & \\
\hline \multirow[t]{2}{*}{ political affiliation with the right } & & & & & & -0.0115 & -0.0165 \\
\hline & & & & & & $1.97^{*}$ & 1.74 \\
\hline \multirow[t]{2}{*}{ upper social class } & & & & & & 0.0024 & \\
\hline & & & & & & 0.63 & \\
\hline \multirow[t]{2}{*}{ trade union member } & & & & & & -0.0003 & \\
\hline & & & & & & 0.06 & \\
\hline number of obs & 23977 & 18202 & 23866 & 21669 & 15066 & 8202 & 8420 \\
\hline Pseudo R-squared & 0.08 & 0.07 & 0.08 & 0.1 & 0.12 & 0.1 & 0.08 \\
\hline
\end{tabular}

The sample excludes all individuals who are not citizens of the country where they are interviewed.

The table contains the estimated marginal effect on the probability of being pro-immigration, given an increase in the value of the relevant regressor, holding all other regressors at their mean value.

The z statistics values of the marginal effect of each relevant regressor - based on standard errors adjusted for clustering on country - are presented under each marginal effect. * significant at $5 \%$; ** significant at $1 \%$

rural is coded as follows: $1=$ urban, $2=$ suburbs/city-town, $3=$ rural.

parents'foreign citizenship is coded as follows: $1=$ both parents are citizens; $2=$ only mother/father is citizen; $3=$ neither parents are citizens.

log of real income is calculated using data in local currency on individual yearly income from the ISSP-NI data set and purchasing power parity conversion factors from the WDI (World Bank).

trade union member equals one if the individual is a member of a trade union, zero if he is not.

political affiliation with the right is coded as follows: $1=$ far left, $2=$ centre left, $3=$ centre, $4=$ right, $5=$ far right.

upper social class is coded as follows: $1=$ lower, $2=$ working, $3=$ lower middle, $4=$ middle, $5=$ upper middle, $6=$ upper. 
Table 1b: Benchmark Model (WVS data set)

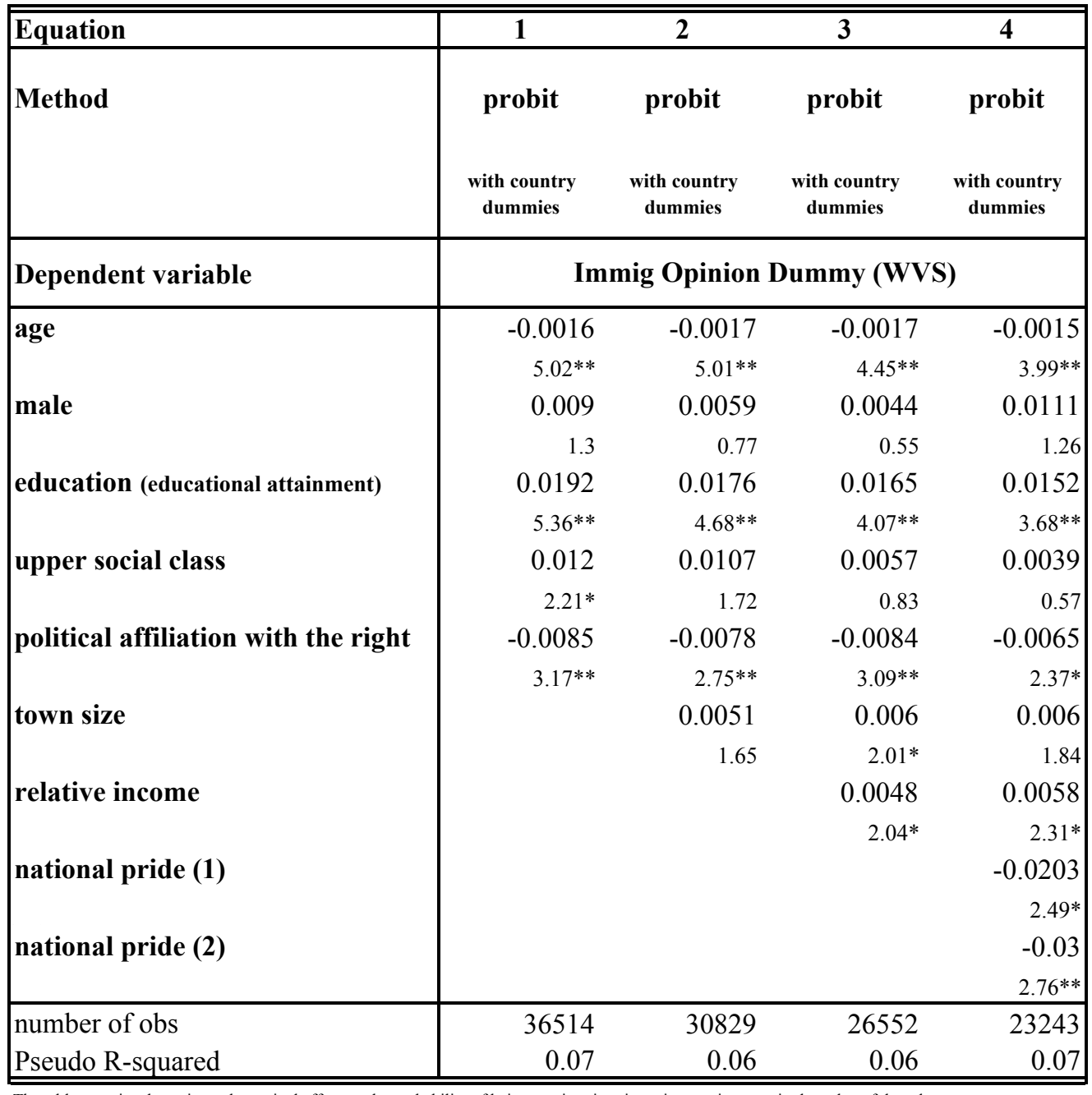

The table contains the estimated marginal effect on the probability of being pro-immigration, given an increase in the value of the relevant regressor,

holding all other regressors at their mean value. The $\mathrm{z}$ statistics values of the marginal effect of each relevant regressor - based on standard errors

adjusted for clustering on country - are presented under each marginal effect. * significant at $5 \%$; ** significant at $1 \%$

The sample excludes all individuals who were not born in the country where they are interviewed.

education (the highest education level attained by the individual) is coded as follows: $1=$ no formal education; 2 =incomplete primary school; $3=$ complete primary school;

4=incomplete secondary school (technical/vocational type); 5=complete secondary school (technical/vocational type);

6=incomplete secondary (university/preparatory type); 7=complete secondary (university/preparatory type); $8=$ some

university-level education, without degree; 9=university-level education, with degree.

upper social class is coded as follows: $1=$ lower class, $2=$ =orking class; $3=$ lower middle class; $4=$ =upper middle class; $5=$ upper class.

political affiliation with the right is coded as follows: in order, from 1 (left-wing) to 10 (right-wing)

town size is coded as follows: in order, from $1=$ under 2,000 to $8=500,000$ and more.

relative income is coded as follows: from $1=$ lowest decile in the country to $10=$ highest decile in the country.

national pride (I) is coded as follows: 1=not at all proud to be (Italian, for example); 4=very proud to be (Italian, for example)

national pride (2) is coded as follows: $1=$ if willing to fight in a war for one's own country; $0=$ if not willing. 
Table 2a: Does the link between individual skill and immigration preferences change across countries? (ISSP-NI data set)

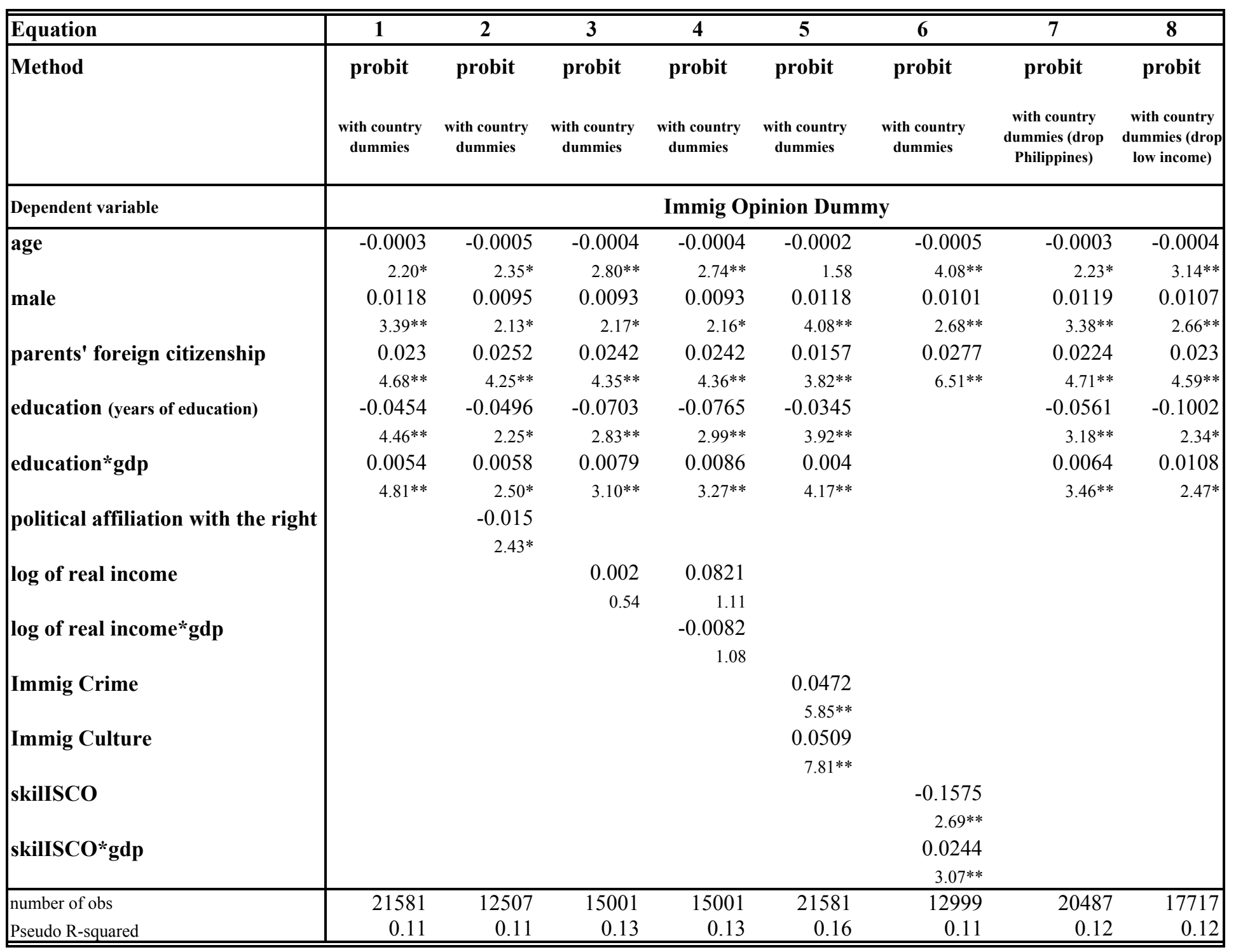

The sample excludes all individuals who are not citizens of the country where they are interviewed.

The table contains the estimated marginal effect on the probability of being pro-immigration, given an increase in the value of the relevant regressor, holding all other regressors at their mean value.

The z statistics values of the marginal effect of each relevant regressor - based on standard errors adjusted for clustering on country - are presented under each marginal effect. * significant at $5 \%$; ** significant at $1 \%$

parents' foreign citizenship is coded as follows: $1=$ both parents are citizens; $2=$ only mother/father is citizen; $3=$ neither parents are citizens.

political affiliation with the right is coded as follows: $1=$ far left, $2=$ centre left, $3=$ centre, 4 -right, $5=$ far right. $g d p$ is the log of per capita GDP in 1995, PPP (current international dollars)

log of real income is calculated using data in local currency on individual income from the ISSP-NI data set and purchasing power parity conversion factors from the WDI (World Bank).

See Appendix 2 for the definition ofImmig Crime and Immig Culture.

skillSCO equals one if the ISCO88 occupation code is 2 (legislators and managers), 3 (professionals) and 4 (technicians); it equals zero if the ISCO 88 occupation code is 5 (clerks), 6 (service and sales workers),

7 (agricultural and fishery workers), 8 (craft and related trades workers), 9 (plant and machine operators) and 10 (elementary occupations) 
Table 2b: Does the link between individual skill and immigration preferences change across countries? (WVS data set)

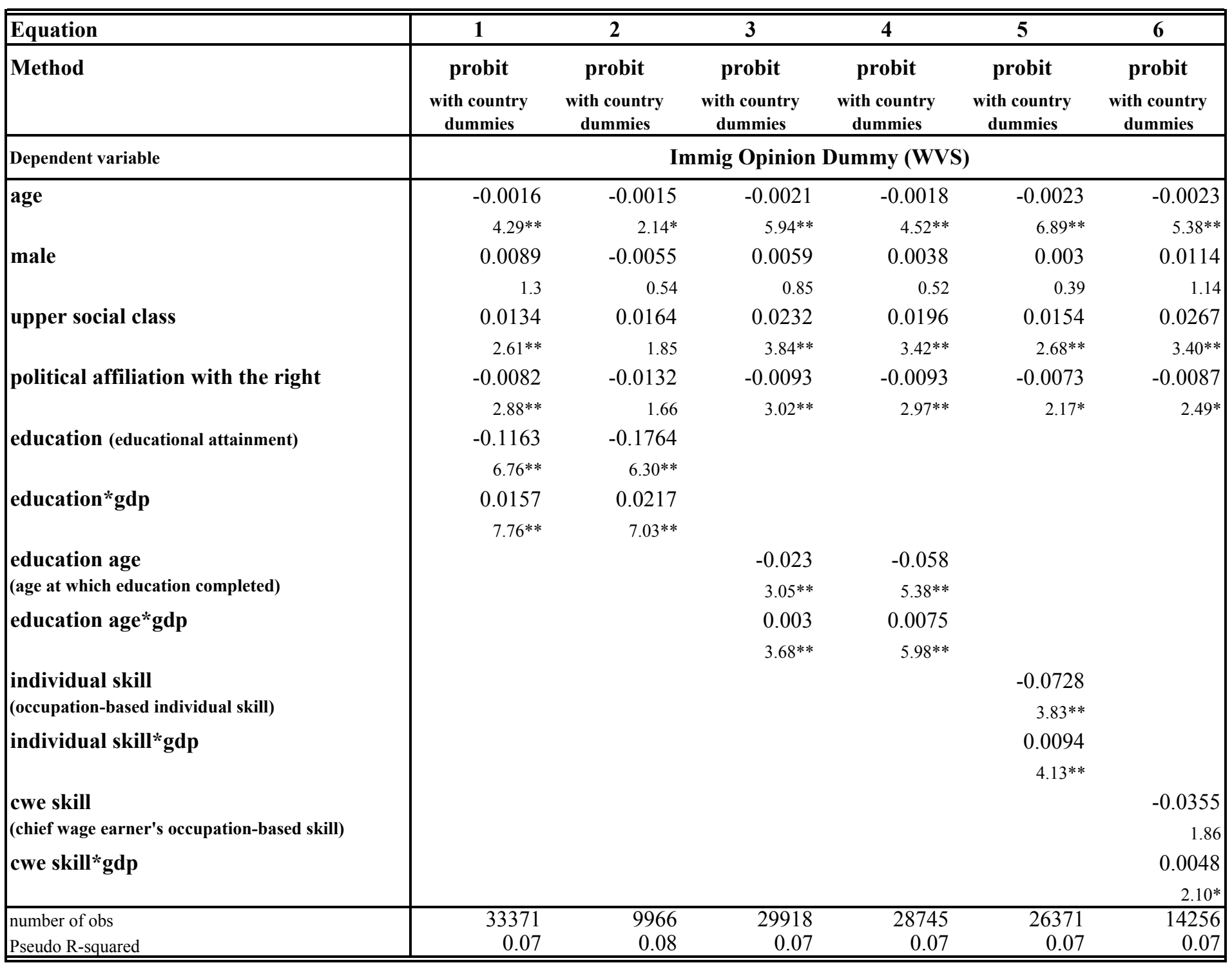

The table contains the estimated marginal effect on the probability of being pro-immigration, given an increase in the value of the relevant regressor, holding all other regressors at their mean value.

The $\mathrm{z}$ statistics values of the marginal effect of each relevant regressor - based on standard errors adjusted for clustering on country - are presented under each marginal effect. * significant at $5 \%$; ** significant at $1 \%$

The sample excludes all individuals who were not born in the country where they are interviewed. The countries' sample for regression in column (2) is the same as in the ISSP data set.

upper social class is coded as follows: $1=$ lower class, $2=$ working class; $3=$ lower middle class; $4=$ upper middle class; $5=$ upper class.

political affiliation with the right is coded as follows: in order, from 1 (left-wing) to 10 (right-wing).

See footnote at the end of Table $1 \mathrm{~b}$ for the definition of education . education age is the age at which the individual finished school.

individual skill is coded as follows: $1=$ agricultural worker; $2=$ farmer (own farm); $3=$ unskilled manual worker; $4=$ semi-skilled manual worker; $5=$ skilled manual worker; $6=$ foreman and supervisor;

7=non manual-office worker (non-supervisory); 8=supervisory-office worker; 9=professional worker (lawyer, accountant, teacher, etc.); 10=employer/manager of

establishment with less than 10 employees; $11=$ employer/manager of establishment with 10 or more employees.

cwe (chief wage earner in the household)skill is coded in the same way as individual skill. 
Table 2c: Differential Impact of Skill on Immigration-Policy Preferences: Labor-Force Participants and Non-Labor-Force Participants (ISSP-NI data set)

\begin{tabular}{|c|c|c|c|}
\hline Equation & 1 & 2 & 3 \\
\hline Method & $\begin{array}{c}\text { probit } \\
\text { with country dummies }\end{array}$ & $\begin{array}{l}\text { probit } \\
\text { with country dummies }\end{array}$ & $\begin{array}{c}\text { probit } \\
\text { with country dummies }\end{array}$ \\
\hline Dependent variable & \multicolumn{3}{|c|}{ Immig Opinion Dummy } \\
\hline Sample & Full Sample & In Labor Force & Not in Labor Force \\
\hline \multirow{4}{*}{$\begin{array}{l}\text { educyrs } \\
\text { (years of education) } \\
\text { educyrs*gdp }\end{array}$} & -0.0345 & -0.0411 & -0.0067 \\
\hline & $3.92 * *$ & $3.59 * *$ & 1.54 \\
\hline & 0.004 & 0.0048 & 0.0008 \\
\hline & $4.17 * *$ & $3.84 * *$ & 1.63 \\
\hline Observations & 21581 & 13237 & 7264 \\
\hline Pseudo R-squared & 0.16 & 0.16 & 0.15 \\
\hline
\end{tabular}

* significant at $5 \% ; * *$ significant at $1 \%$.

The regressions in this table, based on the ISSP-NI data set, include as controls age, male, parents' foreign

citizenship, Immig Crime, Immig Culture and country dummy variables. The z statistic values, under each marginal effect, are based on robust standard errors adjusted for clustering on country.

The labor force subsample includes individuals who are full-time employed, part-time employed, less than part-time employed (main job); unemployed. The out-of-the labor force subsample includes individuals who are retired; housewifes (men), in home duties; permanently disabled, sick; others, not in labour force, not working. I exclude students from the sample since their number of years of education does not reflect their expected future skill. 
Table 3: Factor-Endowments Model (ISSP-NI data set): Additional empirical evidence on the link between individual skill and preferences

\begin{tabular}{|c|c|c|c|c|c|c|c|c|c|}
\hline Equation & 1 & 2 & 3 & 4 & 5 & 6 & 7 & 8 & 9 \\
\hline Method & $\begin{array}{c}\text { probit } \\
\text { with country } \\
\text { dummies }\end{array}$ & $\begin{array}{c}\text { probit } \\
\text { with country } \\
\text { dummies }\end{array}$ & $\begin{array}{c}\text { probit } \\
\text { with country } \\
\text { dummies }\end{array}$ & $\begin{array}{c}\text { probit } \\
\text { with country } \\
\text { dummies }\end{array}$ & $\begin{array}{c}\text { probit } \\
\text { with country } \\
\text { dummies }\end{array}$ & $\begin{array}{c}\text { probit } \\
\text { with country } \\
\text { dummies }\end{array}$ & $\begin{array}{c}\text { probit } \\
\text { with country } \\
\text { dummies }\end{array}$ & $\begin{array}{c}\text { probit } \\
\text { with country } \\
\text { dummies }\end{array}$ & $\begin{array}{c}\text { probit } \\
\text { with country } \\
\text { dummies }\end{array}$ \\
\hline Dependent variable & \multicolumn{9}{|c|}{ Immig Opinion Dummy } \\
\hline \multirow[t]{2}{*}{ age } & -0.0005 & -0.0003 & -0.0005 & -0.0005 & -0.0003 & -0.0004 & -0.0002 & -0.0002 & -0.0005 \\
\hline & $2.68 * *$ & $2.20 *$ & $2.68^{* *}$ & $2.67 * *$ & $2.21 *$ & 1.04 & 0.57 & 0.56 & 1.21 \\
\hline \multirow[t]{2}{*}{ male } & 0.0078 & 0.0107 & 0.0078 & 0.0078 & 0.0106 & -0.0019 & 0.0004 & 0.0004 & -0.0029 \\
\hline & 1.58 & $2.42 *$ & 1.6 & 1.6 & $2.44 *$ & 0.15 & 0.04 & 0.03 & 0.22 \\
\hline \multirow[t]{2}{*}{ parents' foreign citizenship } & 0.0163 & 0.01 & 0.0163 & 0.0163 & 0.01 & 0.0207 & 0.0117 & 0.009 & 0.0194 \\
\hline & $3.24 * *$ & $2.26^{*}$ & $3.19^{* *}$ & $3.22 * *$ & $2.25^{*}$ & $2.08^{*}$ & 1.58 & 1.15 & $2.07 *$ \\
\hline \multirow[t]{2}{*}{ education (years of education) } & -0.0012 & -0.002 & -0.0245 & 0.0066 & 0.0035 & 0.0085 & 0.0056 & 0.0081 & -0.3472 \\
\hline & 1.01 & $2.23 *$ & 0.35 & $4.32 * *$ & $3.05^{* *}$ & $3.17 * *$ & $3.07 * *$ & $3.13 * *$ & $3.38 * *$ \\
\hline \multirow[t]{2}{*}{ education*relative skill ratio } & 0.0099 & 0.0074 & 0.0093 & & & & & & \\
\hline & $6.53 * *$ & $5.80 * *$ & $4.05^{* *}$ & & & & & & \\
\hline \multirow[t]{2}{*}{ education*gdp } & & & 0.0024 & & & & & & 0.0362 \\
\hline & & & 0.33 & & & & & & $3.50 * *$ \\
\hline \multirow[t]{2}{*}{ education*SN*(RSC-1) } & & & & 0.0028 & 0.0023 & & & & \\
\hline & & & & $3.89 * *$ & $3.97 * *$ & & & & \\
\hline \multirow[t]{2}{*}{ education*SM*(1-RSC) } & & & & -0.0077 & -0.005 & & & & \\
\hline & & & & $2.45^{*}$ & $2.12 *$ & & & & \\
\hline \multirow[t]{2}{*}{$\begin{array}{l}\text { Immigrants/Natives ratio in each } \\
\text { occupation (IN ratio) }\end{array}$} & & & & & & -0.2705 & -0.1713 & -0.4489 & -0.1432 \\
\hline & & & & & & $3.83 * *$ & $3.09^{* *}$ & $2.04 *$ & 1.55 \\
\hline \multirow[t]{2}{*}{ Immig Crime } & & 0.0491 & & & 0.0489 & & 0.0389 & & \\
\hline & & $6.99 * *$ & & & $6.99 * *$ & & $4.52 * *$ & & \\
\hline \multirow[t]{2}{*}{ Immig Culture } & & 0.0489 & & & 0.0487 & & 0.0573 & & \\
\hline & & $4.16^{* *}$ & & & $4.16^{* *}$ & & $5.05^{* *}$ & & \\
\hline \multirow[t]{2}{*}{ willingness to move } & & & & & & & & 0.003 & \\
\hline & & & & & & & & 1.48 & \\
\hline \multirow[t]{2}{*}{ willingness to move*IN ratio } & & & & & & & & 0.0872 & \\
\hline & & & & & & & & 1.57 & \\
\hline number of obs & 10414 & 10414 & 10414 & 10414 & 10414 & 3421 & 3421 & 3173 & 3421 \\
\hline Pseudo R-squared & 0.13 & 0.18 & 0.13 & 0.13 & 0.18 & 0.13 & 0.19 & 0.13 & 0.14 \\
\hline
\end{tabular}

of the relevant regressor, holding all other regressors at their mean value. The z statistics values of the marginal effect of each relevant regressor - based on standard errors adjusted for clustering on country -

are presented under each marginal effect. * significant at $5 \%$; * significant at $1 \%$.

parents' foreign citizenship is coded as follows: $1=$ both parents are citizens; $2=$ only mother/father is citizen; $3=$ neither parents are citizens.

The relative skill ratio is the log of one plus the relative skill composition RSC). The relative skill composition is the ratio of skilled to unskilled labor in the native relative to the immigrant populations. For both natives and immigrants, the ratio of skilled to unskilled labor is measured as the ratio of the number of individuals with levels of education 2 and 3 to the number of individuals with level 1 of education (see footnote 13). In order to get the semi-elasticity with respect to the RSC, one needs to multiply coefficients' estimates of thelative skill ratio by $\mathrm{RSC} /(1+\mathrm{RSC})$. The skill composition uses data on the stock of immigrants and natives in 1995 .

$S N$ is an indicator variable of whether the ratio of skilled to unskilled labor in the native relative to the immigrant populations is greater than $1 S M$ is an indicator variable of the same ratio being less than 1.

The variable Immigrants/Natives ratio in each occupation (IN ratio) is equal to the log of one plus the ratio of the number of foreigners to the number of natives in each occupation, in 1995 (the data for foreigners and for natives

referes to the stock of immigrants and natives in 1995).Willingness to move measures the stated willingness to move to another city/town, in order to improve work or living conditions (1=very unwilling, $5=$ very willing).

See Appendix 2 for the definition ofImmig Crime and Immig Culture. 
Table 4a: Non-Economic Determinants Model (ISSP-NI data set)

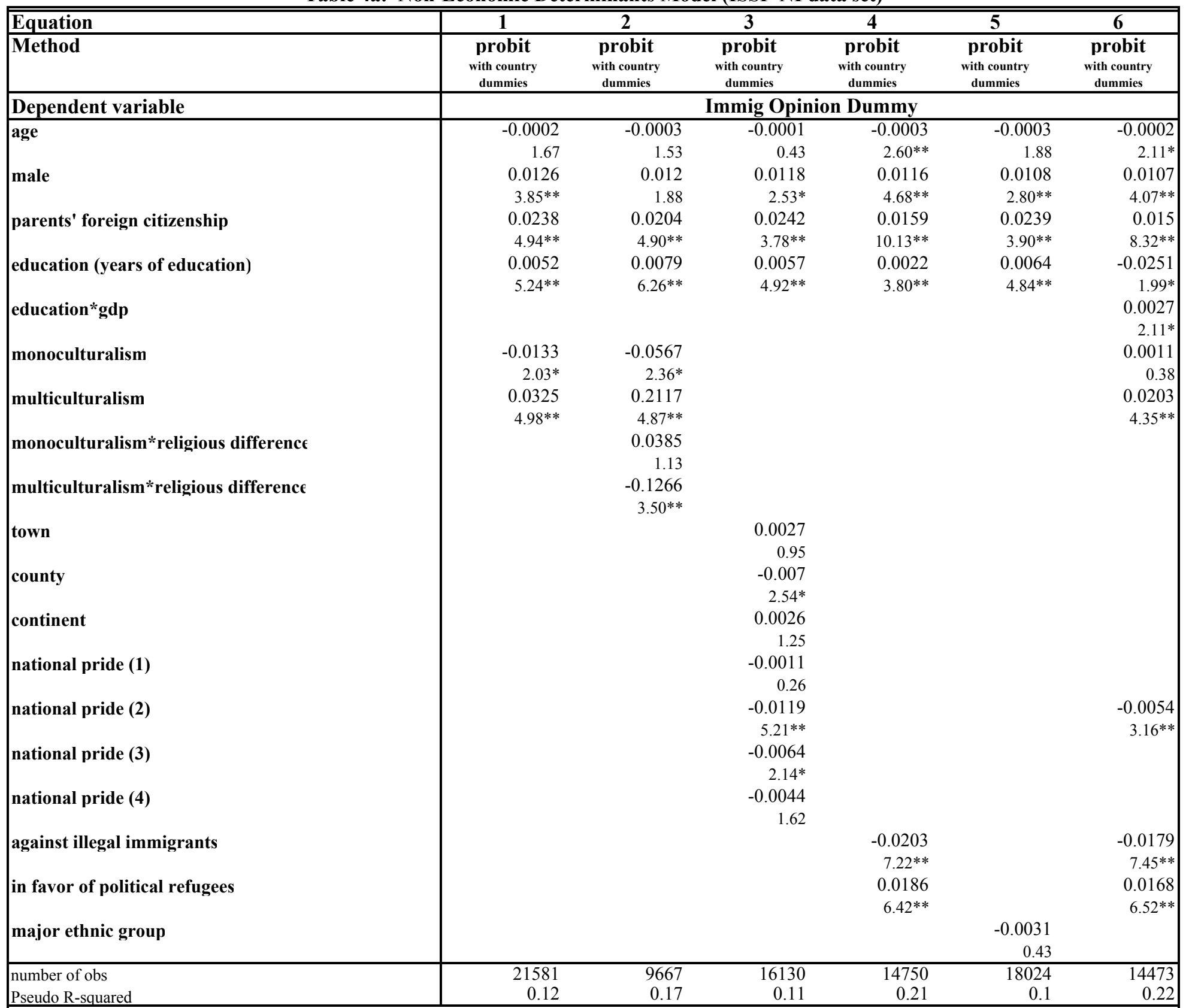

The sample excludes all individuals who are not citizens of the country where they are interviewed. The table contains the estimated marginal effect on the probability of being pro-immigration, given an increase in

the value of the relevant regressor, holding all other regressors at their mean value. The $z$ statistics values of the marginal effect of each relevant regressor - based on standard errors adjusted for clustering

on country - are presented under each marginal effect. * significant at $5 \% ; *$ significant at $1 \%$. parents' foreign citizenship is coded as follows: $1=$ both parents are citizens; $2=$ only mother/father is citizen; $3=$ neither parents are citizens.

The variable multiculturalism (monoculturalism) is an indicator variable of answer 1 (2) to the following question: "Some people say that it is better for a country if different racial and ethnic groups maintain their distinct customs and traditions. Others say that it is better if these groups adapt and blend into the larger society. Which of these views comes closer to your own? 1. It is better for society if groups maintain their distinct customs and traditions; 2. It is better if groups adapt and blend into the larger society." For each destination country, religious difference measures the dissimilarity between natives and immigrants, in terms of religious affiliation.

The variable against illegal immigrants is higher (from 1 to 5) the more the respondent agrees with the following statement: "(R's country) should take stronger measures to exclude illegal immigrants." The variablen favor of political refugees is higher

(from 1 to 5) the more the respondent agrees with the statement that refugees who have suffered political repression in their own country should be allowed to stay in (R's country). The variablemajor ethnic group equals 1 if the respondent belongs to the dominant ethnic group in his country; it equals 0 otherwise. See Appendix 4 and Mayda and Rodrik (2002) for the definition ofown, county, country, continent, national pride (I)-(4). 
Table 4b: Non-Economic Determinants Model (WVS data set)

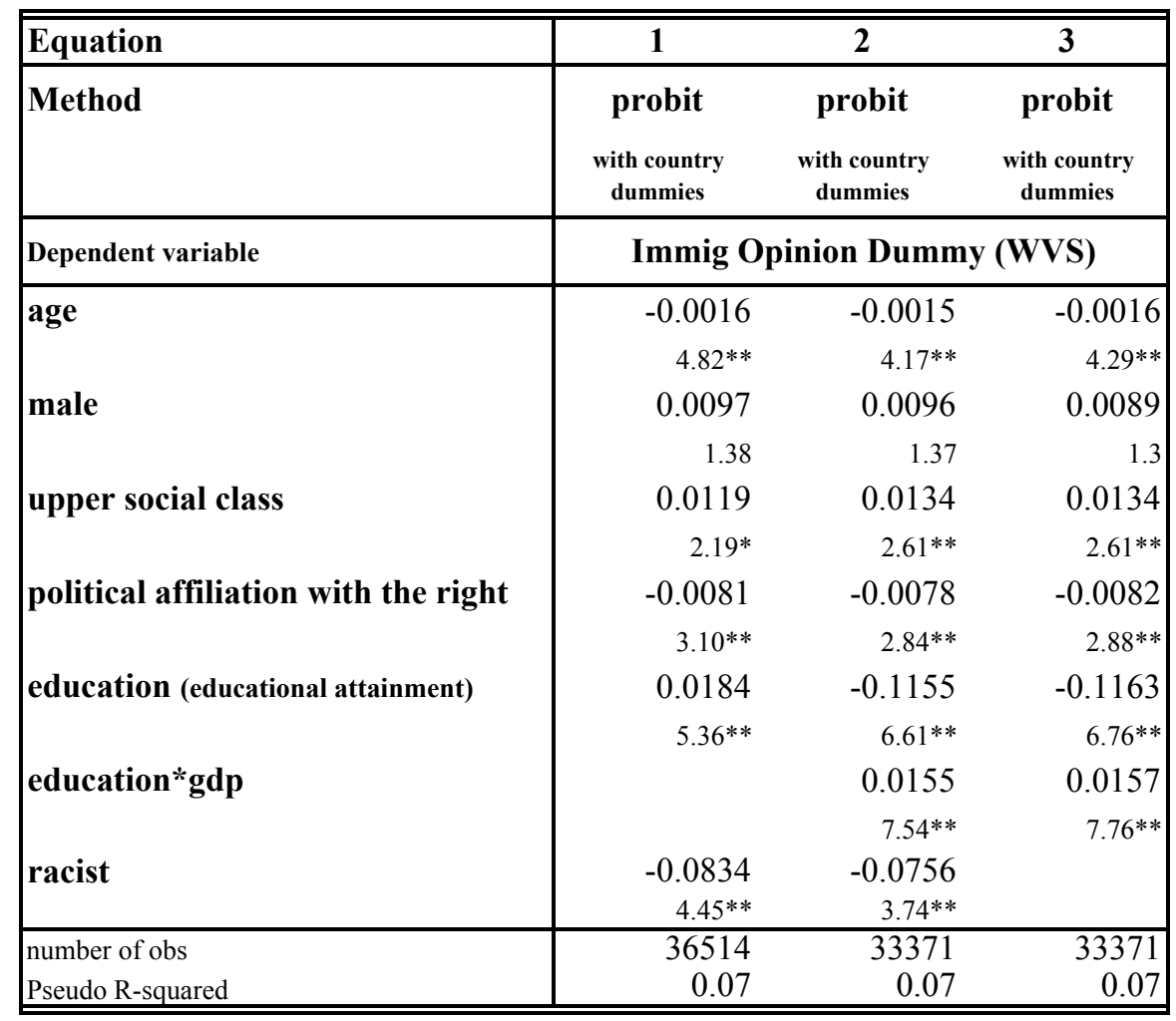

The table contains the estimated marginal effect on the probability of being pro-immigration, given an increase

in the value of the relevant regressor, holding all other regressors at their mean value.

The $\mathrm{z}$ statistics values of the marginal effect of each relevant regressor - based on standard errors adjusted for clustering

on country - are presented under each marginal effect. * significant at $5 \%$; ** significant at $1 \%$

The sample excludes all individuals who were not born in the country where they are interviewed.

upper social class is coded as follows: $1=$ lower class, $2=$ =working class; $3=$ lower middle class; $4=$ =upper middle class; $5=$ =upper class.

political affiliation with the right is coded as follows: in order, from 1 (left-wing) to 10 (right-wing).

See footnote at the end of Table $1 \mathrm{~b}$ for the definition of education.

The variable racist is equal to 1 if, given the question "On this list are various groups of people. Could you please sort out any

that you would not like to have as neighbours?", the respondent mentions "People of a different race"; it equals 0 otherwise. 
Table 5: Immigration vs Trade Preferences (ISSP-NI data set)

\begin{tabular}{|c|c|c|c|c|c|c|}
\hline Equation & 1 & 2 & 3 & $\overline{4}$ & $\overline{5}$ & $\overline{6}$ \\
\hline Method & $\begin{array}{c}\text { probit } \\
\text { with country } \\
\text { dummies }\end{array}$ & $\begin{array}{c}\text { probit } \\
\text { with country } \\
\text { dummies }\end{array}$ & $\begin{array}{c}\text { probit } \\
\text { with country } \\
\text { dummies }\end{array}$ & $\begin{array}{c}\text { probit } \\
\text { with country } \\
\text { dummies }\end{array}$ & $\begin{array}{c}\text { probit } \\
\text { with country } \\
\text { dummies }\end{array}$ & $\begin{array}{c}\text { probit } \\
\text { with country } \\
\text { dummies }\end{array}$ \\
\hline Dependent variable & \multicolumn{3}{|c|}{ Immig Opinion Dummy } & \multicolumn{3}{|c|}{ Trade Opinion Dummy } \\
\hline age & $\begin{array}{r}-0.0003 \\
2.20^{*}\end{array}$ & $\begin{array}{r}-0.0001 \\
0.49\end{array}$ & $\begin{array}{r}-0.0001 \\
0.43\end{array}$ & $\begin{array}{r}-0.0006 \\
1.27\end{array}$ & $\begin{array}{r}-0.0004 \\
0.97\end{array}$ & $\begin{array}{r}-0.0007 \\
1.55\end{array}$ \\
\hline \multirow[t]{2}{*}{ male } & 0.0118 & 0.0099 & 0.0095 & 0.0787 & 0.0797 & 0.0809 \\
\hline & $3.39^{* *}$ & $2.11^{*}$ & $2.14 *$ & $5.74 * *$ & $5.59 * *$ & $7.61^{* *}$ \\
\hline \multirow[t]{2}{*}{ parents' foreign citizenship } & 0.023 & 0.0235 & 0.0254 & 0.0194 & 0.0203 & 0.0301 \\
\hline & $4.68^{* *}$ & $4.58^{* *}$ & $4.87 * *$ & $2.13^{*}$ & $2.14 *$ & $3.96^{* *}$ \\
\hline \multirow[t]{2}{*}{ education (years of education) } & -0.0454 & 0.0063 & 0.0061 & 0.0191 & 0.0193 & -0.127 \\
\hline & $4.46^{* *}$ & $4.24 * *$ & $4.30 * *$ & $5.81^{* *}$ & $5.99 * *$ & $3.99^{* *}$ \\
\hline \multirow[t]{2}{*}{ education*gdp } & 0.0054 & & & & & 0.0154 \\
\hline & $4.81^{* *}$ & & & & & $4.71^{* *}$ \\
\hline \multirow[t]{2}{*}{ non-traded sector } & & & 0.0049 & 0.0305 & & \\
\hline & & & 1.06 & $2.05^{*}$ & & \\
\hline \multirow[t]{2}{*}{ CA (comparatively-advantaged) sector } & & -0.0043 & & & -0.0133 & \\
\hline & & 0.66 & & & 0.53 & \\
\hline \multirow[t]{2}{*}{ CD (comparatively-disadvantaged) sector } & & -0.0124 & & & -0.0306 & \\
\hline & & $2.09 *$ & & & $2.26 *$ & \\
\hline number of obs & 21581 & 10707 & 11365 & 12429 & 11675 & 23415 \\
\hline Pseudo R-squared & 0.11 & 0.11 & 0.11 & 0.06 & 0.07 & 0.08 \\
\hline
\end{tabular}

The sample excludes all individuals who are not citizens of the country where they are interviewed, in both regressions with Immig Opinion Dummy and Trade Opinion Dummy as dependent variables.

The table contains the estimated marginal effect on the probability of being pro-immigration, given an increase in the value of the relevant regressor, holding all other regressors at their mean value.

The z statistics values of the marginal effect of each relevant regressor - based on standard errors adjusted for clustering on country - are presented under each marginal effect. * significant at $5 \%$; ** significant at $1 \%$. parents' foreign citizenship is coded as follows: $1=$ both parents are citizens; $2=$ only mother/father is citizen; $3=$ neither parents are citizens.

A sector is defined as a CA (comparatively-advantaged) sector if its adjusted net imports are less than zero and as a CD (comparatively disadvantaged) sector if its adjusted net imports are greater than zero. 
Data Appendix 1a: Summary Data on Individual Preferences on Immigration Policy (ISSP-NI data set)

\begin{tabular}{|c|c|c|c|c|c|c|c|c|c|c|c|}
\hline Country & 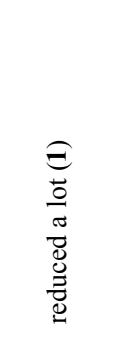 & 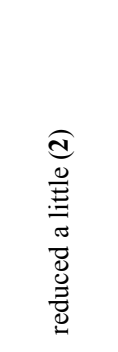 & 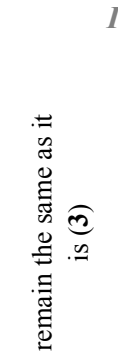 & 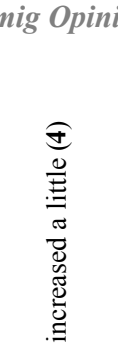 & 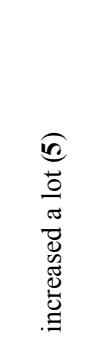 & 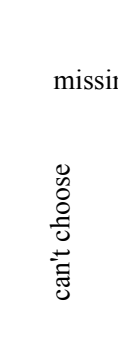 & alues & \multicolumn{2}{|c|}{$\begin{array}{l}\text { average Immig } \\
\text { Opinion }\end{array}$} & \multicolumn{2}{|c|}{$\begin{array}{c}\text { Immig Opinion } \\
\text { Dummy }\end{array}$} \\
\hline Germany West & 46.290 & 23.430 & 17.630 & 2.040 & 0.490 & 8.820 & 1.310 & 1.743 & 20 & 0.028 & 18 \\
\hline Germany East & 51.630 & 20.260 & 16.830 & 1.140 & 0.650 & 8.660 & 0.820 & 1.662 & 21 & 0.020 & 20 \\
\hline Great Britain & 40.100 & 23.770 & 25.890 & 2.800 & 1.060 & 5.700 & 0.680 & 1.942 & 16 & 0.041 & 14 \\
\hline USA & 29.690 & 25.190 & 21.830 & 4.580 & 2.140 & 12.600 & 3.970 & 2.092 & 12 & 0.081 & 9 \\
\hline Austria & 28.360 & 24.720 & 37.740 & 2.930 & 0.810 & 5.450 & 0.000 & 2.187 & 8 & 0.039 & 15 \\
\hline Hungary & 55.950 & 24.190 & 13.510 & 0.710 & 0.710 & 4.640 & 0.300 & 1.591 & 23 & 0.015 & 22 \\
\hline Italy & 41.760 & 30.310 & 19.870 & 2.560 & 0.820 & 4.580 & 0.090 & 1.850 & 17 & 0.036 & 16 \\
\hline Ireland & 6.630 & 13.560 & 55.350 & 15.600 & 2.240 & 6.520 & 0.100 & 2.928 & 1 & 0.191 & 2 \\
\hline Netherlands & 26.370 & 30.990 & 30.790 & 4.420 & 0.680 & 6.220 & 0.530 & 2.164 & 9 & 0.055 & 13 \\
\hline Norway & 29.530 & 29.260 & 27.320 & 5.700 & 1.210 & 6.240 & 0.740 & 2.138 & 10 & 0.074 & 10 \\
\hline Sweden & 35.660 & 29.250 & 21.880 & 4.130 & 2.110 & 6.730 & 0.240 & 2.009 & 14 & 0.067 & 11 \\
\hline Czech Republic & 39.750 & 25.750 & 21.140 & 1.900 & 0.270 & 11.020 & 0.180 & 1.842 & 18 & 0.024 & 19 \\
\hline Slovenia & 29.920 & 29.920 & 31.760 & 1.350 & 0.390 & 6.660 & 0.000 & 2.061 & 13 & 0.019 & 21 \\
\hline Poland & 25.920 & 17.530 & 19.910 & 4.130 & 1.820 & 29.740 & 0.940 & 2.111 & 11 & 0.086 & 6 \\
\hline Bulgaria & 32.580 & 17.190 & 9.770 & 2.170 & 1.540 & 36.470 & 0.270 & 1.781 & 19 & 0.059 & 12 \\
\hline Russia & 16.080 & 22.150 & 22.280 & 3.990 & 1.460 & 34.050 & 0.000 & 2.281 & 5 & 0.083 & 8 \\
\hline New Zealand & 26.790 & 31.650 & 24.060 & 8.590 & 2.220 & 5.260 & 1.420 & 2.226 & 6 & 0.116 & 4 \\
\hline Canada & 16.480 & 20.580 & 32.890 & 12.170 & 5.990 & 11.430 & 0.470 & 2.666 & 2 & 0.206 & 1 \\
\hline Philippines & 31.910 & 27.140 & 25.630 & 7.200 & 3.770 & 4.360 & 0.000 & 2.203 & 7 & 0.115 & 5 \\
\hline Japan & 13.380 & 21.820 & 35.030 & 10.110 & 2.950 & 16.480 & 0.240 & 2.609 & 3 & 0.157 & 3 \\
\hline Spain & 8.770 & 26.640 & 45.490 & 6.390 & 1.070 & 11.640 & 0.000 & 2.596 & 4 & 0.084 & 7 \\
\hline Latvia & 49.740 & 20.050 & 17.190 & 0.260 & 0.130 & 12.500 & 0.130 & 1.638 & 22 & 0.004 & 23 \\
\hline Slovak Republic & 30.220 & 24.510 & 24.300 & 1.810 & 0.650 & 18.510 & 0.000 & 1.996 & 15 & 0.030 & 17 \\
\hline $\begin{array}{l}\text { Mean } \\
\text { Standard Deviation }\end{array}$ & 29.600 & 24.590 & 26.270 & 4.820 & 1.600 & 12.560 & 0.560 & $\begin{array}{l}2.128 \\
1.007\end{array}$ & & $\begin{array}{l}0.074 \\
0.262\end{array}$ & \\
\hline
\end{tabular}

The sample excludes all individuals who are not citizens of the country where they are interviewed.

The second column of the last three variables gives the ranking of countries according to that variable.

Bold numbers correspond to highest and lowest values.

In the definition of Immig Opinion, missing values include "can't choose" and NA responses.

Immig Opinion Dummy=1 if Immig Opinion=4 or $5 ; 0$ if Immig Opinion=1,2 or 3 ; can't choose and NA are missing values.

Immig Opinion gives responses to the following question: "Do you think the number of immigrants to (R's country) nowadays should be ...": reduced a lot (1), reduced a little (2), remain the same as it is (3), increased a little (4), increased a lot (5). 
Data Appendix 1b: Summary Data on Individual Preferences on Trade Policy (ISSP-NI data set)

\begin{tabular}{|c|c|c|c|c|c|c|c|c|c|c|c|c|}
\hline Country & $\begin{array}{l}\widehat{C} \\
\frac{\lambda}{60} \\
0 \\
0 \\
0 \\
0 \\
0 \\
0 \\
0 \\
0\end{array}$ & 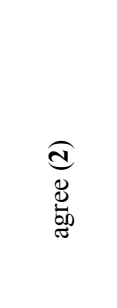 & 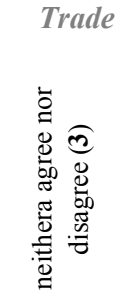 & 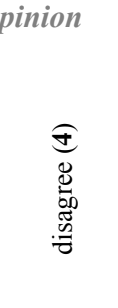 & 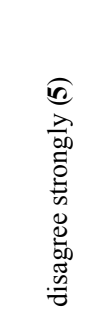 & 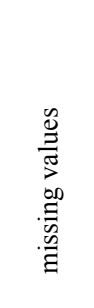 & \multicolumn{2}{|c|}{$\begin{array}{c}\text { average Trade } \\
\text { Opinion }\end{array}$} & \multicolumn{2}{|c|}{$\begin{array}{c}\text { Trade Opinion } \\
\text { Dummy }\end{array}$} & \multicolumn{2}{|c|}{$\begin{array}{c}\text { Trade Opinion } \\
\text { Dummy (against) }\end{array}$} \\
\hline Germany West & 15.130 & 23.710 & 18.490 & 26.830 & 9.520 & 6.320 & 2.913 & 3 & 0.388 & 2 & 0.415 & 20 \\
\hline Germany East & 25.980 & 30.390 & 16.990 & 17.320 & 4.740 & 4.580 & 2.418 & 11 & 0.231 & 13 & 0.591 & 13 \\
\hline Great Britain & 23.160 & 40.170 & 18.530 & 12.380 & 1.420 & 4.350 & 2.255 & 16 & 0.144 & 18 & 0.662 & 10 \\
\hline USA & 21.290 & 43.090 & 16.020 & 10.390 & 2.930 & 6.290 & 2.259 & 16 & 0.142 & 19 & 0.687 & 7 \\
\hline Austria & 37.840 & 31.980 & 10.920 & 12.610 & 3.870 & 2.780 & 2.102 & 20 & 0.170 & 15 & 0.718 & 5 \\
\hline Hungary & 45.400 & 25.800 & 15.800 & 6.900 & 2.600 & 3.500 & 1.917 & 21 & 0.098 & 22 & 0.738 & 4 \\
\hline Italy & 25.780 & 34.730 & 14.530 & 16.090 & 6.580 & 2.290 & 2.416 & 12 & 0.232 & 12 & 0.619 & 12 \\
\hline Ireland & 24.250 & 41.350 & 10.870 & 19.620 & 2.720 & 1.210 & 2.344 & 14 & 0.226 & 14 & 0.664 & 9 \\
\hline Netherlands & 5.120 & 23.930 & 28.240 & 31.930 & 5.510 & 5.270 & 3.092 & 1 & 0.395 & 1 & 0.307 & 23 \\
\hline Norway & 9.100 & 28.490 & 27.370 & 22.790 & 4.910 & 7.330 & 2.848 & 4 & 0.299 & 4 & 0.406 & 21 \\
\hline Sweden & 12.420 & 28.090 & 29.240 & 17.520 & 6.400 & 6.330 & 2.759 & 5 & 0.255 & 10 & 0.432 & 19 \\
\hline Czech Republic & 25.560 & 26.550 & 17.730 & 17.190 & 9.540 & 3.420 & 2.571 & 8 & 0.277 & 6 & 0.540 & 17 \\
\hline Slovenia & 24.030 & 26.830 & 17.950 & 20.460 & 3.960 & 6.760 & 2.501 & 9 & 0.262 & 7 & 0.546 & 15 \\
\hline Poland & 30.040 & 34.860 & 12.700 & 11.760 & 2.630 & 8.010 & 2.153 & 18 & 0.156 & 17 & 0.705 & 6 \\
\hline Bulgaria & 53.570 & 23.800 & 4.980 & 3.260 & 4.520 & 9.860 & 1.684 & 23 & 0.086 & 23 & 0.858 & 1 \\
\hline Russia & 35.580 & 24.480 & 11.740 & 15.020 & 6.810 & 6.370 & 2.284 & 15 & 0.233 & 11 & 0.642 & 11 \\
\hline New Zealand & 17.640 & 34.230 & 19.370 & 19.850 & 4.990 & 3.930 & 2.587 & 7 & 0.258 & 8 & 0.540 & 16 \\
\hline Canada & 14.130 & 31.690 & 21.580 & 21.840 & 6.030 & 4.730 & 2.727 & 6 & 0.293 & 5 & 0.481 & 18 \\
\hline Philippines & 12.750 & 53.750 & 16.330 & 15.170 & 0.830 & 1.170 & 2.368 & 13 & 0.162 & 16 & 0.673 & 8 \\
\hline Japan & 14.090 & 16.800 & 29.540 & 14.970 & 19.030 & 5.570 & 3.085 & 2 & 0.360 & 3 & 0.327 & 22 \\
\hline Spain & 21.210 & 50.120 & 10.970 & 9.250 & 0.980 & 7.450 & 2.121 & 19 & 0.111 & 21 & 0.771 & 2 \\
\hline Latvia & 50.190 & 20.790 & 9.870 & 9.000 & 4.120 & 6.030 & 1.894 & 22 & 0.140 & 20 & 0.755 & 3 \\
\hline Slovak Republic & 26.660 & 28.750 & 15.990 & 16.140 & 8.570 & 3.890 & 2.493 & 10 & 0.257 & 10 & 0.576 & 15 \\
\hline $\begin{array}{l}\text { Mean } \\
\text { Standard Deviation }\end{array}$ & 23.570 & 31.220 & 17.800 & 16.660 & 5.480 & 5.260 & $\begin{array}{l}2.464 \\
1.202\end{array}$ & & $\begin{array}{l}0.234 \\
0.423\end{array}$ & & $\begin{array}{l}0.578 \\
0.494\end{array}$ & \\
\hline
\end{tabular}

The second column of each variable gives the ranking of countries according to that variable

Bold numbers correspond to highest and lowest values.

Trade Opinion Dummy: Trade Opinion Dummy=1 if Trade Opinion=4 or 5; 0 if Trade Opinion=1,2,3.

Trade Opinion Dummy (against): Trade Opinion Dummy (against)=1 if Trade Opinion=1 or 2; 0 if Trade Opinion=3,4,5.

Trade Opinion gives responses to the following question: "Now we would like to ask a few questions about relations between (R's country) and other countries. How much do you agree or disagree with the following statements: (R's country) should limit the import of foreign products in order to protect its national economy." 
Data Appendix 2: Summary Data on Individual Preferences on Immigration Policy (ISSP-NI data set)

\begin{tabular}{|c|c|c|c|c|c|c|c|c|c|c|}
\hline \multirow{2}{*}{$\begin{array}{c}\text { Country } \\
\text { Germany West }\end{array}$} & \multicolumn{2}{|c|}{$\begin{array}{c}\text { Immig Opinion Dummy } \\
\text { The number of immigrants } \\
\text { should be increased }\end{array}$} & \multicolumn{2}{|c|}{$\begin{array}{c}\text { Immig Crime } \\
\text { Immigrants do not increase } \\
\text { crime rates }\end{array}$} & \multicolumn{2}{|c|}{$\begin{array}{l}\text { Immig Economy } \\
\text { Immigrants generally good } \\
\text { for economy }\end{array}$} & \multicolumn{2}{|c|}{$\begin{array}{c}\text { Immigrants do not take jobs } \\
\text { away from people }\end{array}$} & \multicolumn{2}{|c|}{$\begin{array}{c}\text { Immig Culture } \\
\text { Immigr make the country } \\
\text { more open to new ideas and } \\
\text { cultures }\end{array}$} \\
\hline & 0.028 & 18 & 0.207 & 10 & 0.336 & 6 & 0.428 & 7 & 0.618 & 5 \\
\hline Germany East & 0.020 & 20 & 0.132 & 18 & 0.292 & 9 & 0.260 & 14 & 0.500 & 10 \\
\hline Great Britain & 0.041 & 14 & 0.363 & 6 & 0.152 & 16 & 0.232 & 17 & 0.509 & 9 \\
\hline USA & 0.081 & 9 & 0.332 & 7 & 0.292 & 10 & 0.251 & 15 & 0.566 & 6 \\
\hline Austria & 0.039 & 15 & 0.182 & 13 & 0.393 & 4 & 0.348 & 11 & 0.429 & 15 \\
\hline Hungary & 0.015 & 22 & 0.098 & 22 & 0.078 & 23 & 0.164 & 22 & 0.179 & 23 \\
\hline Italy & 0.036 & 16 & 0.207 & 9 & 0.212 & 13 & 0.452 & 5 & 0.428 & 16 \\
\hline Ireland & 0.191 & 2 & 0.678 & 1 & 0.551 & 2 & 0.439 & 6 & 0.743 & 3 \\
\hline Netherlands & 0.055 & 13 & 0.322 & 8 & 0.151 & 17 & 0.416 & 8 & 0.562 & 7 \\
\hline Norway & 0.074 & 10 & 0.100 & 21 & 0.111 & 20 & 0.473 & 4 & 0.466 & 13 \\
\hline Sweden & 0.067 & 11 & 0.149 & 16 & 0.227 & 12 & 0.494 & 3 & 0.646 & 4 \\
\hline Czech Republic & 0.024 & 19 & 0.150 & 15 & 0.079 & 22 & 0.322 & 12 & 0.207 & 21 \\
\hline Slovenia & 0.019 & 21 & 0.206 & 11 & 0.189 & 14 & 0.195 & 21 & 0.271 & 17 \\
\hline Poland & 0.086 & 6 & 0.115 & 20 & 0.304 & 7 & 0.203 & 20 & 0.440 & 14 \\
\hline Bulgaria & 0.059 & 12 & 0.062 & 23 & 0.127 & 18 & 0.105 & 23 & 0.248 & 18 \\
\hline Russia & 0.083 & 8 & 0.172 & 14 & 0.159 & 15 & 0.243 & 16 & 0.245 & 19 \\
\hline New Zealand & 0.116 & 4 & 0.387 & 5 & 0.468 & 3 & 0.304 & 13 & 0.749 & 2 \\
\hline Canada & 0.206 & 1 & 0.527 & 2 & 0.605 & 1 & 0.529 & 2 & 0.773 & 1 \\
\hline Philippines & 0.115 & 5 & 0.482 & 4 & 0.297 & 8 & 0.396 & 9 & 0.486 & 11 \\
\hline Japan & 0.157 & 3 & 0.146 & 17 & 0.363 & 5 & 0.542 & 1 & 0.467 & 12 \\
\hline Spain & 0.084 & 7 & 0.500 & 3 & 0.245 & 11 & 0.369 & 10 & 0.552 & 8 \\
\hline Latvia & 0.004 & 23 & 0.199 & 12 & 0.126 & 19 & 0.217 & 19 & 0.215 & 20 \\
\hline Slovak Republic & 0.030 & 17 & 0.124 & 19 & 0.087 & 21 & 0.218 & 18 & 0.189 & 22 \\
\hline Mean & 0.074 & & 0.255 & & 0.251 & & 0.339 & & 0.462 & \\
\hline Standard Deviation & 0.262 & & 0.436 & & 0.434 & & 0.473 & & 0.499 & \\
\hline
\end{tabular}

The sample excludes all individuals who are not citizens of the country where they are interviewed. The second column of each variable gives the ranking of countries according to that variable. Bold numbers correspond to highest and lowest values.

Immig Opinion Dummy $=1$ if Immig Opinion=4 or 5; 0 if Immig Opinion=1,2 or 3; can't choose and NA are missing values.

Immig Crime $=1$ if Immig Crime Opinion=4 or 5; 0 otherwise. Immig Economy=1 if Immig Economy Opinion=4 or 5; 0 otherwise. Immig Jobs=1 if Immig Jobs Opinion=1 or 2; 0 otherwise. Immig Culture=1 if Immig Culture Opinion=4 or 5; 0 otherwise.

Immig Opinion gives responses to the following question: "Do you think the number of immigrants to (R's country) nowadays should be ...": 1=reduced a lot, reduced a little, remain the same as it is, increased a little, $5=$ increased a lot.

Immig Crime Opinion gives responses to the following question: How much do you agree or disagree with each of the following statements? Immigrants increase crime rates. (1=agree strongly; $5=$ disagree strongly)

Immig Economy Opinion gives responses to the following question: How much do you agree or disagree with the following statement? Immigrants are generally good for (R's country's) economy (disagree strongly=1;agree strongly=5)

Immig Jobs Opinion gives responses to the following question: How much do you agree or disagree with the following statement? Immigrants take jobs away from people who were born in (R's country) (disagree strongly=1;agree strongly=5)

Immig Culture Opinion gives responses to the following question: How much do you agree or disagree with each of the following statement? Immigrants make (R's country) more open to new ideas and cultures (disagree strongly=1;agree strongly=5). 
Data Appendix 3 - Demographic Variables (ISSP-NI data set)

\begin{tabular}{|c|c|c|c|c|c|c|c|c|c|c|c|c|c|c|c|c|c|}
\hline \multirow[b]{2}{*}{ Country } & \multirow{2}{*}{$\begin{array}{c}\text { number of } \\
\text { observations in } \\
\text { the sample }\end{array}$} & \multirow[b]{2}{*}{ age } & \multirow[b]{2}{*}{$\begin{array}{c}\text { average } \\
\text { years of } \\
\text { education }\end{array}$} & \multirow[b]{2}{*}{ male } & \multirow[b]{2}{*}{ rural } & \multirow[b]{2}{*}{$\begin{array}{l}\text { trade union } \\
\text { membership }\end{array}$} & \multicolumn{6}{|c|}{ upper social class } & \multicolumn{5}{|c|}{$\begin{array}{l}\text { political affiliation with the } \\
\text { right }\end{array}$} \\
\hline & & & & & & & 苛 & 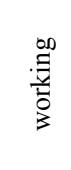 & 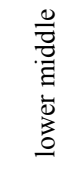 & $\frac{\tilde{g}}{\tilde{z}}$ & 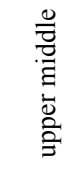 & 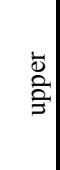 & $\frac{\mathscr{E}}{\vec{E}}$ & $\begin{array}{l}\frac{\sqrt{0}}{0} \\
\text { 竞 } \\
0\end{array}$ & 駦 & 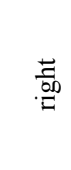 & 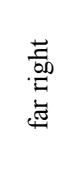 \\
\hline Germany West & 1225 & 47 & 10.909 & 0.536 & - & 0.378 & 2.02 & 0 & 16.9 & 61.36 & 18.31 & 1.41 & 0.35 & 51.18 & 5.94 & 39.65 & 2.88 \\
\hline Germany East & 612 & 48 & 10.950 & 0.503 & - & 0.799 & 9.96 & 0 & 37.14 & 47.83 & 4.71 & 0.36 & 16.79 & 48.01 & 5.6 & 28.16 & 1.44 \\
\hline Great Britain & 1035 & 47 & 11.321 & 0.403 & - & 0.216 & - & - & - & - & - & - & 0.68 & 51.03 & 17.12 & 31.16 & 0 \\
\hline USA & 1310 & 45 & 13.426 & 0.430 & 1.596 & 0.162 & 5.69 & 46.12 & 0 & 44.89 & 0 & 3.31 & 0 & 34.71 & 36.42 & 28.87 & 0 \\
\hline Austria & 991 & 47 & 10.355 & 0.453 & - & 0.462 & 3.95 & 0 & 16.45 & 65.38 & 13.35 & 0.85 & 0 & 51.35 & 6.1 & 42.55 & 0 \\
\hline Hungary & 992 & 48 & 10.491 & 0.427 & 1.969 & 0.148 & 13.14 & 36.29 & 26.17 & 23.15 & 1.25 & 0 & - & - & - & - & - \\
\hline Italy & 1092 & 43 & 11.028 & 0.483 & 1.982 & 0.338 & 1.37 & 0 & 11.54 & 71.25 & 13.37 & 2.47 & - & - & - & - & - \\
\hline Ireland & 981 & 46 & 12.249 & 0.489 & 2.015 & 0.263 & 1.72 & 37.2 & 14.84 & 41.08 & 4.62 & 0.54 & 0 & 6.37 & 91.25 & 2.39 & 2.39 \\
\hline Netherlands & 2059 & 44 & 12.685 & 0.454 & 1.724 & 0.215 & - & - & - & - & - & - & 9.38 & 26.1 & 37.79 & 22.74 & 3.99 \\
\hline Norway & 1490 & 43 & 12.663 & 0.499 & 2.097 & 0.484 & 0 & 35.62 & 7.72 & 46.26 & 9.77 & 0.63 & 0.78 & 49.31 & 24.48 & 25.43 & 0 \\
\hline Sweden & 1234 & 45 & 11.411 & 0.495 & 1.241 & 0.729 & 2.27 & 37.31 & 0 & 49.69 & 9.94 & 0.78 & 8.28 & 46.71 & 19.84 & 25.17 & 0 \\
\hline Czech Republic & 1107 & 43 & 12.911 & 0.508 & 1.648 & 0.330 & 4.36 & 28.63 & 22.27 & 36.68 & 6.73 & 1.33 & 5.93 & 12.47 & 45.11 & 26.09 & 10.4 \\
\hline Slovenia & 1036 & 43 & 10.677 & 0.440 & 2.031 & 0.380 & 3.6 & 37.35 & 0 & 52.06 & 6.77 & 0.21 & 0 & 13.58 & 28.61 & 52.02 & 5.78 \\
\hline Poland & 1597 & 47 & 10.287 & 0.447 & 1.724 & 0.148 & 7.79 & 43.53 & 0 & 41.68 & 4.69 & 2.31 & 0 & 63.32 & 24.34 & 12.34 & 0 \\
\hline Bulgaria & 1105 & 49 & - & 0.476 & 1.916 & 0.193 & 15.59 & 55.28 & 0 & 28.07 & 0 & 1.06 & 14.67 & 36.89 & 19.78 & 22 & 6.67 \\
\hline Russia & 1580 & 45 & 11.187 & 0.449 & 1.505 & 0.619 & 14.95 & 34.61 & 17.08 & 29.23 & 3.31 & 0.81 & 26.24 & 4.52 & 11.58 & 51.4 & 6.24 \\
\hline New Zealand & 989 & 46 & 14.310 & 0.473 & 1.498 & 0.212 & 3.97 & 21.85 & 12.27 & 46.96 & 13.9 & 1.05 & 0 & 6.12 & 86.03 & 7.85 & 0 \\
\hline Canada & 1487 & 42 & 14.761 & 0.486 & 1.157 & 0.333 & 3.48 & 21.66 & 13.55 & 41.89 & 17.47 & 1.96 & 1.3 & 30.59 & 45.74 & 22.37 & 0 \\
\hline Philippines & 1194 & 40 & 9.393 & 0.502 & 1.747 & 0.019 & 24.87 & 61.47 & 0 & 10.89 & 0 & 2.76 & - & - & - & - & - \\
\hline Japan & 1256 & 46 & 11.868 & 0.458 & - & 0.308 & 4.79 & 0 & 20.7 & 52.27 & 18.48 & 3.76 & 4.5 & 13.92 & 16.7 & 64.88 & 0 \\
\hline Spain & 1220 & 45 & 10.127 & 0.476 & 1.480 & 0.084 & 6.28 & 42.13 & 18.01 & 29.4 & 3.85 & 0.34 & 16 & 43.77 & 0.34 & 39.89 & 0 \\
\hline Latvia & 768 & 46 & 11.611 & 0.389 & 1.938 & 0.197 & 14.2 & 48.49 & 24.92 & 0 & 11.63 & 0.76 & - & - & - & - & - \\
\hline Slovak Republic & 1383 & 41 & 11.836 & 0.484 & - & 0.322 & 8.92 & 32.01 & 22.79 & 27.66 & 6.9 & 1.72 & 6.73 & 18.02 & 49.01 & 17.43 & 8.81 \\
\hline $\begin{array}{l}\text { Mean } \\
\text { Standard Deviation }\end{array}$ & total $n=27,743$ & $\begin{array}{l}44.809 \\
16.913\end{array}$ & $\begin{array}{c}11.675 \\
3.572\end{array}$ & $\begin{array}{l}0.468 \\
0.499\end{array}$ & $\begin{array}{l}1.703 \\
0.898\end{array}$ & $\begin{array}{l}0.313 \\
0.464\end{array}$ & 7.24 & 30.51 & 12.36 & 40.54 & 7.89 & 1.45 & 6.14 & 32.95 & 28.87 & 29.49 & 2.56 \\
\hline
\end{tabular}

The sample excludes all individuals who are not citizens of the country where they are interviewed.

Rural is coded as follows: 1 urban, 2 suburbs/city-town, 3 rural.

Male is coded as follows: 1 male, 0 female (i.e., missing values are excluded).

Trade Union Membership is coded as follows: 1 member, 0 non member (i.e., missing values are excluded).

Both Upper Social Class and Political Affiliation with the Right give percentages after missing values have been excluded. 
Data Appendix 4 - Attachment to Own Town/City, County/Region and Continent and National Pride Variables (ISSP-NI data set)

\begin{tabular}{|c|c|c|c|c|c|c|c|c|c|c|c|c|c|c|}
\hline \multirow[b]{2}{*}{ Country } & \multicolumn{14}{|c|}{$\%$ of individuals in each nation declaring } \\
\hline & \multicolumn{2}{|c|}{$\begin{array}{l}\text { attachment } \\
\text { to own } \\
\text { town/city } \\
\text { (town) }\end{array}$} & \multicolumn{2}{|c|}{$\begin{array}{c}\text { attachment } \\
\text { to own } \\
\text { county/region } \\
\text { (county) }\end{array}$} & \multicolumn{2}{|c|}{$\begin{array}{l}\text { attachment } \\
\text { to own } \\
\text { continent } \\
\text { (continent) }\end{array}$} & \multicolumn{2}{|c|}{$\begin{array}{c}\text { attachment } \\
\text { to own } \\
\text { country } \\
\text { (national pride (1)) }\end{array}$} & \multicolumn{2}{|c|}{$\begin{array}{l}\text { "rather be } \\
\text { citizen of own } \\
\text { country" } \\
\text { (national pride (2)) }\end{array}$} & \multicolumn{2}{|c|}{$\begin{array}{c}\text { own country } \\
\text { better than } \\
\text { others } \\
\text { (national pride (3)) }\end{array}$} & \multicolumn{2}{|c|}{$\begin{array}{c}\text { in favor of } \\
\text { country's interests } \\
\text { at any cost } \\
\text { (national pride (4)) }\end{array}$} \\
\hline Germany West & 0.384 & 23 & 0.585 & 19 & 0.498 & 16 & 0.736 & 20 & 0.644 & 21 & 0.345 & 15 & 0.292 & 17 \\
\hline Germany East & 0.456 & 22 & 0.668 & 15 & 0.490 & 17 & 0.761 & 19 & 0.691 & 18 & 0.322 & 18 & 0.250 & 21 \\
\hline Great Britain & 0.500 & 20 & 0.449 & 23 & 0.180 & 22 & 0.631 & 23 & 0.715 & 14 & 0.527 & 9 & 0.491 & 7 \\
\hline USA & 0.587 & 16 & 0.593 & 18 & 0.534 & 11 & 0.783 & 18 & 0.911 & 1 & 0.796 & 2 & 0.423 & 8 \\
\hline Austria & 0.513 & 19 & 0.870 & 3 & 0.655 & 6 & 0.899 & 9 & 0.839 & 8 & 0.655 & 6 & 0.578 & 3 \\
\hline Hungary & 0.838 & 4 & 0.848 & 4 & 0.928 & 1 & 0.963 & 1 & 0.855 & 5 & 0.241 & 21 & 0.372 & 13 \\
\hline Italy & 0.815 & 6 & 0.794 & 7 & 0.680 & 5 & 0.873 & 13 & 0.614 & 22 & 0.361 & 13 & 0.293 & 16 \\
\hline Ireland & 0.799 & 7 & 0.797 & 6 & 0.427 & 18 & 0.909 & 6 & 0.865 & 4 & 0.703 & 5 & 0.619 & 2 \\
\hline Netherlands & 0.691 & 12 & 0.483 & 22 & 0.523 & 13 & 0.857 & 15 & 0.487 & 23 & 0.439 & 11 & 0.264 & 19 \\
\hline Norway & 0.684 & 13 & 0.771 & 8 & 0.523 & 12 & 0.931 & 3 & 0.774 & 11 & 0.647 & 7 & 0.362 & 15 \\
\hline Sweden & 0.575 & 17 & 0.621 & 17 & 0.322 & 19 & 0.795 & 16 & 0.689 & 19 & 0.437 & 12 & 0.409 & 10 \\
\hline Czech Republic & 0.721 & 10 & 0.659 & 16 & 0.731 & 3 & 0.896 & 10 & 0.710 & 16 & 0.206 & 23 & 0.290 & 18 \\
\hline Slovenia & 0.817 & 5 & 0.767 & 9 & 0.646 & 8 & 0.920 & 5 & 0.754 & 12 & 0.256 & 20 & 0.253 & 20 \\
\hline Poland & 0.467 & 21 & 0.584 & 20 & 0.612 & 9 & 0.903 & 8 & 0.839 & 7 & 0.332 & 17 & 0.399 & 12 \\
\hline Bulgaria & 0.884 & 2 & 0.842 & 5 & 0.777 & 2 & 0.907 & 7 & 0.849 & 6 & 0.494 & 10 & 0.622 & 1 \\
\hline Russia & 0.651 & 14 & 0.583 & 21 & 0.162 & 23 & 0.784 & 17 & 0.697 & 17 & 0.358 & 14 & 0.525 & 5 \\
\hline New Zealand & 0.740 & 8 & 0.679 & 13 & 0.511 & 15 & 0.929 & 4 & 0.810 & 9 & 0.753 & 3 & 0.495 & 6 \\
\hline Canada & 0.740 & 9 & 0.727 & 10 & 0.514 & 14 & 0.729 & 21 & 0.780 & 10 & 0.748 & 4 & 0.405 & 11 \\
\hline Philippines & 0.717 & 11 & 0.669 & 14 & 0.321 & 20 & 0.665 & 22 & 0.878 & 3 & 0.590 & 8 & 0.363 & 14 \\
\hline Japan & 0.871 & 3 & 0.875 & 2 & 0.651 & 7 & 0.936 & 2 & 0.883 & 2 & $\mathbf{0 . 8 2 7}$ & 1 & 0.174 & 23 \\
\hline Spain & 0.920 & 1 & 0.902 & 1 & 0.607 & 10 & 0.892 & 11 & 0.722 & 13 & 0.339 & 16 & 0.557 & 4 \\
\hline Latvia & 0.552 & 18 & 0.685 & 12 & 0.301 & 21 & 0.863 & 14 & 0.714 & 15 & 0.273 & 19 & 0.418 & 9 \\
\hline Slovak Republic & 0.594 & 15 & 0.716 & 11 & 0.720 & 4 & 0.877 & 12 & 0.679 & 20 & 0.216 & 22 & 0.217 & 22 \\
\hline whole sample & 0.676 & & 0.692 & & 0.533 & & 0.845 & & 0.749 & & 0.477 & & 0.390 & \\
\hline
\end{tabular}


Data Appendix 5a: Correlation between Trade

Opinion and Immig Opinion (ISSP data set)

\begin{tabular}{|l|c|}
\hline \hline \multicolumn{1}{|c|}{ Country } & $\begin{array}{c}\text { Correlation between Trade } \\
\text { Opinion and Immig Opinion } \\
(I S S P)\end{array}$ \\
\hline Germany West & $0.3502^{*}$ \\
Germany East & $0.3748^{*}$ \\
Great Britain & $0.3230^{*}$ \\
USA & $0.2354^{*}$ \\
Austria & $0.2628^{*}$ \\
Hungary & $0.1549^{*}$ \\
Italy & $0.2455^{*}$ \\
Ireland & $0.1726^{*}$ \\
Netherlands & $0.2762^{*}$ \\
Norway & $0.2358^{*}$ \\
Sweden & $0.2545^{*}$ \\
Czech Republic & $0.1592^{*}$ \\
Slovenia & $0.1107^{*}$ \\
Poland & $0.1615^{*}$ \\
Bulgaria & 0.0678 \\
Russia & $0.1392^{*}$ \\
New Zealand & $0.3174^{*}$ \\
Canada & $0.2784^{*}$ \\
Philippines & 0.0398 \\
Japan & $0.2185^{*}$ \\
Spain & $0.1812^{*}$ \\
Latvia & 0.0658 \\
Slovak Republic & $0.1337^{*}$ \\
\hline whole sample & \\
\hline
\end{tabular}

The sample excludes all individuals who are not citizens of the country where they are interviewed.

All coefficients significant at the $5 \%$ level or better are starred.

Immig Opinion gives responses to the following question: "Do you think the number of immigrants to (R's country) nowadays should be ...": reduced a lot, reduced a little, remain the same as it is, increased a little, increased a lot.

Trade Opinion gives responses to the following question: "How much do you agree or disagree with the following statements: (R's country) should limit the import of foreign products in order to protect its national economy." (1=agree strongly; $5=$ disagree strongly) 
Data Appendix 5b: Correlation between Trade Opinion Dummy and Immig Opinion Dummy (WVS)

\begin{tabular}{|c|c|}
\hline Country & $\begin{array}{c}\text { Correlation between Trade } \\
\text { Opinion Dummy and Immig } \\
\text { Opinion Dummy (WVS) }\end{array}$ \\
\hline Philippines & $0.1874 *$ \\
\hline Puerto Rico & $0.1510^{*}$ \\
\hline Macedonia & $0.3450^{*}$ \\
\hline S.Africa & $0.2521^{*}$ \\
\hline USA & $0.2968 *$ \\
\hline Taiwan & $0.1885^{*}$ \\
\hline India & $0.4372 *$ \\
\hline Finland & $0.2456^{*}$ \\
\hline Germany East & $0.3682 *$ \\
\hline Sweden & $0.0919 *$ \\
\hline Turkey & $0.2224 *$ \\
\hline Venezuela & $0.0625 *$ \\
\hline Lithuania & $0.2015^{*}$ \\
\hline China & $0.1969 *$ \\
\hline Estonia & $0.1013^{*}$ \\
\hline Norway & $0.1469^{*}$ \\
\hline Latvia & $0.2498 *$ \\
\hline Peru & $0.1320^{*}$ \\
\hline Dominican Republic & $0.1729 *$ \\
\hline Japan & $0.2907^{*}$ \\
\hline Montenegro & 0.1025 \\
\hline Australia & $0.0897^{*}$ \\
\hline S.Korea & $0.1955^{*}$ \\
\hline Russia & $0.2192 *$ \\
\hline Moldova & $0.2860^{*}$ \\
\hline Nigeria & $0.2356^{*}$ \\
\hline Switzerland & $0.2400 *$ \\
\hline Bulgaria & $0.2427 *$ \\
\hline Argentina & $0.1034 *$ \\
\hline Serbia & $0.2581 *$ \\
\hline Mexico & -0.0521 \\
\hline Slovenia & $0.1278^{*}$ \\
\hline Chile & $0.1095^{*}$ \\
\hline Croatia & $0.2366^{*}$ \\
\hline Brazil & 0.0391 \\
\hline Georgia & $0.3363 *$ \\
\hline Uruguay & -0.002 \\
\hline Belarus & $0.2644 *$ \\
\hline Germany West & $0.3135^{*}$ \\
\hline Spain & $0.1080^{*}$ \\
\hline Armenia & $0.2403 *$ \\
\hline Ukraine & $0.3389^{*}$ \\
\hline Bosnia & $0.3253 *$ \\
\hline Azerbaijan & $0.2459 *$ \\
\hline whole sample & $0.2405^{*}$ \\
\hline
\end{tabular}

The sample excludes all individuals who were not born in the country where they are interviewed.

All coefficients significant at the $5 \%$ level or better are starred.

See footnote 17 for the definition of Immig Opinion Dummy (WVS). Trade Opinion Dummy (WVS) equals 1 if the individual answers 1. to the following question, 0 if 2 (Don't Knows are coded as missing values): Do you think it is better if: 1 . Goods made in other countries can be imported and sold here if people want to buy them; OR that: 2 . There should be stricter limits on selling foreign goods here, to protect the jobs of people in this country; OR: 9. Don't Know. 
Data Appendix 6: World Value Survey Summary Statistics of Immigration Policy Preferences

\begin{tabular}{|c|c|c|}
\hline country & $\begin{array}{c}\text { Immig Opinion Dummy } \\
\text { (WVS) }\end{array}$ & Don't Knows \\
\hline Philippines & 0.249 & 0.008 \\
\hline Puerto Rico & 0.283 & 0.000 \\
\hline Macedonia & 0.322 & 0.078 \\
\hline S.Africa & 0.339 & 0.023 \\
\hline USA & 0.346 & 0.000 \\
\hline Taiwan & 0.350 & 0.000 \\
\hline India & 0.353 & 0.216 \\
\hline Finland & 0.392 & 0.038 \\
\hline Germany East & 0.403 & 0.012 \\
\hline Sweden & 0.406 & 0.035 \\
\hline Turkey & 0.407 & 0.009 \\
\hline Venezuela & 0.425 & 0.000 \\
\hline Lithuania & 0.438 & 0.034 \\
\hline China & 0.440 & 0.000 \\
\hline Estonia & 0.452 & 0.037 \\
\hline Norway & 0.458 & 0.008 \\
\hline Latvia & 0.466 & 0.020 \\
\hline Peru & 0.475 & 0.077 \\
\hline Dominican Republic & 0.492 & 0.028 \\
\hline Japan & 0.497 & 0.000 \\
\hline Montenegro & 0.514 & 0.109 \\
\hline Australia & 0.533 & 0.000 \\
\hline S.Korea & 0.539 & 0.087 \\
\hline Russia & 0.539 & 0.040 \\
\hline Moldova & 0.540 & 0.031 \\
\hline Nigeria & 0.541 & 0.000 \\
\hline Switzerland & 0.567 & 0.053 \\
\hline Bulgaria & 0.572 & 0.119 \\
\hline Argentina & 0.587 & 0.000 \\
\hline Serbia & 0.599 & 0.062 \\
\hline Mexico & 0.602 & 0.042 \\
\hline Slovenia & 0.604 & 0.000 \\
\hline Chile & 0.612 & 0.017 \\
\hline Croatia & 0.614 & 0.000 \\
\hline Brazil & 0.615 & 0.016 \\
\hline Georgia & 0.666 & 0.032 \\
\hline Uruguay & 0.687 & 0.033 \\
\hline Belarus & 0.705 & 0.063 \\
\hline Germany West & 0.710 & 0.026 \\
\hline Spain & 0.716 & 0.034 \\
\hline Armenia & 0.723 & 0.052 \\
\hline Ukraine & 0.734 & 0.108 \\
\hline Bosnia & 0.759 & 0.061 \\
\hline Azerbaijan & 0.781 & 0.043 \\
\hline total mean & 0.533 & 0.041 \\
\hline standard deviation & 0.499 & 0.197 \\
\hline
\end{tabular}

Immig Opinion Dummy (WVS) equals 1 if the individual answered a. or b. to the immigration-related question, 0 if c. or d.; "Don't Knows" are missing values.

The immigration-related question asks: "How about people from other countries coming here to work. Which one of the following do you think the government should do?

a. Let anyone come who wants to; b. Let people come as long as there are jobs available; c. Place strict limits on the number of foreigners who can come here; $d$. Prohibit people coming here from other countries.

The second column gives the percentages of Don't Knows answers out of the total sample (the total sample is given by all individuals who answer a. through d. or Don't Know). 
Data Appendix 7: Per capita GDP of the countries in the ISSP and WVS samples

\begin{tabular}{|c|c|c|}
\hline country & $\begin{array}{c}\text { per capita GDP in } 1995 \\
\text { (PPP-adjusted) }\end{array}$ & $\begin{array}{l}\text { log of per capita GDP in } \\
1995 \text { (PPP-adjusted) }\end{array}$ \\
\hline Nigeria & 824.990 & 6.715 \\
\hline Bangladesh & 1280.880 & 7.155 \\
\hline Ghana & 1709.830 & 7.444 \\
\hline Pakistan & 1765.360 & 7.476 \\
\hline India & 1871.220 & 7.534 \\
\hline Armenia & 1938.330 & 7.570 \\
\hline Azerbaijan & 1982.220 & 7.592 \\
\hline Georgia & 2016.160 & 7.609 \\
\hline Moldova & 2403.020 & 7.784 \\
\hline China & 2681.390 & 7.894 \\
\hline Philippines & 3633.240 & 8.198 \\
\hline Ukraine & 3811.710 & 8.246 \\
\hline Macedonia & 4299.560 & 8.366 \\
\hline Dominican Republic & 4350.740 & 8.378 \\
\hline Peru & 4419.710 & 8.394 \\
\hline Latvia & 5037.370 & 8.525 \\
\hline Belarus & 5217.670 & 8.560 \\
\hline Lithuania & 5626.700 & 8.635 \\
\hline Bulgaria & 5679.510 & 8.645 \\
\hline Croatia & 5905.530 & 8.684 \\
\hline Turkey & 5924.610 & 8.687 \\
\hline Colombia & 6012.530 & 8.702 \\
\hline Venezuela & 6019.300 & 8.703 \\
\hline Romania & 6543.390 & 8.786 \\
\hline Estonia & 6558.690 & 8.789 \\
\hline Brazil & 6726.440 & 8.814 \\
\hline Poland & 6794.980 & 8.824 \\
\hline Russia & 7206.220 & 8.883 \\
\hline Mexico & 7221.970 & 8.885 \\
\hline Chile & 7733.390 & 8.953 \\
\hline Uruguay & 8017.480 & 8.989 \\
\hline S.Africa & 8631.180 & 9.063 \\
\hline Slovakia & 8667.670 & 9.067 \\
\hline Hungary & 9577.070 & 9.167 \\
\hline Argentina & 10940.100 & 9.300 \\
\hline Czech Republic & 12414.290 & 9.427 \\
\hline Slovenia & 13191.210 & 9.487 \\
\hline S.Korea & 13758.830 & 9.529 \\
\hline Portugal & 13774.940 & 9.531 \\
\hline Spain & 15412.220 & 9.643 \\
\hline Ireland & 17844.910 & 9.789 \\
\hline Finland & 19204.450 & 9.863 \\
\hline Britain & 19880.390 & 9.897 \\
\hline Sweden & 20449.570 & 9.926 \\
\hline Italy & 20888.240 & 9.947 \\
\hline France & 21065.020 & 9.955 \\
\hline Netherlands & 21087.570 & 9.956 \\
\hline Australia & 21562.500 & 9.979 \\
\hline Germany & 22029.480 & 10.000 \\
\hline Austria & 22672.040 & 10.029 \\
\hline Belgium & 22892.860 & 10.039 \\
\hline Iceland & 23305.430 & 10.056 \\
\hline Canada & 23487.480 & 10.064 \\
\hline Denmark & 23527.680 & 10.066 \\
\hline Japan & 23725.340 & 10.074 \\
\hline Norway & 25336.920 & 10.140 \\
\hline Switzerland & 25964.120 & 10.164 \\
\hline USA & 28173.420 & 10.246 \\
\hline
\end{tabular}


Data Appendix 8 - Immigration inflows into higher-income countries (1995)

\begin{tabular}{|c|c|c|c|c|c|c|}
\hline Country & IMS_OECD & $\begin{array}{c}\text { OECD } \\
\text { compendium }\end{array}$ & Trends in IM & $\begin{array}{c}\text { World Bank } \\
\text { (WB) }\end{array}$ & $\begin{array}{c}\text { population } \\
\text { in } 1995 \\
(\mathrm{WB}) \\
\end{array}$ & $\begin{array}{c}\text { immigration } \\
\text { flow/pop in } \\
1995 \\
\end{array}$ \\
\hline Australia & 87,428 & 87,400 & 87,400 & 87,430 & $18,063,000$ & 0.0048 \\
\hline Belgium & 53,138 & 53,100 & 53,100 & 53,140 & $10,137,000$ & 0.0052 \\
\hline Britain & 55,480 & 55,500 & 206,300 & 206,310 & $58,606,000$ & 0.0035 \\
\hline Canada & 212,249 & 212,200 & 212,900 & 212,870 & $29,354,000$ & 0.0073 \\
\hline Denmark & 0 & 0 & 33,000 & 32,970 & $5,228,000$ & 0.0063 \\
\hline Finland & 7,345 & 7,300 & 7,300 & 7,350 & $5,108,000$ & 0.0014 \\
\hline France & 56,739 & 56,700 & 77,000 & 77,000 & $57,847,000$ & 0.0013 \\
\hline Hungary & & & 13,200 & 13,190 & $10,230,000$ & 0.0013 \\
\hline Ireland & & & & 13,600 & $3,602,000$ & 0.0038 \\
\hline Germany & 788,337 & 788,300 & 788,300 & 788,340 & $81,642,000$ & 0.0097 \\
\hline Japan & 209,869 & 209,900 & 209,900 & 209,870 & $125,440,000$ & 0.0017 \\
\hline Luxembourg & 9,591 & 9,600 & 9,600 & & 409,500 & 0.0234 \\
\hline Netherlands & 66,972 & 67,000 & 67,000 & 66,970 & $15,460,000$ & 0.0043 \\
\hline Norway & 16,482 & 16,500 & 16,500 & 16,480 & $4,360,000$ & 0.0038 \\
\hline S.Korea & & & & 173,150 & $44,995,000$ & 0.0038 \\
\hline Sweden & 36,079 & 36,100 & 36,100 & 36,080 & $8,831,000$ & 0.0041 \\
\hline Switzerland & 87,894 & 87,900 & 87,900 & 87,890 & $7,041,000$ & 0.0125 \\
\hline USA & 720,459 & 720,500 & 720,500 & 720,460 & $264,800,000$ & 0.0027 \\
\hline
\end{tabular}

The ratio immigration flow/pop (in 1995) is calculated using World Bank data for both immigrant flows and population (except for Luxembourg, for which data on immigrant flows are from Trends in International Migration. 